\title{
Global Diffusion of a New Product Class: A Study of New World Wine
}

\author{
Andrew Pascoe \\ A thesis submitted for the degree of Master of Commercial Administration \\ Victoria University, Wellington
}

March 2011 


\begin{abstract}
Understanding the drivers of product diffusion in global markets is a key determinant of success in marketing a product internationally. Factors such as national culture that are specific to a particular country market play a significant role in determining the speed of diffusion in that market. Examining the diffusion of New World wine provides an opportunity to test existing theories in the context of a new product class innovation as opposed to a new product innovation (as is the case in the existing literature). In addition, the study of diffusion of a new product class provides an opportunity to measure diffusion rates, within global markets, against a key explanatory variable in diffusion theory, 'prior experience of a previously introduced idea'. This is due to the fact that global markets have had previous experience with other wine product classes, before the advent of New World wine. This explanatory variable is an important part of classic diffusion theory however it has not been tested in a cross national sense. Through the study of 47 countries/regions that encompasses all countries in the world (at time of publication), the research found a strong negative correlation between 'prior experience of a previously introduced idea' and market share growth of New World wine across global markets. The author suggests that a key potential factor for this finding relates to the existence of a quality status hierarchy in existence in countries with higher levels of prior experience, resulting in a lower quality perception for a new product class in this market, when compared to a market that does not have an existing status hierarchy in place due to lower prior experience with a similar product. This concept potentially extends the cross national diffusion literature. In addition this research may provide important implications for managers in developing global marketing strategies.
\end{abstract}




\section{Acknowledgements:}

Thanks to Dr Hongzhi Gao, my primary supervisor, for his time, guidance, patience and ability to keep me motivated.

Thanks also to Dr Tim Beal, my secondary supervisor, for his help.

Thanks to Angela Mills, a librarian at the University of Adelaide, for providing the last 3 years worth of wine compendium data, as well as answering many questions in relation to this data.

Thanks to my partner Lisa for her support.

Thanks to the next door neighbour's cat Dusty, for the volume of meiowing at early hours of the morning to enable me to get up and continue with this research. And sorry Dusty for the rock embedded in your head. 


\section{Table Of Contents:}

Abstract.

Acknowledgements

CHAPTER ONE: INTRODUCTION

1.1 Background and Justification

1.2 Research Questions.

1.3 Methodology.

1.4 Key Findings of the research.

1.5 Outline of the research.

1.6 Limitations and scope of the study

1.7 Conclusion.

CHAPTER TWO: LITERATURE REVIEW

2.1 Introduction

2.2 Wine

2.2.1 Wine Production, Consumption and Trade.

2.2.2 New World Wine Success Factors and Global Diffusion Rates....

2.2.3 Wine Choice Factors

2.2.4 Cross National Wine Purchase Factors.

2.2.5 Summary....

2.3 Diffusion

2.3.1 The Innovation - Decision Process....

2.3.2 Adopter Categories

2.3.3 Diffusion Patterns.

2.3.4 Rate of Adoption.

2.3.5 Determinants of Rate of Adoption.

2.3.6 Cross National Diffusion

2.3.6.1 Country Specific Factors.

2.3.6.2 Marketing Mix Variables in Cross National Diffusion.

2.3.7 Summary.

2.4 Chapter Summary 
3.1 Introduction

3.2 Research Problem

3.3 Dependent Variables

3.4 Independent Variables and Hypothesis Development

3.5 Chapter Summary...

CHAPTER FOUR: RESEARCH METHODOLOGY

4.1 Research Method.

4.2 Data Collection

4.3 Data Sources.

4.4 Construct Measurement.

4.5 Data Analysis

4.6 Chapter Summary

CHAPTER FIVE: RESULTS AND FINDINGS

5.1 Hypothesis Testing and Findings

5.2 Summary of Findings.

5.3 Chapter Summary

CHAPTER SIX: DISCUSSION AND CONCLUSIONS

6.1 Discussion of Key Findings

6.1.1 Conclusion

6.2 Limitations of the Research.

6.3 Managerial Implications

6.4 Areas of Further Research.

REFERENCES. 


\section{List of Tables}

Table 1: Global Production Volumes (hl) 1961 - 2006

Table 2: Volume Wine Production Share 1961 - 2006 hl-000's - Top 25

Table 3: Volume Wine Consumption 1961 - 2006 hl-000's - Top 25

Table 4: Wine as a \% of Total Alcohol Consumption (average 1961 - 89, 1990 - 2006).. (20)

Table 5: Emerging Wine Drinking Nations

Table 6: Global Volume of Wine Imports, Wine Consumption, \% wine imports/wine consumption

Table 7: Global Volume of New World Wine Imports, Wine Consumption, \% new world wine imports/wine consumption

Table 8: Rates of New World wine diffusion....

Table 9: Ratings of Wine Choice factors across several countries

Table 10: Early adopter characteristics

Table 11: Perceived Attributes of Innovations

Table 12: Summary of Selected Cross National Diffusion Studies

Table 13: Results of Cross National Diffusion Studies using Hofstede's National Cultural

Dimensions

Table 14: Variable Measures and Sources

Table 15: Hypothesis 1 results

Table 16: Moderator 1 effect on Hypothesis 1

Table 17: Moderator 2 effect on Hypothesis 1

Table 18: Hypothesis 2 results

Table 19: Hypothesis 3 results

Table 20: Hypothesis 4 results

Table 21: Hypothesis 5 results

Table 22: Hypothesis 6 results

Table 23: Hypothesis 7 results

Table 24: Hypothesis 8 results

Table 25: Hypothesis 9 results

Table 26: Hypothesis 10 results

Table 27: Hypothesis 11 results

Table 28: Hypothesis 12 results

Table 29: Hypothesis 13 results 
Table 30: Summary of Findings

Table 31: tax on wine sales, import tariff \% of total taxes, selected countries

\section{List of Figures}

Figure 1: Conceptual Framework

Figure 2: Adopter Categories

Figure 3: Example s-shaped curve

Figure 4: Variables Determining the Rate of Adoption

Figure 5: New World Wine Innovativeness Continuum

Figure 6: Conceptual Framework Model

Figure 7: Examples of Perfect Positive and Perfect Negative Correlations on a Scattergraph

Figure 8: Scatterplot of Hypothesis 1

Figure 9: Scatterplot of Hypothesis 2

Figure 10: Scatterplot of Hypothesis 3

Figure 11: Scatterplot of Hypothesis 4

Figure 12: Scatterplot of Hypothesis 5

Figure 13: Scatterplot of Hypothesis 6

Figure 14: Scatterplot of Hypothesis 7

Figure 15: Scatterplot of Hypothesis 8

Figure 16: Scatterplot of Hypothesis 9

Figure 17: Scatterplot of Hypothesis 10

Figure 18: Scatterplot of Hypothesis 11

Figure 19: Scatterplot of Hypothesis 12

Figure 20: Scatterplot of Hypothesis 13

\section{List of Appendices}

Appendix 1:- list of World Countries and Regions represented in Global Wine Compendium incl. New World Wine Growth Rate (NW imports/Total Consumption) (1988 - 2006).....(102) Appendix 2: Hofstede 2005 National Cultural Dimension Data - Scores and Ranks.....(103) Appendix 3: List of amendments and proxies to match Hofstede country classifications with Global Wine Compendium country/regions classifications (where appropriate) (104) 


\section{CHAPTER ONE: INTRODUCTION}

\subsection{Background and Justification}

The effects of globalization have meant that an increasing amount of business is done at a global level. Effective understanding of global markets has become a necessity for any business looking to have an effective export strategy.

A key question for exporters has become how to drive sales in these global markets. Inherent in this is the ability to ascertain which markets to target and when. Key to making these decisions is an understanding of why products and ideas diffuse differently across different markets. While some of the drivers across countries are within managerial control e.g., marketing spend and distribution channels, other factors are inherent within the country market and are beyond managerial control e.g. country culture. Indeed many cross national diffusion studies have shown a significant correlation between 'country specific factors' and rates of diffusion (adoption) in country markets (Yaveroglu and Donthu 2002; Yeniyurt and Townsend 2003) . Furthermore, many authors (Rogers 2003; McSweeney 1999; Dwyer et al 2008; Hofstede 2001) have shown a link between consumer behavior and national culture.

Cross national diffusion literature often uses elements of the 'compatibility' attribute of an 'innovation' ('an idea, practice or object that is perceived as new by an individual or other unit of adoption" (Rogers 2003: p. 12)), to help explain diffusion rate. The compatibility attribute of an innovation includes the 'compatibility with socio-cultural values' of a country, and the 'compatibility with previously introduced ideas' within a country.

This study seeks to understand the effect of elements of the compatibility attribute on cross national diffusion of a new product class. The product class selected was New World wine. The selection of New World wine is due to New World wine's large export growth since the early 1990's (Anderson 2003), as well as the importance of wine exports to the New Zealand economy and the New Zealand brand (Hollebeck et al 2007). 


\subsection{Research Questions, Variables and Hypothesis Development}

\section{Research Questions}

Q1: Do country-level elements of the compatibility attribute affect the rate of diffusion of new world wine in global markets?

Q2: What are the variables that moderate the compatibility attribute effects?

Variables and Hypothesis Development

Figure 1:

\section{Conceptual Framework}
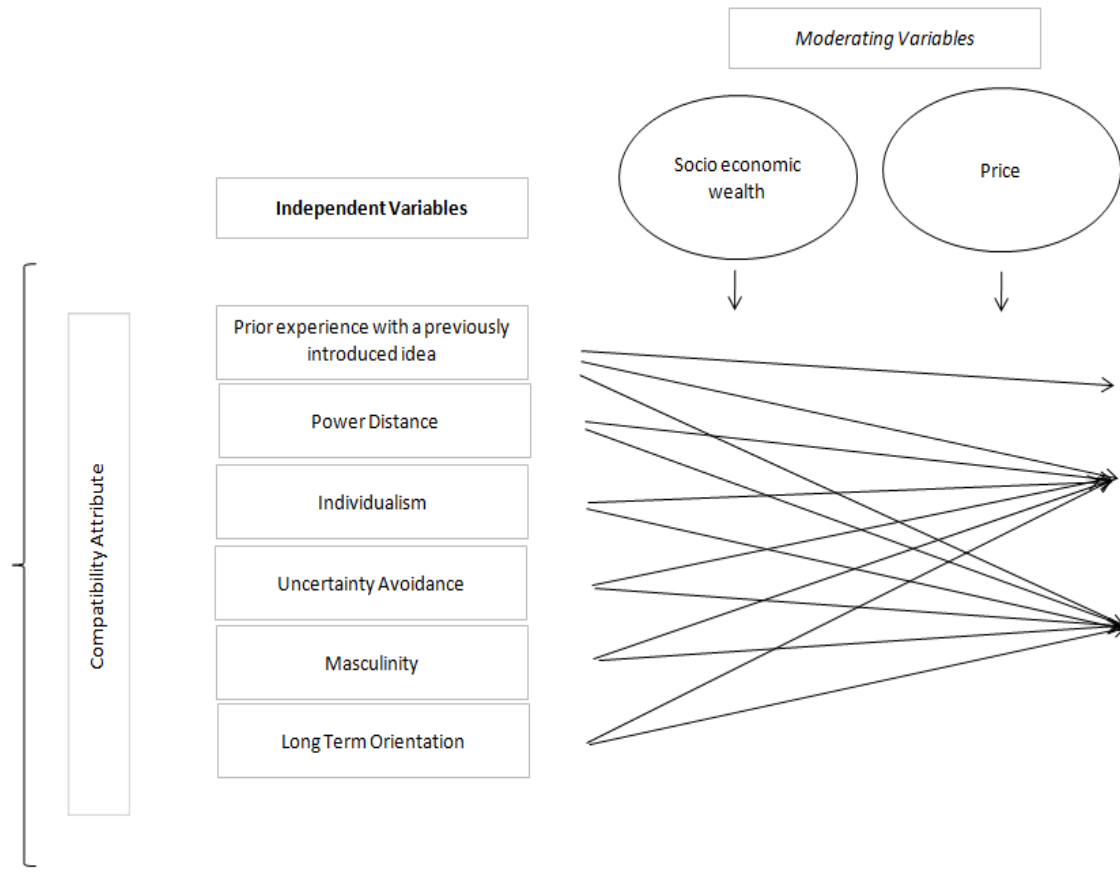

Market Share Growth

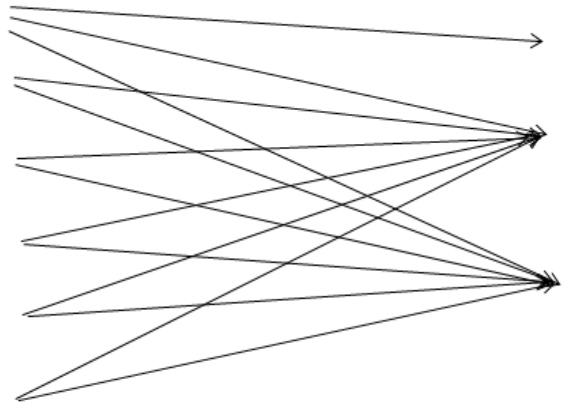

Speed from Take Off

The dependent variables for the study will be 'market share growth', 'time from introduction to take off' and 'speed from take off'. Diffusion literature outlines that there are two distinct stages to the diffusion curve, 'time from introduction to take off', and 'time from take off to market potential' and therefore these have been used in this study along with market share growth over the period. Due to data constraints this study has used 'speed from take off' as a measure for 'time from take off to market potential'. 
The independent variables are elements of the compatibility attribute (as previously described) and include 'prior experience with a previously introduced idea' (Rogers 2003), as well as Hofstede's five national cultural dimensions: Power distance, Individualism, Uncertainty avoidance, Masculinity and Long term Orientation (Hofstede 2001).

The moderating variables are socio economic wealth and price. Socio economic wealth is widely cited as a driver of product diffusion in a country (Gatignon et al 1989; Helsen et al 1993), and price is cited as a key driver of wine purchase behavior within the wine literature ( Batt \& Dean 2000; Ling \& Lockshin 2003) .

'Prior experience with a previously introduced idea' will be tested as an explanatory variable against all dependent variables. Hofstede's cultural dimensions will be tested as explanatory variables for 'time to take off' and 'speed from take-off' only as the literature outlines that these cultural dimensions have different explanatory effects across the different areas of the diffusion curve. Socio economic wealth and price will be tested for moderating effects across all independent variables.

\subsection{Methodology}

This research follows a positivist approach (Laudin 1996). However, a reflective approach rooted in the falsification theory has been adopted when an unexpected empirical finding emerged from the study. It uses secondary quantitative data and follows a scientific methodology. All wine data, as well as socio economic statistics, come from a publically available publication entitled 'Global Wine markets, 1961 - 2006: a statistical compendium' by Glyn Wittwer and Kym Anderson. This was sourced from the Australian Wine and Brandy Corporation for the years 1961 - 2003, and from the University of Adelaide library for years 2004 - 2006. National cultural dimension data was sourced from "Culture's consequences: Comparing values, behaviors, institutions, and organizations across nations", (Hofstede 2001).

Correlation, strength of effect and statistical significance tests were carried out for all hypotheses. These measures were determined through Pearson correlation coefficient tests and regression analysis. 


\subsection{Key Findings of the research}

The key finding from this research was the strong and statistically significant negative correlation found between prior experience of a previously introduced idea and market share growth of New World wine. This result was a rejection of the hypothesis that higher levels of prior experience of a previously introduced idea (or similar product) would correlate with higher diffusion rates in these markets, as was in line with classic diffusion theory. The author forwards the following potential reasons for this result:

- Status and reputation of the New World wine producers versus existing wine producers. Podolny (1993) states that consumers make purchase decisions based around an established product or producer status hierarchy. Where there is a high level of prior experience with a similar product, this status hierarchy is more strongly embedded in the market, and a new product class entering the market will take longer to gain market share as the new product class does not have a position in the status hierarchy and therefore is perceived to be of lower quality. Alternatively, where there is a weaker status hierarchy for the introduced product class, consumers will be more willing to consume the new product. In the case of New World wine this status hierarchy effect is magnified as wine is a defined as a high 'status' product, meaning that consumers risk a higher perceived loss of social status through the consumption of a product with a lower perceived quality reputation in the market.

- Protectionist economic policies for domestically produced wine in countries with high levels of prior wine experience. In countries where there are higher levels of domestically produced wine there are higher percentages of import tariffs placed on wine versus other consumer taxes, when compared to markets where there is less domestic production. This provides cost advantages to the domestic producer in these markets and the research shows there is a strong negative correlation between import tariff as a percentage of total consumer taxes and rates of New World wine market share growth.

- Other potential factors:

- Brand loyalty effect. Higher brand loyalty in markets with higher prior experience due to higher product involvement in these markets. 
- Country of origin effect. Producing countries of New World wine not having a country image that is associated with wine.

- Established distribution systems in place for existing wine producer. More difficulty for New World wine producers to enter traditional distribution networks based upon legacy relationships.

- New World wine acting as a more effective substitute for other alcohol types in those countries with low levels of experience of other wine classes. New World wines are considered fruitier and 'easier to drink' than other wine classes and therefore may be a more effective substitute for existing alcohol product in those countries that have low levels of prior experience with other wine classes.

○ New World wine marketing mix strategies. New World wine marketing strategies around mass market promotion, aggressive pricing and innovative product placement, labeling and presentation (e.g. screw caps) may be more effective in those markets that do not have a quality status hierarchy in place thus aiding the rate of diffusion in these markets. Alternatively, in markets with high levels of prior experience of a similar product and a status hierarchy in place, these strategies may send signals of low quality thus slowing adoption rate.

Hypotheses relating to cultural dimensions and their explanatory effect on the dependent variables were all unsupported due to the lack of statistical significance of the results.

\subsection{Outline of the research}

Chapter two will provide a review of the literature in the areas of wine and diffusion. Chapter three will present the research problem, research questions, hypothesis development and conceptual framework. Chapter four will illustrate the research methods including the construct measurements. Chapter five will present results and findings of the hypothesis tests. Chapter six will provide discussion and conclusions from the research.

\subsection{Limitations and scope of the study}


There are several limitations within the study.

The key dependent variable data was only available from 1988 to 2006 meaning that some countries had already started their diffusion process of New World wine before the first year of study. In addition, the period of study did not allow a long enough period to assess full diffusion. The effects of these limitations were to reduce sample size considerably for the 'time to take off' and 'speed from take off' dependent variables.

Also, it is recognized that there may have been political, economic and market changes across the global markets studied during the years 1998 - 2006, that may have had an effect on diffusion rates.

\subsection{Conclusion}

This research has looked at two 'new' areas of cross national diffusion theory. It therefore has an exploratory feel with very little directly relevant existing literature. Firstly, the cross national diffusion of a new product class is a new area of study. Most existing cross national diffusion studies have concentrated upon innovations, especially in the area of consumer durables and technology products. A study of a 'new product class' innovation differs from a study of diffusion of a 'new product' innovation as there is less 'innovativeness' within the product, therefore less uncertainty within the market, resulting in different purchase behaviours. Secondly, this research has looked at 'prior experience with previously introduced idea' as an explanatory variable at a cross national level. Prior experience with a previously introduced idea is a core part of the compatibility attribute of Rogers' diffusion theory however has not been studied within any cross national diffusion research known to the author. A potential reason for this is that existing research has dealt with products that are highly innovative and therefore prior experience with a previously introduced idea is not as relevant as it is with the diffusion of a new product class.

The fact that a strong and statistically significant negative relationship was found between prior experience with a previously introduced idea and market share growth of New World wine is an important development in the area of cross national diffusion research and provides a foundation for further research. The author sees the rejection of the hypothesis 
and the resulting strong negative correlation as a positive result in the pursuit of knowledge and understanding in this area, in line with Popper's (1972) falsification theory.

The author concludes from this research that for new product classes that can be defined as 'status' products, higher levels of prior experience with a similar product leads to slower rates of diffusion in that market. While there are a variety of potential factors to explain this, in the author's opinion the key factor is the existence of a product (producer) status hierarchy in high prior experience markets, that defines the level of quality in the mind of the consumer before the new product class enters the market. In this circumstance, the new product class needs to establish a position within this perceived hierarchy in order to increase market share. Alternatively, in a market where this status hierarchy does not exist to the same level, the new product class can achieve higher diffusion rates when the new product class enters the market as the consumer is more open-minded to the quality of the new product class. In addition, producers of the new product class can potentially achieve greater gains in a low experience market through price and promotion, and thus achieve faster market share growth.

In the author's opinion, the product type of the new product class is a key variable that is outlined in this research. A 'status' product such as wine would appear to have far higher social status risk if a perceived lower quality product is consumed within a market with an existing status hierarchy, than does a functional product. As more products that once were considered functional become status products e.g. phones and computers, the higher the effect of the status hierarchy becomes.

The author suggests that this research is valuable in furthering cross national diffusion theory. When a new product class enters a market, and the product can be classified as a 'status' product, the 'prior experience with a previously introduced idea' construct of the compatibility attribute needs to be extended. This extension should measure the strength of the perceived status hierarchy in place in the society (market) to help determine the rate of adoption. This addition to the diffusion theory may help explain why Rogers (2003) found mixed results when using 'prior experience with a previously introduced idea' as an explanatory variable in diffusion rate.

In addition, this research provides implications for managers in the areas of market segmentation and targeting as well as promotion, price, placement and product strategies. 


\section{CHAPTER TWO: LITERATURE REVIEW}

\subsection{Introduction}

The following Literature Review will provide a background to understanding patterns of global diffusion rates of New World wine. It is split into two sections:

- Wine

- Diffusion

The purpose of the wine section is to provide an understanding of why, and to what degree, New World wine has infiltrated the global wine market. It will seek to:

- provide a background of the global wine market

- discuss the impact of New World wine on the global market

- provide a review of general wine consumer choice factors

- analyse cross national wine choice factors.

The diffusion section will explain the concept of 'diffusion of innovations' including in a cross national sense. It will provide a background of the innovation diffusion process and the patterns of diffusion. It will look at 'rate of adoption' and seek to understand potential determinants of rate of adoption that apply to New World wine in a cross national sense.

\subsection{Wine}

\section{Introduction}

This section will endeavour to provide a view of the global wine market, including a historical perspective as well as recent trends in the areas of global production, global consumption and global trade. It will look at the advent of New World wine on the global wine market and will seek to understand success factors for New World wine. It will look at wine choice factors, including at a cross national level, and will introduce the concept of varying rates of New World wine growth across various global markets at a country level.

\subsubsection{Wine Production, Consumption and Trade}

History of the Global Wine Market 
Wine has certainly had a long and distinguished history. The first systematic cultivation of grapevines probably took place between, and to the south of the Black and Caspian seas at least 6000 years ago, gradually spreading west to Egypt, Greece and perhaps Southern Spain by $2500 \mathrm{BC}$ and reaching Italy in about $800 \mathrm{BC}$ and France around $600 \mathrm{BC}$. Anderson (2003) explains that by around the $4^{\text {th }}$ century AD, winegrape cultivation was well established in what we now know as the 'Old World' of Europe, as well as North Africa. Cultivation of wine grapes moved to Mexico and South America in the $16^{\text {th }}$ and $17^{\text {th }}$ centuries and into what is now California in the early $19^{\text {th }}$ century (Anderson 2003). Grape cultivation occurred in Australia around 1790, while in NZ it first occurred around 1820. Up until the early/mid 1990's virtually all of the wine production in the 'New World' was for local consumption (Robinson 1994).

Since the early/mid 1990's the global wine landscape has undergone large structural changes in the areas of production, consumption and trade. According to Anderson (2003) the key catalyst of these structural changes has been the emergence of New World wine on the global market. There are various definitions of New World wine producers, however the generally accepted definition, and the one that will be used in this research, is that of the group that comprises Australia, USA, New Zealand, South Africa, Chile and Argentina. This differs from 'Old World' producers who have been defined as countries from Western Europe by Thorpe (2009) amongst others, and Europe by many other authors, including Cholette et al (2005), and Geraghty et al (2009). For the purposes of this research 'Old World' will be defined as Western and Central Europe which is line with Anderson (2003) and includes: France, Italy, Spain, Portugal, Germany, Hungary, Bulgaria, Romania, Austria, Moldova, Austria, Switzerland, Croatia and Greece. There are of course other wine producing countries and regions around the world which could be classified as New World producers such as China and Canada. For the purposes of this study, these countries will not be considered as New World, due to the current lack of wine export scale of these countries, and in line with the generally accepted definition as prescribed by Thorpe (2009) and others. The author notes that these 'other' producers, especially China, have high current production (and consumption) growth rates and large further production and export growth potential.

\section{Current Trends in Global Production, Consumption and Trade}

This section will seek to outline recent trends in the production of wine globally, recent consumption trends and recent global trade trends. It will present changes in the global wine 
market over the past 30 - 50 years to provide a background in understanding how New World wine has diffused across international markets.

\section{Global Production}

Overall world wine production has stabilised in the period since the mid 1990's compared to the equivalent prior period $(1980-1995)$ where it had declined significantly (see table 1). Thorpe (2009) explains that this stabilisation has been due to rising production outputs from New World producers, that have countered decreasing production outputs from Old World producers. Table 2 shows how the global production share has changed on a per country basis from 1961 - 2006. Of the Old World producers, France and Italy have decreased in this period while Spain has increased. All New World Wine producers have increased their production volume share significantly with the exception of Argentina which has decreased their share in this period.

Table 1:

Global Production Volumes (hl) 1961 - 2006

\begin{tabular}{|c|c|c|c|c|c|c|c|}
\hline Year & World & New World & Old World & Other & NW(\%) & OW(\%) & Other(\%) \\
\hline $1961-64$ (ave) & 24876 & 3609 & 18206 & 3061 & $15 \%$ & $73 \%$ & $12 \%$ \\
\hline 1965 - 69 (ave) & 27815 & 3982 & 19451 & 4382 & $14 \%$ & $70 \%$ & $16 \%$ \\
\hline $1970-74$ (ave) & 31178 & 4673 & 21362 & 5143 & $15 \%$ & $69 \%$ & $16 \%$ \\
\hline 1975 - 79 (ave) & 32053 & 5502 & 21332 & 5219 & $17 \%$ & $67 \%$ & $16 \%$ \\
\hline $1980-84$ (ave) & 34376 & 5976 & 22547 & 5853 & $17 \%$ & $66 \%$ & $17 \%$ \\
\hline 1985 - 89 (ave) & 30630 & 5357 & 20629 & 4644 & $17 \%$ & $67 \%$ & $15 \%$ \\
\hline 1990 - 94 (ave) & 26859 & 4833 & 18656 & 3370 & $18 \%$ & $69 \%$ & $13 \%$ \\
\hline 1995 - 99 (ave) & 26817 & 5379 & 18165 & 3273 & $20 \%$ & $68 \%$ & $12 \%$ \\
\hline 2000 & 28376 & 6285 & 19374 & 2717 & $22 \%$ & $68 \%$ & $10 \%$ \\
\hline 2001 & 26722 & 6325 & 17666 & 2731 & $24 \%$ & $66 \%$ & $10 \%$ \\
\hline 2002 & 26725 & 6527 & 17508 & 2690 & $24 \%$ & $66 \%$ & $10 \%$ \\
\hline 2003 & 26744 & 6457 & 17306 & 2981 & $24 \%$ & $65 \%$ & $11 \%$ \\
\hline 2004 & 30055 & 7049 & 19795 & 3211 & $23 \%$ & $66 \%$ & $11 \%$ \\
\hline 2005 & 28795 & 7314 & 18269 & 3212 & $25 \%$ & $63 \%$ & $11 \%$ \\
\hline 2006 & 28443 & 7285 & 18075 & 3083 & $26 \%$ & $64 \%$ & $11 \%$ \\
\hline
\end{tabular}

source: winetrac 2009 
source: winetrac 2009

\section{Global Consumption}

Until the early 1990's, wine consumption was mainly concentrated in the 'Old World' wine producing countries. Table 3 shows total wine consumption across the top 25 wine consuming countries (by volume) in the period 1961 - 2006. Since 1990, global wine demand within Old World producing countries has decreased as has demand within Chile and Argentina, while large growth has been experienced in 'non-traditional' consumption markets (those countries outside of the 'Old World' producing countries), with UK, USA, Ireland, Australia, Canada, The Netherlands, Scandinavia, Russia and China experiencing strong demand growth over this period on a volume basis. Thorpe (2009) reasons that this growth in non-traditional markets maybe due to growing affluence in these areas as well as changing preferences, although adds that rising income does not necessarily drive increased demand for wine. Rose and Gordon (2006) speculate that abundant global supplies and resultant falling prices have contributed to growth in non-traditional markets, while mass marketing, especially through supermarkets, has certainly contributed to growth in the UK market (Thorpe 2009). The author feels that the opening of trade restrictions over the past 20 years, including free trade agreements and import tariff restrictions, have also contributed to increased demand through increased supply and increased wine choice. 
Table 3:

Volume beverage wine consumption - 1961 - 2006 - $\mathrm{hl}$ (000's) - Top 25

\begin{tabular}{|c|c|c|c|c|c|c|c|c|c|c|c|c|c|c|c|c|c|}
\hline & $1961-64$ & $1965-69$ & $1970-74$ & $1975-79$ & $1980-84$ & $1985-89$ & $1990-94$ & 1995-99 & 2000 & 2001 & 2002 & 2003 & 2004 & 2005 & 2006 & growth 1961-2006 & growth 1990-2006 \\
\hline France & 5,860 & 5,721 & 5,513 & 5,275 & 4,737 & 4,224 & 3,803 & 3,562 & 3,450 & 3,392 & 3,482 & 3,290 & 3,314 & 3,260 & 3,300 & $-44 \%$ & $-13 \%$ \\
\hline Italy & 5,465 & 5,940 & 5,943 & 5,184 & 4,801 & 3,913 & 3,431 & 3,232 & 3,080 & 3,015 & 2,932 & 2,934 & 2,830 & 2,760 & 2,733 & $-50 \%$ & $-20 \%$ \\
\hline US & 667 & 787 & 1,221 & 1,538 & 1,950 & 2,132 & 1,784 & 1,987 & 2,120 & 2,125 & 2,254 & 2,380 & 2,431 & 2,511 & 2,590 & $288 \%$ & $45 \%$ \\
\hline Germany & 1,105 & 1,205 & 1,494 & 1,852 & 1,990 & 1,840 & 1,896 & 1,890 & 2,015 & 2,004 & 2,027 & 2,015 & 1,959 & 1,944 & 1,994 & $80 \%$ & $5 \%$ \\
\hline Spain & 1,902 & 2,063 & 2,348 & 2,522 & 2,165 & 1,762 & 1,589 & 1,463 & 1,405 & 1,424 & 1,396 & 1,380 & 1,374 & 1,374 & 1,351 & $-29 \%$ & $-15 \%$ \\
\hline UK & 110 & 142 & 235 & 337 & 460 & 620 & 735 & 932 & 908 & 979 & 992 & 1,113 & 1,130 & 1,200 & 1,170 & $968 \%$ & $59 \%$ \\
\hline Argentina & 1,787 & 1,948 & 2,004 & 2,210 & 2,097 & 1,791 & 1,628 & 1,405 & 1,249 & 1,204 & 1,199 & 1,234 & 1,111 & 1,097 & 1,110 & $-38 \%$ & $-32 \%$ \\
\hline Russia & 734 & 1,256 & 2,021 & 1,854 & 1,901 & 1,044 & 689 & 902 & 524 & 580 & 663 & 931 & 855 & 1,007 & 1,066 & $45 \%$ & $55 \%$ \\
\hline Oth Cent/east euro & 678 & 785 & 968 & 1,291 & 1,233 & 1,222 & 1,249 & 1,134 & 664 & 702 & 703 & 703 & 704 & 705 & 706 & $4 \%$ & $-44 \%$ \\
\hline China & 0 & 0 & 0 & 0 & 0 & 43 & 303 & 393 & 365 & 381 & 398 & 438 & 506 & 591 & 601 & na & $99 \%$ \\
\hline Romania & 510 & 529 & 552 & 700 & 637 & 591 & 494 & 676 & 522 & 471 & 496 & 505 & 580 & 590 & 555 & $9 \%$ & $12 \%$ \\
\hline Portugal & 889 & 911 & 764 & 755 & 776 & 657 & 570 & 536 & 460 & 470 & 465 & 529 & 483 & 482 & 479 & $-46 \%$ & $-16 \%$ \\
\hline Australia & 57 & 81 & 124 & 197 & 287 & 336 & 318 & 347 & 389 & 398 & 401 & 420 & 436 & 452 & 457 & $698 \%$ & $44 \%$ \\
\hline Canada & 43 & 59 & 103 & 159 & 223 & 250 & 219 & 221 & 276 & 280 & 288 & 344 & 361 & 379 & 399 & $832 \%$ & $82 \%$ \\
\hline Netherlands & 31 & 51 & 103 & 160 & 198 & 224 & 242 & 324 & 310 & 333 & 333 & 356 & 360 & 347 & 351 & $1047 \%$ & $45 \%$ \\
\hline Brazil & 159 & 166 & 194 & 277 & 326 & 272 & 275 & 311 & 318 & 308 & 318 & 327 & 318 & 371 & 347 & $118 \%$ & $26 \%$ \\
\hline SA & 142 & 186 & 243 & 240 & 268 & 306 & 339 & 389 & 389 & 390 & 388 & 349 & 351 & 345 & 345 & $143 \%$ & $2 \%$ \\
\hline Greece & 315 & 332 & 344 & 372 & 417 & 308 & 322 & 286 & 286 & 294 & 242 & 245 & 293 & 348 & 320 & $2 \%$ & $-1 \%$ \\
\hline Hungary & 301 & 349 & 391 & 364 & 335 & 239 & 304 & 296 & 315 & 320 & 345 & 312 & 308 & 310 & 311 & $4 \%$ & $3 \%$ \\
\hline Belgium/Luxembourg & 124 & 125 & 163 & 179 & 210 & 231 & 229 & 248 & 276 & 240 & 272 & 238 & 266 & 278 & 286 & $130 \%$ & $25 \%$ \\
\hline Switzerland & 206 & 237 & 281 & 283 & 312 & 319 & 306 & 292 & 309 & 308 & 301 & 297 & 293 & 285 & 277 & $34 \%$ & $-9 \%$ \\
\hline Chile & 485 & 437 & 494 & 490 & 515 & 414 & 314 & 255 & 286 & 247 & 245 & 255 & 255 & 264 & 259 & $-47 \%$ & $-18 \%$ \\
\hline Austria & 163 & 235 & 267 & 269 & 272 & 258 & 260 & 251 & 248 & 229 & 240 & 238 & 240 & 240 & 245 & $50 \%$ & $-6 \%$ \\
\hline Japan & 15 & 30 & 36 & 57 & 78 & 103 & 127 & 242 & 263 & 279 & 278 & 254 & 234 & 241 & 238 & $1543 \%$ & $88 \%$ \\
\hline Croatia & 0 & 0 & 0 & 0 & 0 & 0 & 83 & 206 & 187 & 192 & 189 & 188 & 189 & 189 & 189 & na & $128 \%$ \\
\hline Denmark & 16 & 22 & 40 & 63 & 87 & 109 & 130 & 156 & 162 & 177 & 171 & 171 & 172 & 177 & 183 & $1027 \%$ & $40 \%$ \\
\hline Old World big 5 & 15,221 & 15,841 & 16,062 & 15,587 & 14,468 & 12,397 & 11,289 & 10,683 & 10,409 & 10,305 & 10,302 & 10,148 & 9,960 & 9,819 & 9,858 & $-35 \%$ & $-13 \%$ \\
\hline Old World & 16,705 & 17,494 & 17,836 & 17,521 & 16,379 & 14,050 & 12,987 & 12,620 & 12,097 & 11,958 & 11,943 & 11,762 & 11,690 & 11,608 & 11,575 & $-31 \%$ & $-11 \%$ \\
\hline New World & 3,248 & 3,579 & 4,320 & 5,012 & 5,577 & 5,600 & 5,118 & 5,315 & 5,342 & 5,343 & 5,478 & 5,751 & 5,714 & 5,870 & 5,931 & $83 \%$ & $16 \%$ \\
\hline World & 22,344 & 24,272 & 26,572 & 27,447 & 27,192 & 24,181 & 22,614 & 23,408 & 22,129 & 22,145 & 22,517 & 22,959 & 22,875 & 23,298 & 23,408 & $5 \%$ & $4 \%$ \\
\hline
\end{tabular}

source: winetrac 2009

Table 4 shows wine as a $\%$ of total alcohol consumption for selected global markets for the period 1961 - 1989, and for the period 1990 - 2006. It shows that 'Old World' producers have a higher percentage of wine consumed as a percentage of total alcohol compared to 'New World' producers and other non traditional markets across both periods. These 'Old World' countries are frequently described as having a 'wine drinking tradition' (Anderson 2003) and have been described as having a 'wine culture' (Aurifielle et al 2001). It is also evident that wine as a percentage of total alcohol in 'Old World' countries has generally decreased over the past 50 years while 'Other' countries have generally shown an increase, especially in 'Other' European countries. New World wine countries as a whole have experienced a decrease in wine percentage of alcohol consumption between the two periods. This is explainable by Argentina and Chile experiencing heavy declines, in line with 'Old World' countries. Other New World countries such as New Zealand, Australia and USA have experienced significant increases across the periods. 
Table 4:

Wine as \% of total alcohol consumption (average 1961-89, 1990-2006)

\begin{tabular}{|c|c|c|c|}
\hline Country/Area & Average 1961 - 1989 & Average of $1990-2006$ & Difference \\
\hline Austria & $40 \%$ & $38 \%$ & $-4 \%$ \\
\hline Bulgaria & $42 \%$ & $35 \%$ & $-16 \%$ \\
\hline France & $75 \%$ & $64 \%$ & $-14 \%$ \\
\hline Germany & $23 \%$ & $29 \%$ & $28 \%$ \\
\hline Greece & $74 \%$ & $52 \%$ & $-29 \%$ \\
\hline Hungary & $40 \%$ & $38 \%$ & $-4 \%$ \\
\hline Italy & $84 \%$ & $78 \%$ & $-7 \%$ \\
\hline Portugal & $85 \%$ & $60 \%$ & $-30 \%$ \\
\hline Romania & $57 \%$ & $38 \%$ & $-33 \%$ \\
\hline Spain & $63 \%$ & $42 \%$ & $-33 \%$ \\
\hline Switzerland & $52 \%$ & $56 \%$ & $9 \%$ \\
\hline Old World & $58 \%$ & $56 \%$ & $-3 \%$ \\
\hline Argentina & $90 \%$ & $72 \%$ & $-21 \%$ \\
\hline Australia & $20 \%$ & $33 \%$ & $67 \%$ \\
\hline Chile & $85 \%$ & $43 \%$ & $-50 \%$ \\
\hline New Zealand & $14 \%$ & $33 \%$ & $138 \%$ \\
\hline South Africa & $37 \%$ & $25 \%$ & $-32 \%$ \\
\hline United States of America & $11 \%$ & $16 \%$ & $43 \%$ \\
\hline New World & $43 \%$ & $37 \%$ & $-14 \%$ \\
\hline Belgium-Luxembourg & $24 \%$ & $33 \%$ & $41 \%$ \\
\hline Brazil & $30 \%$ & $6 \%$ & $-79 \%$ \\
\hline Canada & $11 \%$ & $20 \%$ & $86 \%$ \\
\hline Denmark & $18 \%$ & $42 \%$ & $141 \%$ \\
\hline Finland & $10 \%$ & $25 \%$ & $157 \%$ \\
\hline Ireland & $5 \%$ & $15 \%$ & $214 \%$ \\
\hline China & $0 \%$ & $1 \%$ & $178 \%$ \\
\hline Japan & $2 \%$ & $5 \%$ & $175 \%$ \\
\hline Netherlands & $17 \%$ & $33 \%$ & $92 \%$ \\
\hline North Africa & $52 \%$ & $44 \%$ & $-15 \%$ \\
\hline Other Central Eastern Europe & $16 \%$ & $14 \%$ & $-13 \%$ \\
\hline Other Latin America Caribbean & $3 \%$ & $2 \%$ & $-6 \%$ \\
\hline Other Western Europe & $9 \%$ & $30 \%$ & $222 \%$ \\
\hline Russia & $25 \%$ & $10 \%$ & $-59 \%$ \\
\hline Sweden & $17 \%$ & $33 \%$ & $89 \%$ \\
\hline Turkey & $18 \%$ & $7 \%$ & $-60 \%$ \\
\hline United Kingdom & $10 \%$ & $27 \%$ & $170 \%$ \\
\hline Uruguay & $70 \%$ & $68 \%$ & $-4 \%$ \\
\hline Other & $28 \%$ & $37 \%$ & $33 \%$ \\
\hline
\end{tabular}

source: global wine compendium 2006 (Wittwer, Anderson)

Since the early/mid 1990's, as discussed above, there has been a large growth in wine consumption in many countries. Anderson (2003) refers to these high consumption growth countries as 'emerging'. In the author's opinion, there is a lack of adequate classification for these levels of 'emergence' and therefore forwards the following classification template (see Table 5 below): Quick emerger (>3.5\% average annual growth in consumption per capita 1990 - 2006), eg. Ireland, China, Russia; slow emerger (1\% - 3.5\% average annual growth in consumption per capita 1990 - 2006) eg USA, Brazil; and de-emerger (less than $1 \%$ average growth annual consumption per capita 1990 - 2006) eg. France, Italy. It is apparent that nonemerger's are mainly 'traditional wine drinking' countries ('Old World' producers), while quick emergers are mainly non-traditional markets. 


\begin{tabular}{|c|c|c|c|c|c|}
\hline \multicolumn{6}{|c|}{$\begin{array}{l}\text { Emerging Wine Drinking Nations } \\
\text { Average Annual Growth in wine consumption per capita - } 1996-2006\end{array}$} \\
\hline \multicolumn{2}{|c|}{ quick emerger } & \multicolumn{2}{|c|}{ slow emerger } & \multicolumn{2}{|l|}{ non-emerger } \\
\hline Ireland & $13.18 \%$ & Denmark & $1.93 \%$ & Bulgaria & $-0.21 \%$ \\
\hline Ukraine & $12.73 \%$ & Greece & $1.85 \%$ & world & $-0.25 \%$ \\
\hline China & $9.09 \%$ & Other Latin/Carrib & $1.82 \%$ & Switzerland & $-0.60 \%$ \\
\hline Canada & $7.60 \%$ & |Brazil & $1.70 \%$ & Austria & $-0.78 \%$ \\
\hline Russia & $7.36 \%$ & Croatia & $1.65 \%$ & France & $-0.95 \%$ \\
\hline Other West Euro & $7.35 \%$ & & $1.35 \%$ & Other Cent/East Euro & $-1.15 \%$ \\
\hline Finland & $5.22 \%$ & Belgium- & $1.30 \%$ & Italy & $-1.22 \%$ \\
\hline & $4.65 \%$ & Uruguay & $0.72 \%$ & Portugal & $-1.27 \%$ \\
\hline Netherlands & $3.94 \%$ & Japan & $0.51 \%$ & Azerbaijan & $-1.75 \%$ \\
\hline sweden & $3.79 \%$ & Germany & $0.47 \%$ & & $-1.76 \%$ \\
\hline & $3.09 \%$ & Hungary & $0.45 \%$ & Argentina & $-2.40 \%$ \\
\hline Georgia & $2.26 \%$ & Romania & $0.34 \%$ & Uzbekistan & $-6.34 \%$ \\
\hline Australia & $2.16 \%$ & Spain & $0.18 \%$ & Moldova & $-7.70 \%$ \\
\hline & & & & & \\
\hline & & & & & \\
\hline
\end{tabular}

Global Trade

The International Organisation of Vine and Wine (2008) reports that global exports have risen from $18 \%$ of all wine produced in 1990 to $30 \%$ in 2008. Exports as a share of production for New World producers have risen from 3\% to $28 \%$ in the period $1990-2005$, and for Old World producers, from $20 \%$ to $31 \%$. Table 6 shows the change in volume of wine imports/wine consumption for Old World, New World and Other consumer markets, and shows an increase in the import percentage from $17 \%$ to $33 \%$ over the period $1988-$ 2006 across all consumer groups. This broken down as: Old World 12\% - 21\%, New World $6 \%-17 \%$, Other $40 \%-62 \%$.

Table 6:

Global Volume of Wine Imports, Wine Consumption and \% of wine imports/consumption - Old World, New World, Other

\begin{tabular}{|c|c|c|c|c|c|c|c|c|c|c|c|c|c|c|c|c|c|c|c|c|}
\hline & & 1988 & 899 & 990 & 1991 & 1992 & 1993 & 1994 & 1995 & 1996 & 1997 & 1998 & 1999 & 2000 & 2001 & 2002 & 2003 & 2004 & 2005 & $2 v$ \\
\hline \multirow[t]{4}{*}{ Volume Wine Imports } & Old World & 1,767 & 1,937 & 1,839 & 2,025 & 1,950 & 1,909 & 2,182 & 2,031 & 1,739 & 1,998 & 2,155 & 2,196 & 1,979 & 2,021 & 1,732 & 2,476 & 2,913 & 2,054 & 2,43 \\
\hline & N & 316 & 294 & 263 & 299 & 283 & 280 & 329 & 385 & 448 & 585 & 536 & 551 & 597 & 636 & 713 & 770 & 756 & 847 & \\
\hline & & 2,143 & 2,297 & 2,142 & 2,028 & 2,317 & 2,535 & 2,769 & 3,147 & 3,237 & 3,628 & 3,709 & 3,475 & 3,650 & 4,015 & 3,887 & 4,110 & 4,270 & 4,625 & 5,00 \\
\hline & To & 4,227 & 4,528 & 4,244 & 4,352 & 4,551 & 4,723 & 5,280 & 5,563 & 5,425 & 6,211 & 6,401 & 6,223 & 6,226 & 6,672 & 6,331 & 7,357 & 7,939 & 7,525 & 8,3 \\
\hline \multirow[t]{4}{*}{ Volume Wine Consumption } & 010 & 14,339 & 13,147 & 13,450 & 13,474 & 13,346 & 13,205 & 12,776 & 12,623 & 12,623 & 12,837 & 12,541 & 12,242 & 12,061 & 12,153 & 12,186 & 12,062 & 11,978 & 11,879 & 11,8 \\
\hline & $\mathrm{Ne}$ & 4,990 & 4,743 & 4,727 & 4,503 & 4,456 & 4,176 & 4,248 & 4,250 & 4,367 & 4,409 & 4,517 & 4,873 & 4,941 & 4,952 & 5,020 & 5,170 & 5,069 & 5,122 & 5,1 \\
\hline & Other & 5,358 & 5,489 & 5,478 & 5,654 & 5,188 & 5,029 & 5,124 & 5,425 & 5,621 & 5,965 & 6,013 & 6,310 & 6,404 & 6,599 & 7,304 & 7,599 & 7,627 & 8,006 & 8,0 \\
\hline & Total & 24,687 & 23,379 & 23,655 & 23,631 & 22,990 & 22,409 & 22,148 & 22,298 & 22,611 & 23,211 & 23,071 & 23,424 & 23,406 & 23,703 & 24,510 & 24,831 & 24,674 & 25,007 & 25,0 \\
\hline \multirow[t]{4}{*}{ \% Imports/Consumption } & Old Wo & $12 \%$ & $15 \%$ & $14 \%$ & $15 \%$ & $15 \%$ & $14 \%$ & $17 \%$ & $16 \%$ & $14 \%$ & $16 \%$ & $17 \%$ & $18 \%$ & $16 \%$ & $17 \%$ & $14 \%$ & $21 \%$ & $24 \%$ & $17 \%$ & \\
\hline & New World & $6 \%$ & $6 \%$ & $6 \%$ & $7 \%$ & $6 \%$ & $7 \%$ & $8 \%$ & $9 \%$ & $10 \%$ & $13 \%$ & $12 \%$ & $11 \%$ & $12 \%$ & $13^{\circ}$ & 14 & 15 & $15 \%$ & $17 \%$ & \\
\hline & Other & $40 \%$ & $42 \%$ & $39 \%$ & $36 \%$ & $45 \%$ & $50 \%$ & $54 \%$ & $58 \%$ & $58 \%$ & $61 \%$ & $62 \%$ & $55 \%$ & $57 \%$ & $61 \%$ & 530 & $54 \%$ & $56 \%$ & $58 \%$ & \\
\hline & Total & $17 \%$ & $19 \%$ & $18 \%$ & $18 \%$ & $20 \%$ & $21 \%$ & $24 \%$ & $25 \%$ & $24 \%$ & $27 \%$ & $28 \%$ & $27 \%$ & $27 \%$ & $28 \%$ & $26 \%$ & $30 \%$ & $32 \%$ & $30 \%$ & \\
\hline
\end{tabular}

source: global wine compendium 2006 (Wittwer, Anderson)

Anderson (2003) states that New World wines have triggered this global export/import expansion, making inroads into Old World domestic markets as well as strongly competing in 
rapidly expanding non-traditional 'Other' markets . Table 7 illustrates this idea with New World wine imports as a percentage of total wine consumption growing from 0\% in 1988 to $9 \%$ of all wine consumed globally in 2006. In 'Other' markets New World wine imports as a percentage of total wine consumed has grown from $2 \%$ in 1988, to $20 \%$ in 2006.

Table 7:

Global Volume of New Word Wine Impoots, Total Wine Consumption and ' o o N New World Wine imports consumpion - Old Word, New Word, Other

\begin{tabular}{|c|c|c|c|c|c|c|c|c|c|c|c|c|c|c|c|c|c|c|c|c|}
\hline & & 1988 & 1989 & 1990 & 1991 & 1992 & 1993 & 1994 & 1995 & 1996 & 1997 & 1998 & 19999 & 2000 & 2001 & 2002 & 2003 & 2004 & 2005 & 2006 \\
\hline \multirow[t]{4}{*}{ Volume New World Wine Impor } & Old World & 4 & 10 & 19 & 16 & 18 & 18 & 24 & 206 & 92 & 72 & 76 & 91 & 106 & 113 & 106 & 184 & 238 & 279 & 268 \\
\hline & New World & 16 & 16 & 23 & 45 & 42 & 65 & 79 & 84 & 118 & 162 & 149 & 153 & 181 & 202 & 219 & 323 & 331 & 385 & 407 \\
\hline & Other & 101 & 115 & 161 & 198 & 245 & 205 & 306 & 377 & 501 & 593 & 645 & 748 & 789 & 896 & 969 & 1,099 & 1,377 & 1,368 & 1,591 \\
\hline & Total & 121 & 142 & 203 & 258 & 305 & 347 & 408 & 667 & 711 & 828 & 871 & 992 & 1,076 & 1,211 & 1,324 & 1,606 & 1.945 & 20.2 & 2266 \\
\hline \multirow[t]{4}{*}{ Volume Vine Consumption } & Old World & 14,339 & 13,147 & 13,150 & 13,474 & 13,346 & 13,205 & 12776 & 12,623 & 12,623 & 12,837 & 12,541 & 12,242 & 12,061 & 12,153 & 12,186 & 12,062 & 11,978 & 11,879 & 11,024 \\
\hline & New World & 4,990 & 4,743 & 4,727 & 4,503 & 4,456 & 4,76 & 4,248 & 4,250 & 4,367 & 4,409 & 4,517 & 4,873 & 4,44 & 4,952 & 5,020 & 5,170 & 5,069 & 5,12 & 5,156 \\
\hline & Other & 5,558 & 5,489 & 5.478 & 5,654 & 5,188 & 5,029 & 5,124 & 5425 & 5,621 & 5,965 & 6,013 & 6,310 & 6,404 & 6,599 & 7,304 & 7,599 & 7.627 & 8006 & 8048 \\
\hline & Total & 24,687 & 23379 & 23655 & 23.631 & 22,990 & 22409 & 22148 & 22228 & 22.611 & 232.211 & 23.071 & 23.24 & 23,406 & 23703 & 24510 & 24.831 & 24674 & 25,007 & 25008 \\
\hline \multirow[t]{4}{*}{ \% NWW Imports Consumntion } & OldWorld & $0 \%$ & $0 \%$ & $0 \%$ & $0 \%$ & $0 \%$ & $0 \%$ & W\% & $2 \%$ & $1 \%$ & $1 \%$ & $1 \%$ & $1 \%$ & $1 \%$ & $1 \%$ & $1 \%$ & $2 \%$ & $2 \%$ & $2 \%$ & $2 \%$ \\
\hline & New World & $0 \%$ & $0 \%$ & $0 \%$ & $1 \%$ & $1 \%$ & $2 \%$ & $2 \%$ & $2 \%$ & $3 \%$ & $4 \%$ & $3 \%$ & $3 \%$ & $4 \%$ & $4 \%$ & $5 \%$ & $6 \%$ & $7 \%$ & $8 \%$ & $8 \%$ \\
\hline & Other & $2 \%$ & $2 \%$ & $3 \%$ & $3 \%$ & $5 \%$ & $5 \%$ & $6 \%$ & $7 \%$ & $9 \%$ & $10 \%$ & $11 \%$ & $12 \%$ & $12 \%$ & $14 \%$ & $13 \%$ & $14 \%$ & $18 \%$ & $17 \%$ & $20 \%$ \\
\hline & Total & $0 \%$ & $1 \%$ & $1 \%$ & $1 \%$ & $1 \%$ & $2 \%$ & $2 \%$ & $3 \%$ & $3 \%$ & $4 \%$ & $4 \%$ & $4 \%$ & $5 \%$ & $5 \%$ & $5 \%$ & $6 \%$ & $8 \%$ & $8 \%$ & $9 \%$ \\
\hline
\end{tabular}

source: global vine compendium 2006 Nititwe, Anderson)

Along with the New World wine 'explosion' onto the global wine market, and the environmental changes that have changed global demand patterns as has been described in the 'Global Consumption' section above, the authors opinion is that the increase in the global wine trade has also been enabled by the increase in free trade agreements and reduction in trade tariffs over this period. The author also reasons that other globalization trends have added to this including better global information flow (specifically through the internet), and more international travel meaning more product and knowledge being disseminated between international markets.

This section has sought to provide an overview of recent global trends regarding wine production, consumption and trade. The key finding from this section is that New World wine has made a large impact on the global wine market from around 1990 with export shares and global demand for New World wines, especially from non-traditional emerging markets, growing significantly in this period.

The next section will look at why this New World wine phenomenon has happened, at a global level and at a country level. It will also look further into factors determining wine choice, including differences in wine choice behavior across countries. 


\subsubsection{New World Wine Success Factors and Global Diffusion Rates}

Arkell (1999), in her book 'New World Wines', states that New World wine differentiates itself from Old World wine by having 'fresh, clean, fruit-driven flavours'(p. 6), complemented by innovative winery technology and an ability to adapt and experiment to meet consumers tastes. Aylward (2003) states that New World wines offer uniqueness and innovative blending as well as value for money and goes on to say that this has been achieved through the use of innovative viticultural technologies, when compared to traditional producing countries.

\section{Factors in the success of New World Wines}

Many factors have been involved in the success of New World wines v Old World wines from a global exporting and consumption perspective. These range from production and sales differences to changing consumer demands. Many authors agree with the Australian Food and Drink Report (Q2, 2010) summation of this success as being driven essentially by providing a quality level wine at an affordable price. Campbell and Guibert (2006) state that the success and dramatic rise of New world wines is due to rapid horizontal and vertical integration, the use of new techonologies to develop new cultivars, and strong marketing strategies. From a variety of research sources, the author summarises the key success factors as follows:

o Expansion of production in New World countries creating an increase in supply over demand in domestic markets driving exports and lower prices

o The 'need' to export for New World producers as domestic markets lack size and scale compared to Old World producers' domestic markets

o An earlier realisation and higher understanding of new markets and their potential, and the ability to move more quickly and effectively than old world producers

o Consolidation within New World producing companies (including cross national) creating economies of scale, driving cheaper, more effective distribution and lower prices as opposed to fragmented producers in the more traditional old world

o An ability and willingness to 'mass market' wine products, chiefly due to consolidation within New World producers driving distribution and marketing 
cost advantages. Accentuating this is the loosening of regulations in some countries (e.g. UK) enabling the selling of wine in supermarkets

o An understanding of consumer preference changes; new grape varieties, innovative bottles and labelling, and innovative marketing campaigns etc.

While these factors have contributed to New World wine overall global success since 1990, New World wine has been adopted at different rates in different countries.

Rates of New World Wine Diffusion

Table 8 below shows New World wine as a \% of overall wine consumption for selected countries from 1988 - 2006. It shows that in some countries (e.g. UK), New World wine has grown at a faster rate during this period than in other countries (e.g. Switzerland). 
Table 8:

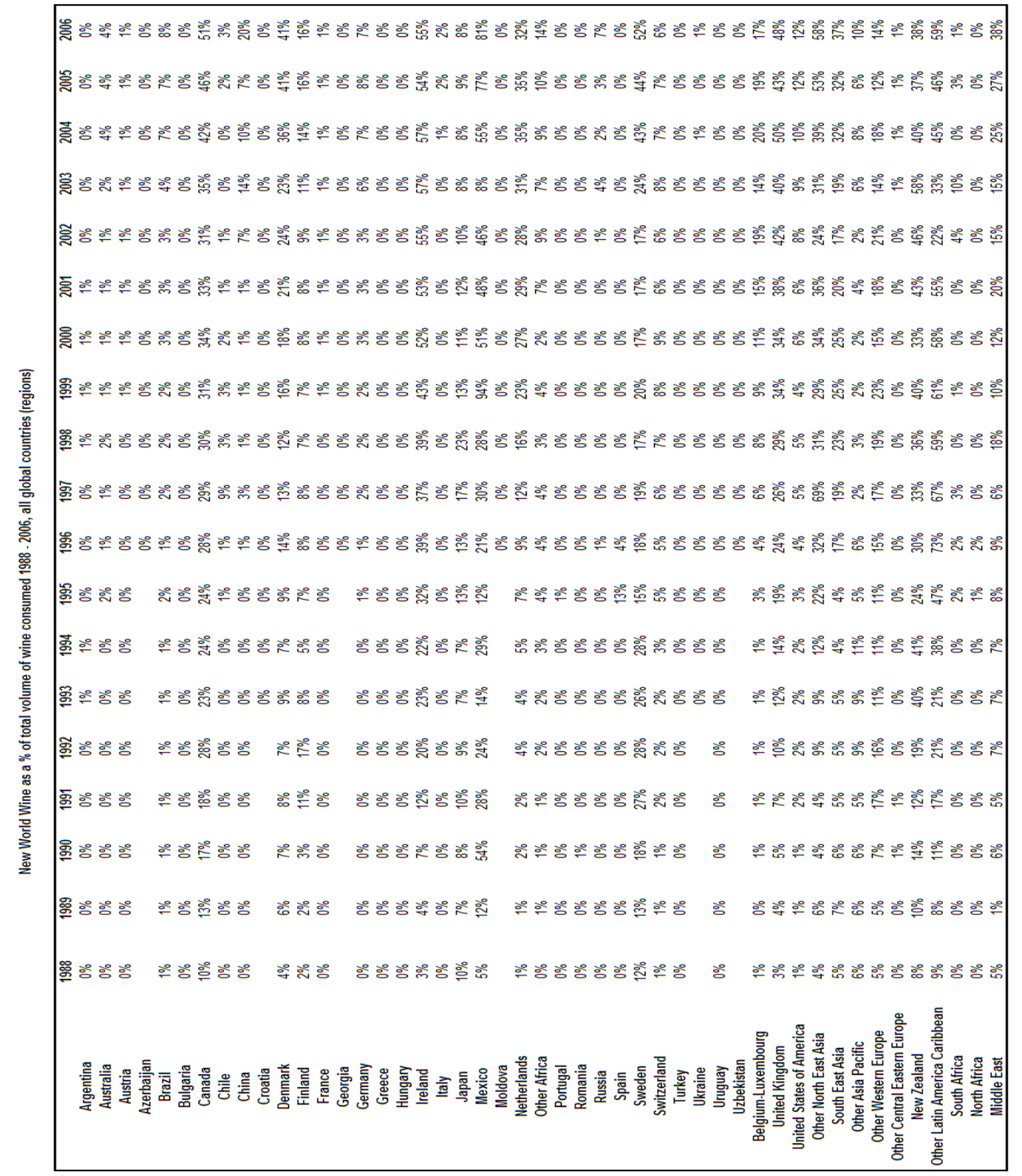

The cornerstone of this research is to seek explanations for the differences in rates of New World wine imports as a percentage of total wine consumption across countries.

\subsubsection{Wine Choice Factors}


Thomas (2000) notes that as the global wine industry has evolved, emphasis has shifted from a concentration on production, to a concentration on marketing, to the addition of a concentration on consumer understanding.

Much research has been done in the area of wine choice. The author finds that while initially research concentrated on external cues such as price and region of origin, more recently research is starting to look at internal factors such as personal values and social status, and their relationship with wine purchase decisions. In addition, market segmentation research is a growing area of study, as is cross-national wine purchase behaviour. The following section looks at these areas of wine choice.

\section{External Factors}

Lockshin and Hall (2003) reviewed over 75 articles concerning consumer behaviour for wine. They found varying 'importance factor' ratings across the literature, which in the authors opinion infers that wine purchase decisions can be a combination of many factors. The most important decision criteria cited were:

- Pricing (Batt and Dean 2000; Ling and Lockshin 2003) and Price Discounting (Thomas 2000)

- Region of Origin ( Quester and Smart 1998; Tustin and Lockshin 2001)

In addition the following factors were also prominent decision criteria in Lockshin and Hall's (2003) review:

- Previously having tasted the wine

- Grape variety

- Brand name

A further area of wine choice consideration is wine/food match. Goodman (2009) points out that wine/food match has varying levels of importance depending on country and culture. Goodman (2009) finds that traditional wine countries (eg France, Germany, Italy) place far higher importance on wine/food match than non-traditional wine countries such as UK, Australia and China. Interestingly, Beal and Rod (2008) found that Japan also places a high emphasis on wine/food match. While not considered a traditional wine country, Japan has had a long history with rice wine as an accompaniment for meals. 


\section{Internal Factors}

In addition to external cues, Thomas (2000) states that the strength of a motive, the presence of an attitude, or the recalling of particular information, can all act as internal influences on an individual's purchase behavior, and that needs, emotions and other psychological and social factors have a role to play.

According to Hall et al (2001), when a consumer decides to buy a product, the decision is not dependent upon selecting the attribute desired in the product per se, but on the perceived consequences of product use. If the consumer perceives that the product is a means to some important consequence that will subsequently lead to the satisfaction of a particular value, they will buy the product in order to reach the 'end state' desired.

\section{Product Involvement}

Product involvement is defined as a level of interest and/or experience in an object or activity (Hollebeck et al 2007) and is a common theme through purchase choice literature. Hollebeck et al (2007) and Geraghty \& Torres (2009) have looked at product involvement from a wine perspective.

Hollebeck et al (2007) segmented retail wine shoppers in New Zealand by product involvement, and found that higher product involvement corresponded to:

- higher region of origin influence on purchase decision

- more willingness to spend higher amounts on wine

Geraghty \& Torres (2009) labelled their high involvement customer segment 'wine traditionalists', and found this segment to be more willing to spend higher amounts of money compared to casual and value seeking wine buyers, and states that price is not one of the top 5 criteria for 'wine traditionalists'. It is worth noting that the above research refers to retail wine choice (off sales) as opposed to on-sales in restaurants, bars and cafes etc. The author suggests there are differences within these choice environments, with on-sales choice being characterized by less price sensitivity, more status related decisions and more wine/food matching. 


\subsubsection{Cross National Wine Purchase Factors}

Goodman (2009) tested wine preferences across retail consumers in 12 countries across the world, under the condition of "using the wine for dinner with friends". Goodman's results (see table 9) show that wine choice determinants varied widely across the countries researched. Goodman found some similarities between traditional and non-traditional wine drinking markets in the area of wine/food matching (as described above) and overall it can be seen that Italy and France share some fairly close wine choice similarities, as do the anglo speaking countries studied: Australia, NZ, UK and USA. A key outcome of Goodman's research was that there was such a variety of wine choice rankings across the countries studied. Goodman states that it is important to understand similarities and differences between countries to devise effective international wine marketing strategies (p. 41).

Table 9:

\begin{tabular}{|c|c|c|c|c|c|c|c|c|c|c|c|c|}
\hline & Rating of $\mathrm{V}$ & Vine Choi & Factors & cross Sel & ted Coun & tries & & & & & & \\
\hline Attribute & Australia & Austria & Brazil & China & France & Germany & Israel & Italy & $\mathrm{NZ}$ & Taiwan & UK & USA \\
\hline Tasted the wine previously & 65 & 34 & 40 & 34 & 36 & 50 & 76 & 47 & 65 & 56 & 56 & 54 \\
\hline Someone recommended it & 31 & 1 & 20 & 22 & 13 & 38 & 18 & 9 & 23 & 36 & 22 & 33 \\
\hline Grape variety & 23 & 36 & 14 & -7 & 18 & 14 & 17 & 10 & 38 & 1 & -3 & 18 \\
\hline Origin of the wine & 15 & 25 & 19 & 31 & 40 & 24 & -21 & 19 & 19 & 19 & 12 & 9 \\
\hline Brand name & 15 & -7 & 60 & 37 & 6 & -21 & 18 & 0 & 25 & 4 & 2 & 9 \\
\hline Medal/award & 12 & -7 & -37 & 4 & 12 & -14 & -4 & -5 & 27 & 13 & -11 & 3 \\
\hline I read about it & 0 & -17 & -11 & -11 & 0 & -4 & 17 & 16 & -9 & 19 & -3 & 1 \\
\hline Matching food & -7 & 24 & 26 & -25 & 44 & 33 & 23 & 42 & -19 & -18 & -5 & 7 \\
\hline Information on back label & -7 & 5 & -20 & 1 & -23 & 7 & -17 & 11 & -24 & -16 & 11 & -18 \\
\hline Information on the shelf & -22 & -18 & -19 & -16 & -43 & -2 & -32 & -30 & -27 & -22 & -7 & -11 \\
\hline An attractive front label & -26 & 6 & -44 & -22 & -40 & -10 & -30 & -37 & -25 & -24 & 19 & -7 \\
\hline Promotional display in-store & -35 & -50 & -24 & -11 & -19 & -45 & -18 & -43 & -22 & -19 & -10 & -25 \\
\hline Alcohol level below 0.13 & -66 & -31 & -23 & -36 & -44 & -68 & -46 & -39 & -71 & -49 & -44 & -74 \\
\hline$n=$ & 305 & 182 & 293 & 197 & 154 & 160 & 184 & 314 & 364 & 317 & 303 & 196 \\
\hline
\end{tabular}

source: Goodman 2009

Goodman suggests that a logical extension of his trans-country research is to look at cultural similarities within the country set to see if there are correlations between cultural dimensions and wine choice behaviour. In 'Unlocking the Asian wine market', Beverland (2002) stresses that consumer behaviour is strongly influenced by culture. Other researchers (Telukdar 1997) have found a clear link between culture, personal values and purchase behavior.

\subsubsection{Summary}

This section has briefly looked at the history of wine cultivation and has taken a look at recent production, consumption and global wine import/export trends. It has sought to 
introduce the concept that there has been a sharp increase in New World wine consumption globally since around the early 1990's and looks at some reasons for this phenomenon. The chapter points out that New World wine has diffused at different rates in different countries. The chapter then seeks to understand some of the drivers of wine choice, initially in a general context, and then within a cross-national sphere. Although there are very few cross national wine purchase behavior studies existing in the literature, Goodman's 2009 study (Goodman, 2009), shows varying wine purchase behaviours across countries. This concept, aligned with the varying national New World wine diffusion trends, would indicate that further study around understanding the drivers of New World wine diffusion at a country level would be important in assessing global market trends for wine consumption.

\subsection{Diffusion}

\section{Introduction}

This section will seek to outline the general theory of diffusion of innovations as well as look closely at rate of adoption and determinants of the rate of adoption, especially in a cross national sense.

To effectively understand New World wine diffusion patterns at a country level, an understanding of diffusion theory is required, specifically the broad sub-category of 'diffusion of innovations'. This section will define and explain the 'diffusion of innovations' and look to understand 'rate of diffusion' (also known as 'rate of adoption') determinants, especially in a cross-national setting.

There has been a wealth of research performed in the area of diffusion across many disciplines, products and ideas. The most cited and generally accepted general theory of diffusion by scholars over the past half century is work done by Rogers. Rogers (2003) has effectively summarised a large scope of diffusion research into a broad category he has named 'diffusion of innovations'. Rogers (2003:p 12) defines 'innovation' as “an idea, practice or object that is perceived as new by an individual or other unit of adoption" and defines diffusion as "the process in which an innovation is communicated through certain 
channels over time among members of a social system". This section will seek outline the 'diffusion of innovation' concept through a review of the following areas:

- the innovation - decision process

- adopter categories

- diffusion patterns

○ introduction, take off and market potential

○ communication

- rate of diffusion (adoption)

○ time from introduction to take off point

○ time from take off point to market potential

- determinants of the rate of adoption

\subsubsection{The Innovation - Decision Process}

The innovation-decision process is the process by which an adoption unit passes from first knowledge of an innovation through to its adoption or rejection

Rogers (2003) explains the steps in the innovation-diffusion process and describes it as the process where the adoption unit passes from gaining initial knowledge of an innovation, to forming an attitude toward the innovation, to aiming a decision to accept or reject, to implementation of the new idea, and to confirmation of this decision. He distinguishes these stages as follows:

- Knowledge - occurs when an adoption unit is exposed to an innovations existence and gains an understanding of how it functions

- Persuasion - occurs when an adoption unit forms a favourable or unfavourable attitude towards the innovation

- Decision - is where the adoption unit engages in activities that lead to a choice to adopt or reject the innovation

- Implementation - occurs when an adoption unit puts a new idea into use

- Confirmation - occurs when an adoption unit seeks reinforcement of an innovationdecision already made, with the ability to reverse this previous decision if exposed to conflicting messages about the innovation

\subsubsection{Adopter Categories}


Adopter categories refer to where adopter units lie on their 'earliness' to adopt an innovation. The normal bell curve illustrated in Figure 2 below shows the distribution of the adopter categories as prescribed by Rogers (2003:p. 281). Rogers' explains these adopter categories as the following:

- Innovators - the first $2.5 \%$ of the population to adopt an innovation, innovators are characterized by their venturesomeness, cosmopolitanism, usually some technical knowledge and the ability to cope with a high degree of uncertainty about an innovation

- Early Adopters - the next $13.5 \%$ of the population to adopt, early adopters are characterised by being more integrated with their social system than innovators and being considered respected opinion leaders within their social system

- Early Majority - the next $34 \%$ of adopters, are considered to be frequent interacters with their social system without being opinion leaders, and are deliberate in their approach to adopting an innovation

- Late Majority - the next 34\% of adopters, are considered to be fairly sceptical and cautious with regards adopting an innovation.

- Laggards - the last $16 \%$ of adopters, laggards are considered to have traditional values, be quite conservative and have relatively more to lose through the adoption of an innovation

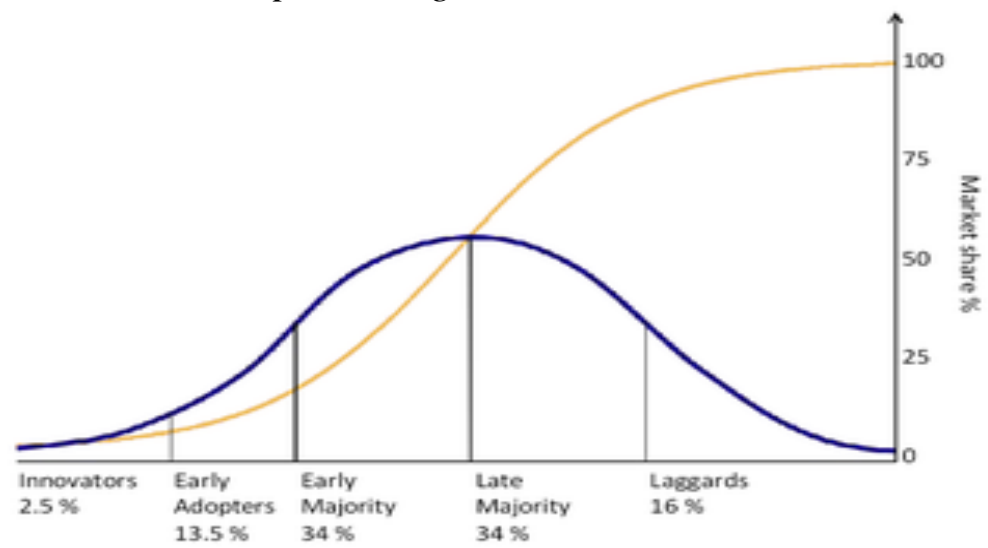

A further way to view adopter categories involves defining adopter categories as 'opinion leaders' and 'followers'. Rogers classifies 'opinion leaders' as innovators and early adopters, 
while 'followers' include the early majority, late majority and laggards as per the above classification system. Rogers (2003) indicates that opinion leaders look at things other than other peoples behaviours and cues and are regarded as innovators, while followers decide to adopt based upon cues from other people (opinion leaders) and are also referred to as imitators. Table 10 below shows characteristics of earlier adopters when compared to later adopters.

Table 10:

Early adopter characteristics

\begin{tabular}{|c|c|c|}
\hline Socioeconomic & Personality & Communication Behaviour \\
\hline more educated & more empathy & more social participation \\
more literate & less dogmatic & more interconnected \\
more upward social mobility & greater rationality \\
& higher intelligence & more interpersonal channels \\
& more favourable toward change \\
& higher aspirations & \\
\hline
\end{tabular}

\subsubsection{Diffusion Patterns}

Figure 3:

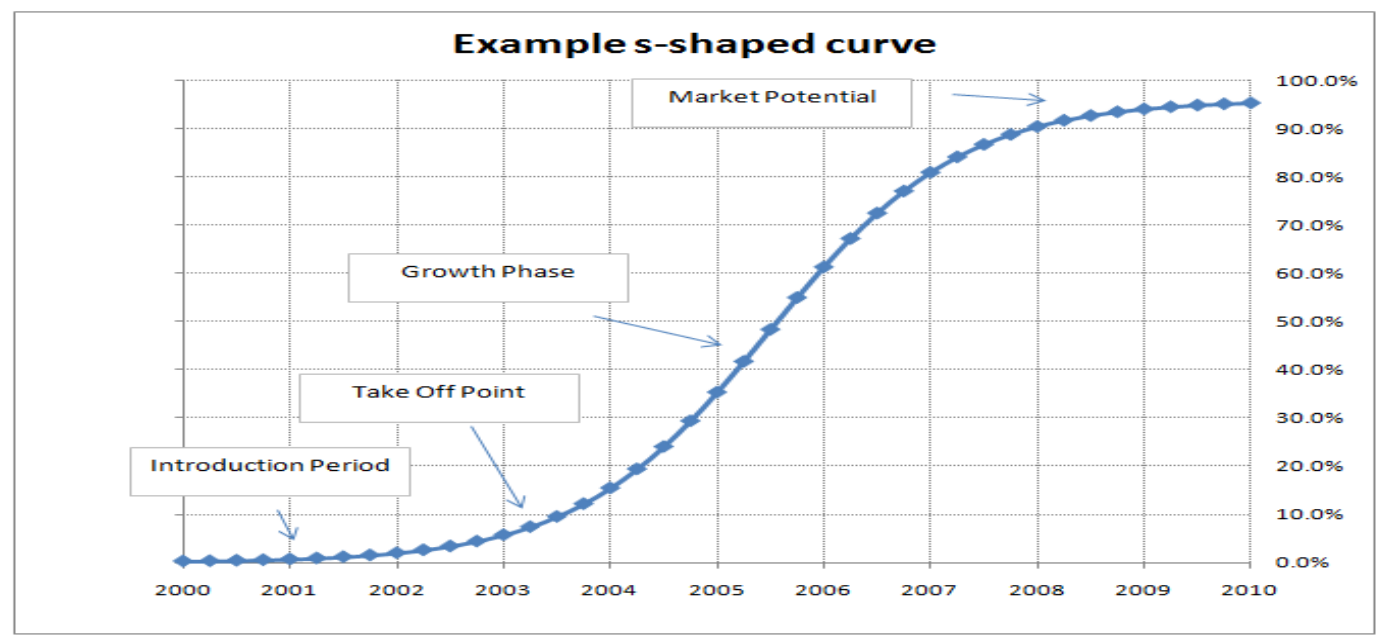

Patterns of diffusion over time are explained in the form of an s-shaped curve (as seen in Figure 3 above), also known as the product life cycle. This s-shaped curve is typically characterized by an initial period of slow growth (introduction) followed by a sharp increase in sales (take off) followed by a smoothing out of sales as the product reaches maturity and market potential (Agarwal and Bayus 2002). Rogers (2003) has provided a rule of thumb 
that states that take off point occurs at $16 \%$ of market potential, which encompasses innovators $(2.5 \%)$ and early adopters $(13.5 \%)$ from his list of adopter categories. While some authors have followed this rule (Garber et al. 2004; Goldenberg et al. 2001), other authors have found and used other take off points:

- Chandrasekaran \& Tellis (2008) used 2\% market penetration as a heuristic for take off point in line with Golder and Tellis' (1997) findings of $1.7 \%$ market penetration at time of take off, before concluding that time of take off varied significantly across product and countries.

- Mahajan et al. (1990) estimated that take off point was around 2.8\% of market penetration in line with their upper bounds for innovative members of society (and loosely in line with Rogers' $2.5 \%$ of innovators).

- Agarwal and Bayus (2002) found the take off point in their study was determined by a change in sales of $136 \%$.

Diffusion authors do agree that the time between introduction and take off, and the time between takeoff point and market potential are determined by differing behaviours within the purchasing populations. In the introduction phase, product purchasers are generally regarded as innovators while in the growth period after product take off, imitators are the key purchasers. This is in line with the theory around take off point being the point of critical mass, whereby purchases made after this part of the process happen with, or without change agent intervention (Rogers 2003).

\section{Communication:}

process by which participants create and share information with one another in order to reach a mutual understanding. Regarding innovations, this involves the message content being concerned with a new idea.

Key to the process of diffusion is getting the message out through the social system. Two elements are key to this process: (1) mass media communication, and (2) interpersonal communication.

- Mass media communication refers to communication that can reach a large audience quickly such as newspapers, radio, internet and large scale marketing campaigns. This type of communication creates high levels of awareness and knowledge, while having low levels of persuasiveness to adopters, relative to interpersonal communication. 
- Interpersonal communication refers to two way communication between members of a social system through various mediums including face to face and the internet.

While diffusion scholars see interpersonal communication as being more persuasive than mass media in regards the adopter making the decision to adopt, it is generally accepted that mass media is more effective at earlier stages of the diffusion process, while interpersonal communication is more effective at later stages of the process. Bass (2004) explains that mass media is the key communication channel for innovators, while interpersonal communication is the key channel for imitators. Bass designed and developed the 'Bass Forecasting Model' in 1969 to predict adoption levels of innovations and this has had widespread use in the marketing field as a means to understand the process and potential outcomes of new product launches (Bass 2004).

It is worth noting that both types of communication types have undergone, and are continuing to undergo, large changes in their functionality and effectiveness within the diffusion process (Olhavsky 1980). Olhavsky adds that changes in communication channels as well as more sophisticated marketing efforts have been abundant over the past 50 years and he points out that this has had a large bearing on speed and makeup of the diffusion process. In the authors opinion the key change within communication types over the past 15 years has been the internet, which has opened up social systems significantly as well as the means and speed of communication, while additionally it has blurred the lines between mass media and interpersonal communication.

\subsubsection{Rate of Adoption}

An innovation's rate of adoption in a system, usually measured as the number of members of the system who adopt the innovation in a given time period.

Rogers (2003) defines the rate of adoption as "the relative speed with which an innovation is adopted by members of the social system". Other diffusion scholars (Agarwal and Bayus 2002; Garber et al. 2004; Goldenberg et al. 2001) have taken measurement of the rate of adoption a step further, by looking at adoption as a two stage process:

- Time from introduction to take off point

- Time from take off point to market potential 
As has been described in a previous section, the area of diffusion research has evolved to incorporate distinct rate of adoption findings for these 2 areas, mainly due to the difference in characteristics of the population, as well as methods of communication, evident for each part of the diffusion process.

To accurately determine time from introduction to take off point and time from take off point to market potential, 3 key points along the diffusion curve need to be measured: introduction point, take off point and point of market potential.

While measurement of introduction point (year) appears fairly self evident ie. the year of the introduction of the product into a population, there are various factors that make this slightly more complex including how to deal with a limited release, availability and distribution issues, product trials, products bought from one country and consumed in another etc. Also, databases commonly only include sales when they have become 'non-trivial'

(Chandarasekaran and Tellis 2008). Authors have dealt with introduction time in a variety of ways. Commonly, introduction year has been defined as year of commercialisation which is defined as 'year of first sales in product category' (Golder and Tellis 1997). Agarwal and Bayus (2002) and Chandarasekaran and Tellis (2008) define commercialization as a point where the product has become available on the mass market or achieved some minimal level of sales or penetration. Tellis et al (2003) have applied a rule that says that the year of commercialisation must not have a market penetration of over $0.5 \%$, while Chandarasekaran and Tellis (2008) apply a rule of below $0.25 \%$.

As described in a previous section, takeoff point within diffusion curves varies significantly depending on several factors. Chandarasekaran and Tellis (2008) found that average time to takeoff varies substantially between developed and developing countries, between work and fun products, across cultural clusters and over calendar time. Indeed Tellis et al (2003) found that take off time is four times shorter for entertainment products than kitchen and laundry appliances, while Golder and Tellis (1997) found that the average time to take off was 18 years before World War II, and 6 years after World War II.

Various methodologies have been used to measure take off point:

- Bass (1969) and Rogers (2003) have used a \% of final market potential (16\%). This methodology has been followed by Garber et al. (2004) and Goldenberg et al. (2001). 
- Golder and Tellis (1997) define take off as the first year in which a new products sales growth rate relative to the prior year's sales crosses a threshold based upon sales levels, validated by a visual examination.

- Tellis et al (2003) follow a similar methodology to Golder and Tellis (1997), however use a base of penetration levels rather than sales levels. These methodologies are based around the idea that early in the products life, ie where there is a low level of base sales, growth rates can be large without signalling a takeoff point, and therefore the growth rate is subject to a certain level of base sales.

- Chandrasekaran and Tellis (2008) measure take off point as the first year the market penetration reaches $2 \%$. They base this on the final finding of Golder and Tellis (1997) of a take off point of $1.7 \%$ of market penetration, validate this with the idea of $2.5 \%$ of population being innovators (Rogers 2003), and Mahajen et al's (1990) upper bound for innovators of $2.8 \%$ of population.

- Agarwal and Bayus (2002) define take off as the year between a pretake off period and post takeoff period as determined by a percentage change in sales. To this end, the year that lies between the largest percentage of sales change between periods is defined as take off point.

Market potential is the point (usually year) where the product has reached its peak level of sales. Determining the market potential in retrospect can be identified where sales have had a consistent drop off from a peak point (Rogers 2003), however identifying market potential during or before the sales curve can be more problematic. Bass (1969) uses market potential of already diffused similar products which he adds has proved to be a useful measure.

\subsubsection{Determinants of Rate of Adoption}

\section{Overview of factors effecting rate of adoption}

The greatest amount of diffusion research has concentrated on understanding the determinants of the rate of adoption. Figure 4 shows the 5 areas that according to Rogers, determine any given adoption rate. 
Figure 4:

Variables Determining the Rate of Adoption

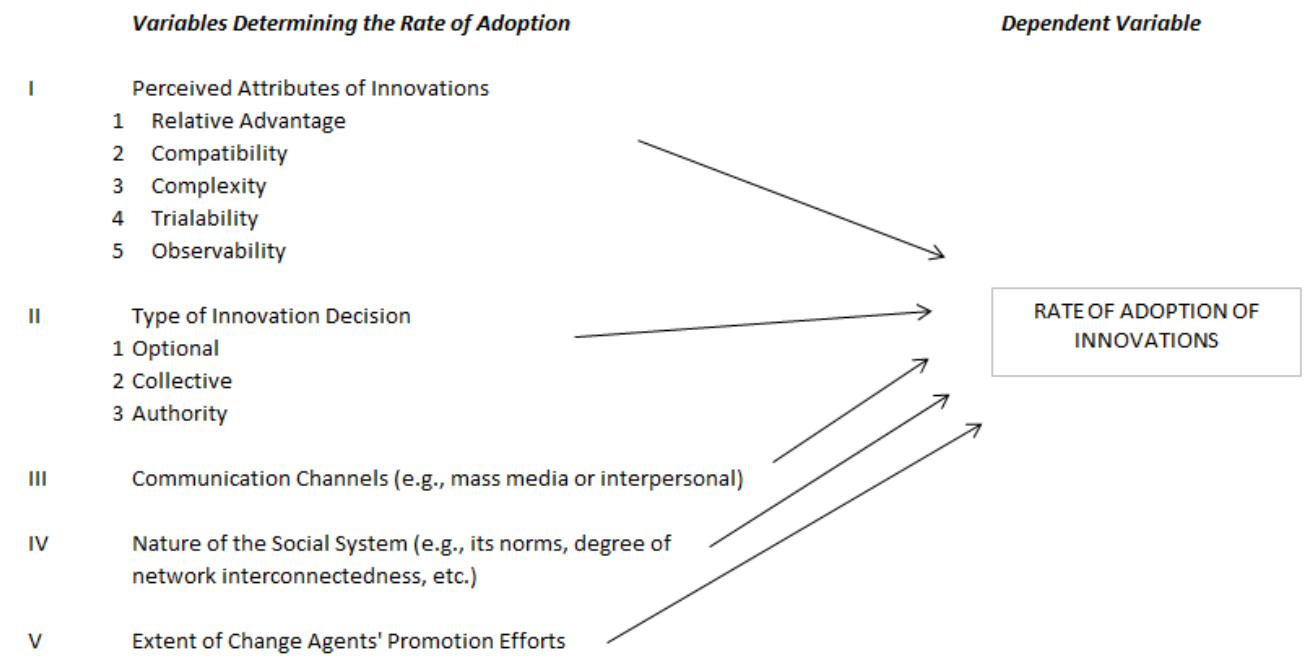

According to Rogers (2003:p 221) the 'perceived attributes of an innovations' explain between 49 and 87 percent of the variance in rate of adoption. Rogers (2003) adds that these attributes are what most of the diffusion research has concentrated upon. Table 11 provides a description and some examples of these perceived attributes:

Table 11:

Perceived Attributes of Innovations

\begin{tabular}{|c|c|c|}
\hline Perceived Attribute & Description & Influence on rate of adoption \\
\hline Relative Advantage & $\begin{array}{l}\text { Degree to which the } \\
\text { innovation is perceived as } \\
\text { being better than the idea it } \\
\text { supersedes }\end{array}$ & $\begin{array}{l}\text { Value gain for adopters } \\
\text { ·economic profitability } \\
\text { (including incentives) } \\
\text { ·low intial cost } \\
\text { ·social prestige } \\
\text {-time and effort saving } \\
\text {-immediacy of reward }\end{array}$ \\
\hline Compatibility & $\begin{array}{l}\text { Degree to which an } \\
\text { innovation is perceived as } \\
\text { consistent with the existing } \\
\text { values, past experiences, } \\
\text { and needs of potential } \\
\text { adopters }\end{array}$ & $\begin{array}{l}\text { Less uncertainty } \\
\text { compatible with socio- } \\
\text { cultural values } \\
\text { compatible with previously } \\
\text { introduced ideas (prior } \\
\text { knowledge) } \\
\text { compatible with needs of } \\
\text { adopters }\end{array}$ \\
\hline
\end{tabular}




\begin{tabular}{|l|l|c|}
\hline Complexity & $\begin{array}{l}\text { Degree to which an } \\
\text { innovation is perceived as } \\
\text { relatively difficult to } \\
\text { understand and use }\end{array}$ & $\begin{array}{c}\text { User - friendly } \\
\text { needs technical expertise } \\
\text { needs social expertise }\end{array}$ \\
\hline Trialability & $\begin{array}{l}\text { Degree to which an } \\
\text { innovation may be } \\
\text { experimented with on a } \\
\text { limited basis }\end{array}$ & $\begin{array}{c}\text { Accessibility } \\
\text { barriers to trial? } \\
\bullet \quad \text { cost } \\
\text { distribution }\end{array}$ \\
\hline Observability & $\begin{array}{l}\text { Degree to which the results } \\
\text { of an innovation are visible you buy? } \\
\text { to others }\end{array}$ & $\begin{array}{c}\text { Easy to observe benefits } \\
\text { tangible } \\
\text { communicatable }\end{array}$ \\
\hline
\end{tabular}

This section has outlined the key literature around understanding the 'diffusion of innovation' concept. It has sought to explain the adopter process, the patterns of diffusion, the rate of adoption as well as determinants of rate of adoption. It has introduced the core diffusion concepts of:

○ Time from introduction to take off point

- Time from take off point to market potential

The next section will look at diffusion in a specifically cross-national sense.

\subsubsection{Cross National Diffusion}

As the prior section has indicated, diffusion research entails a large amount of factors and variables in determining how diffusion patterns are created. It also outlined that there are a large amount of different types of diffusion, including across different product types and markets. Cross-national diffusion refers to understanding innovation diffusion patterns between different countries, and why there are different adoption processes between these different countries (Steenkamp et al 1999). Why does the same product take a long time to diffuse in one country, while it has relatively rapid adoption in another country? The importance of understanding these relative adoption rates between countries is helpful for: making global launch decisions, allocating resource over time, making effective strategic and tactical marketing decisions as well as providing the ability to forecast total adoption and 
total adoption over time Bass (2004). Bass (2004) adds that cross national diffusion studies are taking on more importance and significance with the growth of the global economy.

Existing cross national diffusion studies have mainly concentrated upon the 'compatibility attribute' as a determinant of the rate of adoption in a cross national sense. As outlined in a previous section, the compatibility attribute involves 3 key areas in helping determine the rate of adoption:

$$
\begin{aligned}
& \text { - } \\
& \text { - } \\
& \text { - } \\
& \text { compatibility with previously introduced ideas (prior knowledge) } \\
& \text { compatibility with needs of adopters }
\end{aligned}
$$

The majority of cross national diffusion literature has centred on three areas of the compatibility attribute:

- National Culture (Steenkamp et al. 1999; Dwyer, Mesak et al. 2005; Yaveroglu and Donthu 2002; Yeniyurt and Townsend 2003)

- Country Specific factors such as socio-economic wealth and other macro socio variables (Gatignon, Eliashberg et al. 1989; Helsen, Jedidi et al. 1993; Kumar, Ganesh et al. 1998; Takada and Jain 1991; Gerard, Stefan et al. 2003; Singh 2006; Kumar and Krishnan 2002)

- Country Interaction factors including the learning effect, lead/lag effect and mixing effect (Takada and Jain 1991; Putsis et al. 1997; Ganesh and Kumar 1996; Helsen, Jedidi et al. 1993; Kumar, Ganesh et al. 1998)

Various studies have also pointed out that product specific factors have played a role in determining diffusion rate (Dwyer, Mesak et al. 2005; Tellis et al 2003). Additionally, marketing mix variables, which fall under the 'relative advantage' attribute also play a role in cross national diffusion (Yeniyurt and Townsend 2003). 
Table 12 provides a summary of relevant cross national diffusion studies.

Table 12:

Summary of Selected Cross National Diffusion Studies

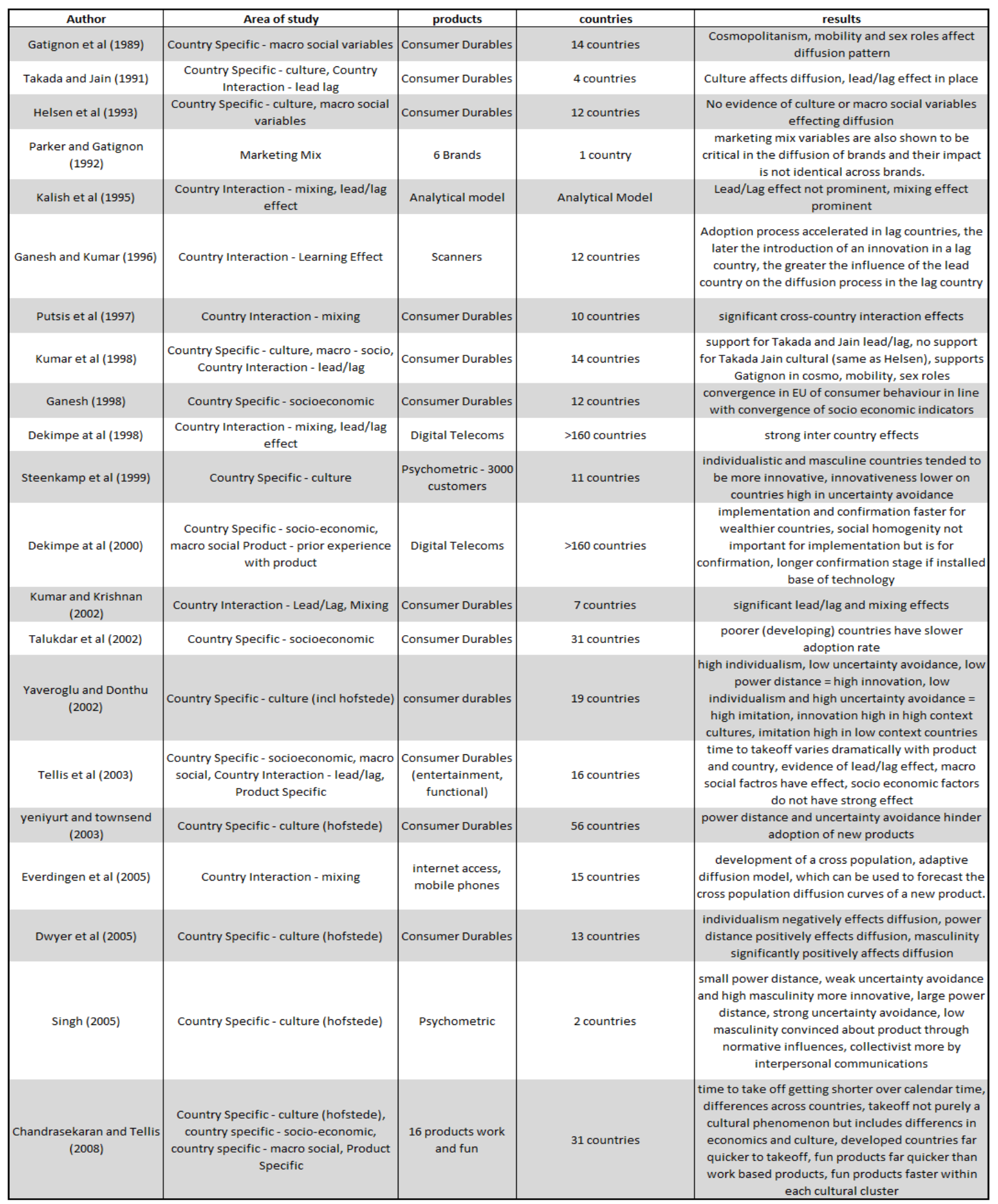

As can be seen above, the vast majority of studies in the area of cross national diffusion have centred on the country specific and country interaction areas. The country specific variables will be studied in depth further in this section. 
Country Interaction Effects, including lead/lag effect, learning effect and mixing effect, will not be a part of this study due to the difficulty in data collection. It is the authors opinion that the internet has changed the scope of the country interaction effects in such a huge way as to make the effects of country interaction a) a completely changed landscape during the course of the range of data collection dates, and b) very difficult to measure. Therefore it is seen that country interaction effects are beyond the scope of this study. However, in the authors opinion, it is worth providing a description of these effects.

Takada and Jain (1991) explain that the lead/lag effect in cross national diffusion refers to the idea that a diffusion in a lag country diffuses faster than a diffusion in a lead country due to various factors including less uncertainty over the innovations performance and results, the improvement of the innovation based on previous experience in the lead country, improved marketing efforts through previous experience in the lead country, as well as cross national mass media and interpersonal communication. Takada and Jain's study found evidence of the lead/lag effect and this has been supported in various studies including Kumar (1998), Dekimpe et al (1998) and Kumar and Krishnan (2002).

Ganesh and Kumar (1996) extended this idea and found that the later the introduction of an innovation in a lag country, the greater the effect of the lead country in the diffusion of the innovation - they labelled this the 'learning effect'. Kalish et al (1995) did not find support for a lead/lag or learning effect, Tellis et al (2003) and Chandrasekaran and Tellis (2008) have provided some potential explanation for this in the fact that the lead/lag effect can be superseded by other factors such as culture and economic wealth.

Putsis et al (1997) found significant cross-country interaction effects during the diffusion process which was labelled the 'mixing effect'. The mixing effect refers to members of each country population (social system) communicating between themselves, either through mass media and/or interpersonally. This mixing effect theory has been supported by Dekimpe et al (1998), Kumar and Krishnan (2002) and Everdingen et al (2005). In the authors opinion, it is highly likely that the internet has increased this mixing due to the cross national mass media opportunities, as well as the cross national interpersonal communication opportunities that abound through this medium. 


\subsubsection{Country Specific Factors}

Existing research regarding cross national diffusion determinants mainly involve country specific factors. It has been suggested in previous research that disparities in the diffusion process are the result of differences in several variables, including national economies, inflation, population, and other macro or socio-economic factors (Lindberg 1982). Rogers (2003) states that high standards of living are also associated with quick adoption rates, however Helsen et al (1993) argue that macro level, socio-economic variables do not alone fully explain differences in cross national diffusion patterns of new product innovations. The following section splits country specific factors into three areas: Cultural dimensions, socioeconomic variables and macro social variables. This section will seek to explain these areas and identify existing research that pertains to them.

\section{Cultural Dimensions}

National culture is a fundamental factor that distinguishes consumers of one country from those of another country (Dwyer, Mesak et al. 2005). A country's values have long been identified as a factor that influences consumer behaviour (Roth 1995) and these values influence the diffusion of innovations in a society as a whole (Dwyer et al. 2005).

Yalcinkaya et al (2007) say that while individuals all share a common humanity, there are important cultural differences among them that must be considered when operating internationally. Consumers from different cultures have different attitudes, perceptions, preferences and values (Dwyer et al 2005; Suh and Kwon 2002). Hofstede (2001) has found no material change in cultural index scores between 1981 and 2001, indicating that cultural values remain fairly constant over time. Because cultural values and norms are strong drivers in determining people's attitudes and behaviours (Yeniyurt and Townsend 2003), it is logical to assume that cultural differences have an impact on adoption and diffusion of new products/innovations.

Perhaps the earliest high profile study of cultural dimensions and their determination on cross national diffusion was conducted by Takada and Jain (1991) where they found support for the effect of high context cultures positively effecting cross national diffusion rates. Contrary to this, Helsen et al (1993) found no support for this effect as did Kumar et al (1998). Dwyer et al (2005) have offered the suggestion that these mixed results may be due to the high/low 
context cultural typology forwarded by Hall (1976) and Hall and Hall (1987). Dwyer summises that this cultural typology, while widely accepted, is an "anecdotally derived, unidimensional typology with attendant limitations in its application", and may be too much of a 'broad stroke' approach to culture.

Another approach to differentiating national culture is provided by Hofstede (1981, 1991, 2001). Hofstede ranks over 50 countries on 4 cultural dimensions: Individualism collectivism, masculinity-femininity, high/low uncertainly avoidance, high/low power distance. In his 2001 study, Hofstede added high/low long term orientation as a further cultural dimension. Hofstede (2001) states that these dimensions largely account for cross cultural differences in peoples values, beliefs, and behaviour patterns world wide. Although Hofstede's typology has its critics (McSweeney 2002), it does have considerable empirical support in study extensions and replications (Hoppe 1990; Sondergaard 1994). Furthermore, Hofstede's framework of culture is widely accepted in marketing and other international business disciplines (Sivakumar and Nakata 2001).

Recently Hofstede's national cultural dimension typology has been widely used in cross cultural studies including cross national diffusion studies. Table 13 shows the results of some of the more notable research around the effect of Hofstede national cultural dimensions and cross national diffusion rate.

Table 13:

Results of Cross National Diffusion Studies using Hofstede’s National Cultural Dimensions

\begin{tabular}{|c|c|c|c|c|c|c|}
\hline \multirow[b]{2}{*}{ Author } & \multirow[b]{2}{*}{ Description } & \multicolumn{5}{|c|}{ Effect on diffusion (or other outcome - see decription) } \\
\hline & & Uncertainty Avoidance & Individualism & Masculinity & Power Distance & Long term Orientation \\
\hline Steenkamp et al 1999 & Innovativeness & low & High & high & $\mathrm{n} / \mathrm{a}$ & $\mathrm{n} / \mathrm{a}$ \\
\hline Yaveroglu and Donthu 2002 & High Innovation & low & high & $n / a$ & low & $\mathrm{n} / \mathrm{a}$ \\
\hline Tellis et al 2003 & time to take off & low & $\mathrm{n} / \mathrm{a}$ & $n / a$ & $\mathrm{n} / \mathrm{a}$ & $\mathrm{n} / \mathrm{a}$ \\
\hline Yeniyurt and Townsend 2003 & acceptance rates of new products & low & high & no support & low & $\mathrm{n} / \mathrm{a}$ \\
\hline Dwyer et al 2005 & Diffusion Rate & no support & low & high & high & low - tentative \\
\hline Singh 2005 & propensity to innovate & low & high & high & low & $\mathrm{n} / \mathrm{a}$ \\
\hline
\end{tabular}

As can be seen in table 13 above, Dwyer et al's (2005) research found different results from the other studies listed for some of these national cultural dimensions. Dwyer at el's (2005) study looked at diffusion rate between $20 \%$ and $80 \%$ of market penetration, thus differing from other studies listed that have looked at the relationship of cultural dimensions with innovativeness. As indicated in a previous section, innovativeness is positively correlated to 'time to take off'. 
Socio-economic Variables

In addition to culture, socio-economic variables have been used within cross national diffusion literature as potential determinants of adoption rate. Gatignon et al (1989) looked at cosmopolitanism, the phenomenon of individuals being oriented beyond their immediate social systems, mobility, how mobile the population is, and working women in the workforce to attempt to explain propensity to innovate and propensity to imitate. Results showed that cosmopolitanism supported the propensity to innovate, mobility provided mixed results as a positive influence on propensity to imitate, and level of working women showed support for a propensity to innovate, although this was dependent upon the specific product. Gatignon et al (1989) also noted that working women are directly related to higher household incomes and therefore this may be the determining factor, in line with Rogers (2003) ascribed theories and previous research.

Helsen et al (1993) looked at how diffusion patterns across country clusters matched with country clusters of a basket of macro socio-economic variables including mobility, health, trade, lifestyle, cosmopolitanism and other miscellaneous measures such as hospital beds and CPI. They did not find supportive evidence of a cluster relationship between these dependent variables and the shape of diffusion across country clusters, or support for Gatignon et al's (1989) mobility and cosmopolitanism variables, however they did find supporting evidence for a positive relationship between the lifestyle variables (GDP per capita, phones per capita, electricity consumption per capita) and diffusion patterns. These findings are in line with previous research by Rogers (2003) and Gatignon and Robertson (1985).

Kumar et al (1998) sought to replicate Gatignon et al's (1989) study by again looking at cosmopolitanism, mobility and women in the work force and found that these variables "are useful for identifying the differences in diffusion patterns across countries and innovations" (p. 255).

Ganesh (1998: p. 37) notes that diffusion studies suggest "that the diffusion/adoption process is influenced by macroeconomic variables". He finds support for this statement in his study correlating convergence of macroeconomic variables in the EU, reflecting in a similar pattern of innovation diffusion in those countries. In addition to their cultural determinations of cross-national diffusion (see culture section above), Steenkamp et al (1999) also find support 
for the premise that ethnocentrism played a negative role in innovativeness and diffusion, as does a 'favourable attitude towards the past'. Interestingly, and contrary to Rogers (2003) and other findings, income levels did not have a positive relationship with innovativeness and diffusion in Steenkamp's study.

Talukdar et al (2002) looked at a variety of macroenvironmental variables to explain diffusion patterns and rates. By looking at a dependant variable of penetration potential, they found that a change in per capita income has a significant positive effect on market penetration potential, as does international trade and urbanization. They find a strong negative effect for illiteracy level and increased ethnic diversity, and a positive effect for access to mass media, as would be expected from the general diffusion literature. Dekimpe et al (2000) also find that wealth has a positive impact on diffusion rates. Tellis et al (2003) looked at a variety of factors in analysing cross national 'time to take off'. They found that wealth, open economies, industriousness, high media intensity, mobility and education are all determining factors in a country's time to take off. Chandrasekaran and Tellis (2008) looked at economic development, economic disparity, information access and trade openness as independent variables as well as cultural variables described above. They found that a high level of wealth is associated with a shorter time to take off, while economic disparity, openness, and other socio-economic variables do not have a significant correlation. As described above, research indicates (with the exception of Steenkamp et al (1999)) that a country's wealth is a positive determinant on rate of diffusion. Some of the logic behind this is that innovators are generally wealthier than imitators (Rogers 2003), wealthier people can better afford the risks of adopting a new product early (Dickerson and Gentry 1983) and prices of new products tend to start high and then drop steadily (Golder and Tellis 1998) meaning wealthier people will be able to buy these products earlier.

\subsubsection{Marketing Mix Variables in Cross National Diffusion}

Marketing mix variables include price, promotion (including advertising), distribution and product. As has been described in an earlier section, marketing mix variables clearly have an effect on diffusion in any context, including cross nationally, however the vast majority of existing cross national diffusion research has not looked at the effects of marketing mix variables in an empirical fashion. The reasons for this seem to be largely two-fold. Firstly, there appear to be difficulties attaining effective marketing mix data which is largely 
confidential and very difficult to source. Tellis et al (2003) stated "we were unable to get consistent measures of price and distribution...we were thus unable the role of important variables that managers can control to trigger take-off." Secondly, from the author's assessment, the concentration of the majority of these studies has been to look at noncontrollable 'environmental' variables such as culture and socio-economic variables, which are regarded as pre-cursors to controllable factors which include the marketing mix variables. Part of the practical reasoning behind this involves providing insights into the market environment to provide marketers with foundation information to adapt global marketing strategies and allocate resources.

Despite this much of the existing literature has made reference to marketing mix variables being an important part of diffusion. Yeniyurt and Townsend (2003) stress the importance of understanding how marketing mix variables interact with the cultural and socio-economic factors to understand which activities are most successful over time, and under what circumstances. Talukdar et al (2002) state that "while we analyzed the role of large set of macroenvironmental variables on product diffusion process, we did not investigate the role of marketing mix variables. Although it is a considerably difficult task to collect marketing mix data in a large number of countries for several products, we believe this can help improve explanatory and predictive power...”. Chandrasekaran and Tellis (2008) explain that an extension of their study into brand and brand extensions will yield additional insights. Ganesh and Kumar (1996) explain that future research in this area should address the effect of price on the diffusion process.

\subsubsection{Summary}

The 'Diffusion' section has sought to outline the general theory of diffusion of innovations as well as look closely at rate of adoption and determinants of the rate of adoption, especially in a cross national sense. Key points to emerge from this section include the following:

- Diffusion is a two stage process: time from introduction to take off point, and time from take off point to market potential

- Cross national diffusion patterns are especially determined by parts of the compatibility attribute, most importantly country specific factors, including culture, socio economic factors, and macro social factors 
In understanding reasons for varying New World wine diffusion rates across global markets, this chapter outlines that country specific factors will be important independent variables, while the dependent variable will need to include the two stages of the diffusion process: 'introduction to take off point', and 'take off to market potential'.

\subsection{Chapter Summary}

The Literature review chapter has outlined the global wine market, and specifically New World wine's position within this market. It has outlined wine consumer choice factors including in a cross national setting. The diffusion section has introduced the theory of 'diffusion of innovations' and looked at the determinants of rate of adoption, including in a cross national sense. Key findings from this chapter are:

- New World Wine has diffused quickly across international markets but at different rates across different countries

- Wine choice factors vary across countries

- Diffusion is a two stage process: time from introduction to take off point, and time from take off point to market potential

- Cross national diffusion patterns are especially determined by parts of the compatibility attribute, most importantly country specific factors, including culture, socio economic factors, and macro social factors

The following chapter 'conceptual framework', will look to present and conceptualise the research problem and develop the research hypotheses in order to further explain the research problem. 


\section{CHAPTER THREE: CONCEPTUAL FRAMEWORK}

\subsection{Introduction}

The literature is fairly consistent in stating that the start of the New World wine 'explosion' onto the global market was around the early 1990's. Over the past decade there has been a large amount of media attention on New World wine growth, as well as significant research performed regarding wine consumption trends, factors and New World wine success factors. While there has been several studies looking at individual country wine markets, there have been very few that compare wine consumption differences across countries, and none to the authors knowledge that look at specific country attributes to determine why New World wines diffuse at different rates across different country markets.

While innovation diffusion research is a vast field, cross national diffusion research is a fairly recent addition to the research field. The cross national research area appears to be growing significantly in line with globalisation trends and a need for more understanding in this area across industry and academia. To this point, the vast majority of cross national diffusion research has used consumer durables and technological innovations as their dependent variable. This is perhaps due to:

- an effort at consistency with other research to more effectively isolate the effect of new independent variables

- the accessibility of cross national data

- the distinctive 'innovativeness' of the technological innovations studied.

\subsection{Research Problem}

From the literature it is evident that it is important to consider where New World wine fits into the innovation definition in order to understand its diffusion cross nationally. The literature explains that New World wine is a differentiated product from traditional or old world wines from a production point of view as well as from a consumption point of view. In the authors opinion, New World wine therefore fits into the accepted innovation definition offered by Rogers (2003) of 'an idea, practice or object that is perceived as new by an individual or other unit of adoption'. From the literature it is evident that the extent of 
innovativeness is important to understanding diffusion as it determines the level of uncertainty within the adopter units.

New World wine is clearly not a new product, while at the same time is far more differentiated than a new brand. Therefore, the author feels that it is reasonable to categorize New World wine as a 'new product class', similar to the categorization of Japanese cars on the global automobile market in 1980's and 1990's. The following innovativeness continuum has been developed to potentially illustrate the level of innovativeness of New World Wine.

Figure 5:

New World Wine Innovativeness Continuum

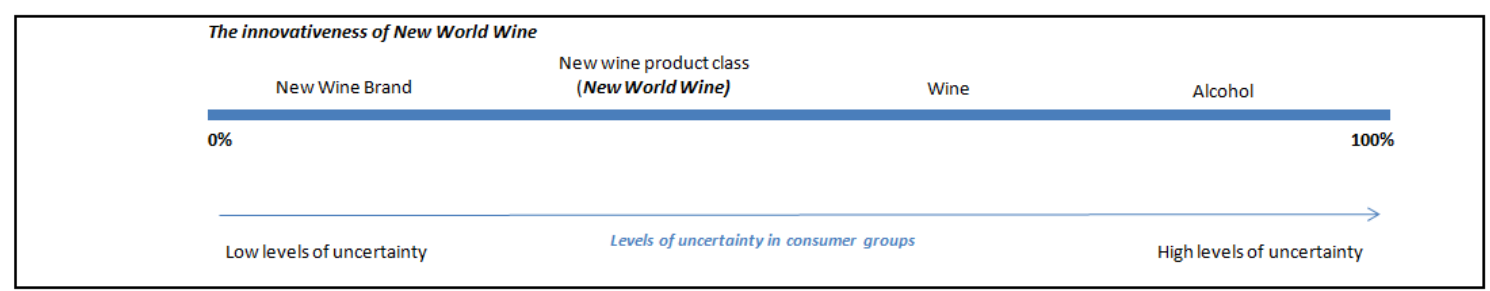

The above pictorial shows that alcohol as new type of drink provides very large levels of uncertainty amongst consumers (social system), wine as a new type of alcohol provides large levels of uncertainty, while a new wine brand provides very low levels of uncertainty. The author proposes that a new wine product class such as New World wine, has far more uncertainty than a new wine brand, while far less uncertainty than a new alcohol product such as wine.

\section{The central problem investigated in this study is the diffusion of innovation for a new product class in the cross-national setting.}

In addition, this research will look at a new product class, New World wine, that differs from existing cross national diffusion studies that have concentrated on consumer durables and technological innovations. Also, from a wine research perspective, this research adds to the few studies that look at reasons why wine consumption patterns differ across countries.

\section{Research Questions}


The positioning of New World wine in a global diffusion context provides some reasonably unique research potential. As the literature review points out, the compatibility attribute is especially important in a cross national diffusion research sense, and this research will look to explore the effects of elements of the compatibility attribute including culture and national wealth. In addition, the research will look at 'prior experience with previously introduced idea' as a key construct of the compatibility attribute. The ability to study this part of the compatibility attribute is especially enabled in this study due to the nature of New World wine as a new product class, and thus experience with other wine product classes would seem to be important in assessing diffusion patterns of the new product class (New World wine). This differentiates from cross national diffusion studies based around new consumer durables and new technologies, as these products/innovations are more 'innovative' on the innovativeness scale. In addition, price has been established in the literature as a key determiner of wine purchase, and therefore will be included as a potential moderating variable within this research. The research questions of this study are:

\section{Q1: Do country-level elements of the compatibility attribute affect the rate of diffusion of new world wine in global markets?}

\section{Q2: What are the variables that moderate the compatibility attribute effects?}

\subsection{Dependent Variables}

Roger's (2003) definition of rate of adoption is "the relative speed with which an innovation is adopted by members of the social system". In line with previous studies, this author interprets this as the growth rate of an innovation relative to the population studied. The literature reviewed has clearly pointed out that it is more relevant to break down this relative growth rate into 2 distinct areas of the diffusion curve; 'time to take off', and 'time from take off to market potential' (Agarwal and Bayus 2002; Garber et al. 2004; Goldenberg et al. 2001). As the literature points out, these distinctions in the diffusion curve are important as determinants of 'time to take off' are different from the adoption rate determinants of 'time from take off to market potential'. From the literature, time to take off is determined by innovative behavior and mass market communication methods amoung early adopters in the population. Time from take off to market potential is determined by levels of imitative behavior in the population and levels of interpersonal communication (Rogers 2003). In 
order to determine the diffusion rate of New World wine, and in line with other diffusion studies, the author believes it is necessary to measure the following dependent variables:

- Market share growth rate of New World wine over a period of time across international markets

- Time taken between introduction and take off across international markets

- Time taken between take off and realisation of market potential across international markets

\subsection{Independent Variables and Hypothesis Development}

The key independent variables will be based around the 'compatibility' construct of diffusion theory, in line with other cross national diffusion studies. These variables are:

- Prior experience with a previously introduced idea (Rogers 2003)

- National cultural dimensions (Steenkamp et al. 1999; Dwyer, Mesak et al. 2005; Yaveroglu and Donthu 2002; Yeniyurt and Townsend 2003)

Prior experience with a previously introduced idea

The 'research problem' section of this chapter has outlined that New World wine, as a new product class, differs from products in previously researched cross national diffusion studies such as new consumer durables and new technological products. New World wine is less innovative than these new products, meaning that there is less uncertainty in the adoption of the product. The other studies mentioned have therefore not included 'prior experience with a previously introduced idea' as an independent variable due to lack of relevance. In the authors opinion 'prior experience with a previously introduced idea' is very relevant for this study due to the potential effect of lower levels of uncertainty on the adoption of New World wine in those populations that have experience with other wine classes. Indeed, Rogers (2003) has outlined 'prior experience with a previously introduced idea' as a key part of the compatibility attribute in determining the rate of diffusion. Rogers (p. 243) states "Old ideas are the mental tools that individuals utilize to assess new ideas and give them meaning. Individuals cannot deal with an innovation except on the basis of the familiar. Previous practice provides a standard against which an innovation can be interpreted, thus decreasing 
its uncertainty." It is logical, based upon this concept, that a higher level of previous experience with other wine product classes prior to the availability of New World wine would decrease uncertainty in the New World wine product class and therefore increase speed of diffusion.

On the other hand, there is the possibility of experience of existing wine product classes creating loyalty to existing wine types and an unwillingness to change, which might actually slow down the diffusion of New World wines. Rogers (2003) adds "Compatibility of an innovation with a preceding idea can either speed up or retard its rate of adoption" (pg 243). In addition, the related concept of 'product involvement' has been identified as an important factor in wine consumption behavior (Hollebeck et al 2007; Geraghty \& Torres 2009). Product involvement theory as it relates to wine indicates that consumers with high product involvement use factors outside of the New World wine success factors such as affordability in their wine choice.

Having considered the above factors, the author hypothesizes that 'prior experience with a previously introduced idea' would increase the rate of diffusion due to the lower levels of uncertainty around purchase of New World wine within the 'high experience' markets.

H1: Prior experience with other wine product classes positively correlates with the speed of market share growth for New World wine.

H2: Prior experience with other wine product classes negatively correlates with the higher time to take off for New World wine.

H3: Prior experience with other wine product classes positively correlates with the speed from take off point for New World wine.

\section{National Cultural Dimensions}

Based upon the literature review, culture affects attitudes and behaviours and therefore consumer behavior and diffusion rates (Roth 1995; Dwyer et al. 2005) . Roth (1995) states “a country's values have long been identified as a factor that influences consumer behaviour". Several cross national diffusion studies have used Hofstede's national cultural dimension model (Kumar and Krishnan 2002; Tellis et al 2003). Dwyer et al (2005) use 
Hofstede's cultural dimensions as an "insightful means to assess culture's association with product diffusion". Although there has been some discontent with Hofstede's framework (McSweeney 2002), it is heavily supported in the cross national diffusion academic community and will be used as independent variables in this study.

The first of Hofstede's cultural dimensions that may affect the rate of New World wine diffusion is Power Distance. Power distance is "the extent to which the less powerful members of institutions and organizations within a country expect and accept that power is distributed unequally" (Hofstede 2001: 98). Yaveroglu and Donthu (2002) state that "people in a society of large power distance show greater reliance on centralization and formalization of authority, and greater tolerance for the lack of autonomy". Due to this reliance on centralization and authority, it is expected that people will be more reluctant to try things of their own free will (Yaveroglu and Donthu 2002). In general, people in high power distance societies tend to be less innovative (Hofstede 2001; Yeniyurt and Townsend 2003). Alternatively, low power distance cultures individuals are more independent and can develop and apply leadership qualities and decision-making skills, making 'time to take off' faster (Van den Bulte and Stremersch 2004). Indeed Yaveroglu and Donthu (2002) found that the coefficient of innovation was significantly higher in countries with low power distance. Conversely, those cultures that display high power distance should display relatively faster diffusion rates from take off point, as seen in Dwyer et al (2005).

H4: Countries with higher power distance positively correlates with higher time to take off for New World wine.

H5: Countries with higher power distance positively correlates with faster speed from take off for New World wine.

Individualism: In individualistic cultures, independence is highly valued (Yalcinkaya 2008). Individualism is defined as the extent to which people are expected to stand up for themselves as member of the group or organization (Hofstede 2001). In individualistic cultures, people tend to give more importance to their own and immediate family's well being (Yalcinkaya 2008), and there is a belief in individual decisions (Yaveroglu and Donthu 2002). Previous empirical results indicate that countries scoring higher in the individualist dimension have higher coefficients of innovation (Yaveroglu and Donthu 2002) and a positive impact on the innovativeness of consumers (Steenkamp 1999; Hofstede et al. 1999). 
Collectivist cultures are notable for high interdependence and belief in group decisions. In a collectivist culture, individuals feels as though they are part of a group, the well being of which supersedes the needs of the individual (Yeniyurt and Townsend 2003). Generally, due to the research that indicates individualistic cultures are more innovative, it is likely that individualism supports a positive effect on 'time to take off' of new world wines. Conversely, as supported by Dwyer et al (2005), more collectivist cultures are expected to have a faster speed of diffusion from take off.

H6: Countries with higher individualism negatively correlates with higher time to take off for New World wine.

H7: Countries with higher individualism negatively correlates with faster speed from take off for New World wine.

Uncertainty Avoidance is defined as "the extent to which the members of a culture feel threatened by uncertain or unknown situations" (Hofstede 2001: 161). Cultures that are high in uncertainty avoidance possess an intolerance for and anxiety towards uncertain or ambiguous situations. Therefore members reduce their stress levels by imposing rules and structures in their activities that provide desired predictability to their lives (Dwyer et al. 2005). In addition, Yeniyurt and Townsend (2003) note there is an innate need for clear rules, and a formality to the structure of life. Steenkamp et al (1999) found that high uncertainty avoidance has a negative impact on consumer innovativeness. On the other hand, cultures with low uncertainty avoidance have a high tolerance for improbability and ambiguity and people tend to be more innovative and entrepreneurial (Yeniyurt and Townsend 2003), and are more tolerant of risk taking activities and more willing to try new things (Yaveroglu and Donthu 2002).

H8: Countries with higher uncertainty avoidance positively correlates with higher time to take off for New World wine.

H9: Countries with higher uncertainty avoidance positively correlates with faster speed from take off for New World wine.

Masculinity Hofstede (2001) describes masculinity as the value placed on traditionally male values. He also observes that, in general, people in a masculine society ' live to work', as opposed to a 'work to live' agenda that is more indicative of a feminine society. Masculine 
societies have a greater emphasis on competition, ambition and career advancement ( Everdingen 2005). Rewards are placed on performance and importance is placed upon accomplishments and the acquisition of material goods that signify success (Dwyer et al, 2005). Yalcinkaya (2008) stresses that a symbolic means of demonstrating achievement is by having the latest and most novel product, hoping that new products bring success and ultimately higher status in society. Stremersch and Tellis (2004) explain that individuals in masculine cultures are more motivated to find innovations that create clear distinctions between them and the others. Previous research (Hofstede et al. 1999; Singh 2006) has shown a positive effect of masculinity on innovativeness within a culture and Dwyer et al. (2005) have found a positive effect on diffusion and speed from take off point. A feminine culture on the other hand, values care, sympathy and intuition (Hofstede 2001), and stress modesty, equality, and a concern for the living environment (Tellis et al 2003). Therefore, recognition and advancement are apt to be less effective moderators in these cultures (Dwyer et al 2005). Generally therefore, having a masculine culture will positively affect the time to take off within a country.

H10: Countries with higher masculinity negatively correlates with higher time to take off for New World wine.

H11: Countries with higher masculinity negatively correlates with faster speed from take off for New World wine.

Long term orientation is defined as the extent to which a society exhibits a pragmatic, future oriented perspective rather than a conventional historic or short term perspective (Hofstede 2001). Long term orientation looks toward the future, which is represented in values such as prestige, ordering relationships by status and observing this order, thrift and having a sense of shame (Hofstede 1991). Because long-term oriented cultures value perseverance toward slow results, thrift, and adaptations of traditions to new circumstances, individuals are seen to be cautious to novel ideas and doubtful to sudden changes (Dwyer et al, 2005). New products with little or no past history are likely to be viewed with caution from individuals in long-term orientation cultures (Yalcinkaya 2008). Short term orientation is orientation towards the past and present, represented by values such as personal steadiness and stability, respect for tradition, and reciprocation of greeting favours and gifts (Hofstede 1991). Individuals in these cultures expect to see quick outcomes and value novelty (Yalcinkaya 2008), and experience materialist consumption pressures (eg keeping up with 
trends). To gain higher status within these cultures, individuals are willing to gather information about new products in every way. Although previous empirical studies have been unclear about results in this area, it is expected that 'time to take off' is slower in long term oriented cultures than in short term oriented cultures. Of the literature studied, only Dwyer et al (2005) have looked at speed from take off as explained by long term orientation. Their findings were tentative. It is the authors opinion that higher long term orientation should increase speed from take off as long term oriented cultures tend to place higher value on ideas and products once they have been tested within the population and therefore should be more apt to embrace an innovation after take off point has been reached, as opposed to those cultures that have shorter term orientations.

H12: Countries with higher ratings in Long Term Orientation positively correlates with higher time to take off for New World wine.

H13: Countries with higher ratings in Long Term Orientation positively correlates with faster speed from take off for New World wine.

Moderating Variables

The following variables will be used as moderating variables in the study:

- Socio economic wealth (Helsen et al 1993; Gatignon and Robertson 1985; Gatignon et al 1989; Rogers 2003)

- Price (Batt \& Dean, 2000; Ling \& Lockshin, 2003).

\section{Socio Economic Wealth}

Diffusion literature clearly shows that wealth is an attribute of innovators and is recognised as a key determiner of rate of adoption across cross national and general diffusion studies (Talukdar et al 2002; Dekimpe et al 2000; Tellis et al 2003). The reasons for this include accessibility to new products, more mass media awareness and more functional and wider social groups amongst other things. In the case of New World wine we can therefore expect higher national wealth to be positively correlated to speed of market share growth, time to take off and speed from take off across the independent variables.

\section{Price}


In the case of New World wine, marketing mix variables should be especially important in determining the rate of diffusion as in theory, the less innovative the innovation is on the innovation continuum, the more susceptible consumers should be to change agent efforts. To the author's knowledge, most existing cross national diffusion studies have not used marketing mix variables as independent or moderating variables. As explained in a previous section this is due to the difficulty in sourcing reliable data. It is notable however that many studies mentioned the importance of marketing mix variables in the diffusion process

For this study, the author deems it important to include price as a moderating variable as the literature points out that one of the reasons for New World wine export success is a quality wine at an affordable price (Batt and Dean 2000; Ling and Lockshin 2003). In this study the relative price of New World wine $\mathrm{v}$ other wine classes will be used as a moderating variable It is expected that the lower the relative New World wine price is, the higher the speed of market share growth, the faster the time to take off, and the high speed from take off.

Figure 6 shows a model of the conceptual construct:

Figure 6:

\section{Conceptual Model}
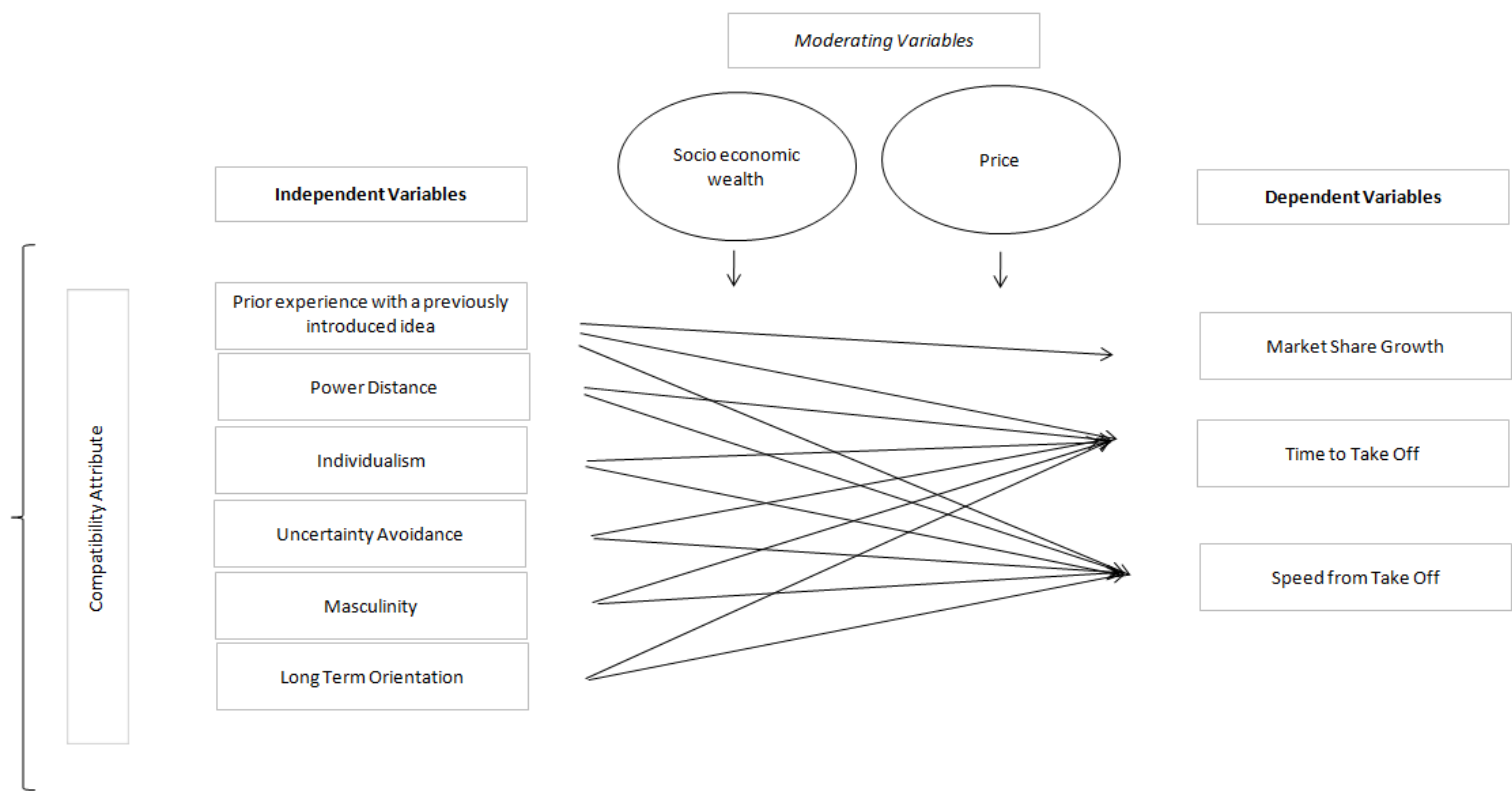

Speed from Take off

\subsection{Chapter Summary}


The conceptual framework chapter has introduced the research problem and the research questions.

\section{Research Problem:}

The diffusion of innovation for a new product class in the cross-national setting.

Research Questions:

Q1: Do country-level elements of the compatibility attribute affect the rate of diffusion of new world wine in global markets?

Q2: What are the variables that moderate the compatibility attribute effects?

It has also identified the dependent, independent and moderating variables within the study and has developed and presented the hypotheses.

The next chapter, methodology, will outline the research approach, explain how the constructs are measured, and indicate how the data will be analysed. 


\section{CHAPTER FOUR: METHODOLOGY}

\subsection{Research Method}

Following the recommendation by Burns and Burns (2008), "research is a process of systematic enquiry or investigation into a specific problem or issue that leads to new or improved knowledge".

The author will take a positivist approach to this research. Laudin (1996) describes the positivist approach as a "methodological approach to understanding phenomenon based on: a scientific approach, empirical data and objectivity". Laudin (1996) adds that the positivist approach does have some drawbacks: that the positivist approach ignores subjectivity, that the positivist approach can infer determinism thus not taking other causes into account, and that the positivist approach infers that results are objective which is never truly the case. The positivist approach is the correct approach to this study as it uses a scientific approach, is quantitiative, and seeks to be as objective as possible.

This research is based on a cross sectional research design. Bryman and Bell (2007) state that a cross sectional research design 'entails the collection of data on more than one case and at a single point in time in order to collect data in connection with two or more variables, which are examined to detect patterns of association'. The research also employs a longitudinal design aspect as it 'involves drawing on phenomena at horizontal and vertical levels of analysis and the interconnections between those levels through time'. (Bryman and Bell 2007: 60). The longitudinal aspect of this research is due to a desire to understand trends and patterns of behavior across a period of time, in this case 19 years.

After the conceptualization of the research problem in the preceding chapter, the focus of this chapter is to show how the constructs are operationalised and measured in this study.

\subsection{Data Collection}

Secondary data sources will be used to collect all data within this research. Bryman and Bell (2007) list the advantages of secondary data analysis as follows:

- Cost and Time 
- High Quality data - usually reliable, able to be replicated and consistent

- Provide opportunity for longitudinal analysis

- Provide opportunity for cross-cultural analysis

These four advantages are very pertinent to this study. The time and cost of collecting data across over 5 decades at a country level are virtually impossible within a Masters Thesis time frame and cost allocation. The quality of the secondary data has been validated by other research and has been put together by respected researchers in the field of global wine research. The secondary data sources used are already longitudinal in design and can be further replicated, and the data is at a country level, in line with the requirements of this research.

Bryman and Bell (2007) also list some potential limitations of secondary data analysis. They are:

- Lack of familiarity with data

- Complexity of the data

- No control over data quality

- Absence of key variables

Although lack of familiarity with the data is an issue, a period of familiarisation has been undertaken to understand the data more completely. As the data has been presented at a summarized level the data is not considered too complex within this research. While there is no control over data quality, one of the advantages of secondary data is the reliability of the data and the author feels that in this case the data is from a reliable source. All key variables have been able to be garnered from the various data sources available. One potential limitation in the data sources that has been identified by the author is that by using variable data sources, there may be some differences in the country/region classification used across the data sources.

\subsection{Data Sources}

For the purposes of collecting data on wine trade and consumption over the period studied at a country level, the author used the publication 'Global Wine markets, 1961 - 2006: a statistical compendium' by Glyn Wittwer and Kym Anderson. This compendium provides annual data for 47 countries/regions that encompasses all countries of the world (as in 
existence at time of publication). Data is presented at a country level where available. Where specific country level data was not available in the construction of the compendium, the authors use data at a regional level. This country/region classification used within the compendium may present country/region consistency problems across other data sources, specifically with cultural dimension classifications.

The data was sourced initially from the Australian Wine and Brandy Corporation as a free publication on their website. This encompassed the years $1961-2003$. For the years $2004-$ 2006 the data was sourced from the University of Adelaide library.

The compendium contains a swathe of wine measures including production, consumption, import and export data at a volume and value level, as well as other pertinent data such as GNP per capita. The data is presented at a 5 yearly average level from $1961-1989$, and at an annual level from 1988 - 2006 across 47 separate countries and regions (see appendix 1). Wittwer and Anderson (2006) have collected this data from a variety of sources, see table 14 for a list of sources used by these authors, for use within this research. A key limitation to this data set is that New World wine imports into global markets have been collected only since 1988, which would not take into account New World wine imports prior to this year. Therefore there may be occasions where 'time to take off' and 'speed from take off' are not measureable due to New World wine being introduced in a country/region before 1988 .

National cultural dimensions are delineated at a country level in line with Hofstedes (2001) country-culture delineations for power distance, uncertainty avoidance, individualism, masculinity and long term orientation. Hofstedes data for national cultural dimensions has been collected at 3 different points in time: 1983, 1990 and 2001. Hofstede (2001) has found that these national cultural dimension scores have remained consistent over time and therefore the author will use the 2001 set of measures. For power distance, uncertainty avoidance, individualism and masculinity, Hofstede has collected data from 74 countries and/or regions, while for long term orientation 40 countries are represented with the data set (see appendix 2 for a list of countries/regions). The data used in this study was sourced directly from Hofstede (2001). As indicated previously, a potential limitation with this data is that the countries/regions with Hofstede's data set may not correspond with the countries/regions contained within the 'Global Wine Compendium'. Where countries/regions do not match across the data sources, an attempt to match 'significant country within a 
region', against a region, will take place. Where there is a region in the compendium that is effectively represented in Hofstedes data by a country, these matches will be made (see appendix 3 for a list of matches)..

Table 14:

Variable Measures and Sources

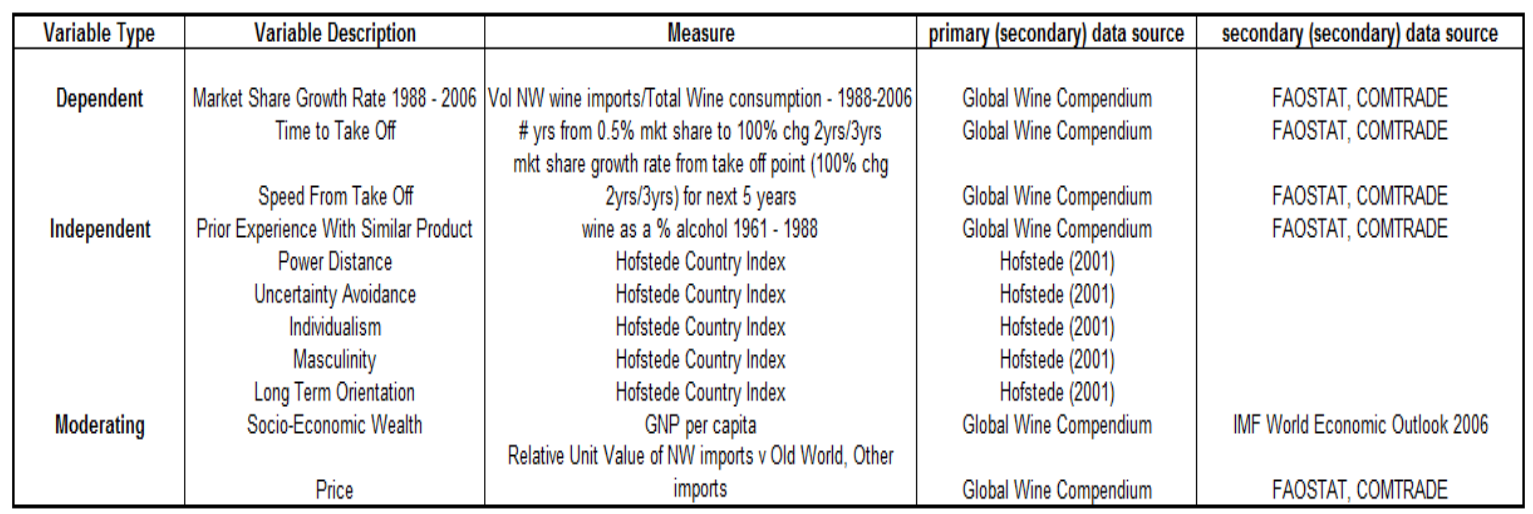

Table 14 above shows the dependent and independent variable data source including the direct secondary source and the original data source. In addition, table 14 states the variable measure. The next section, construct measurement, will look in detail at how each variable is measured within this study.

\subsection{Construct Measurement}

\section{Dependent Variables}

As described in the conceptual framework chapter, there are three dependent variables within this research:

- Market share growth rate of New World Wine over a period of time across the global markets studied

- Time taken between introduction and take off across the global markets studied

- Time taken between take off and realisation of market potential across the global markets studied 
For (1) above, this research will look at market share growth rate of New World wine for each international market studied for the years 1988 - 2006. This market share growth rate is in line with Rogers" (2003) definition of rate of adoption as the "number of members of the system who adopt the innovation in a given time period'. Market share will be measured as New World wine imported into the particular international market as a \% of total wine consumed in that international market. The author considered 'total wine imported by market' as an alternative denominator however decided upon 'total wine consumed by market'. This measure takes into account consumption of domestically produced wine and therefore provides a more accurate view of how New World wine diffuses in a population. Market share growth will be measured in absolute terms ie the actual market share change/numbers of years, rather than growth rate year on year - this is due to the low numbers involved. As mentioned above, the first year of study, 1988, may be after New World wine has captured some market share in some countries/regions. However, 1988 is the earliest year that data is available and is recognized from the literature as being before the recognized sharp increase of New World wines in global markets. The last year, 2006, provides the last year that data is publicly available and is considered to provide a reasonable market penetration time frame (19 years).

For (2) above, a determination of time of introduction and take off point are required. From the literature the time of introduction is based around the first year of material sales. Following on from Tellis et al (2003) this research will use the year where market share reaches $0.5 \%$ of total wine consumption within the market. This measure enables a fair representation between markets where there was a minimal level of New World wine sales before 1988 (the first year of study) and those markets where there were no sales at all before 1988. The key limitation of the introduction point construct measure is that there are potentially countries where introduction point had been reached before the 1988 , therefore reducing sample size. As no data is available prior to 1988, this limitation cannot be mitigated and therefore those countries with an introduction year before 1988 will be excluded from the time to take off analysis.

The determination of take off point is an inexact science based upon the literature reviewed. A measure of $16 \%$ of market potential has been used by Rogers (2003), Garber et al. (2004) and Goldenberg et al. (2001), a measure of around $2 \%$ of market potential has been used by 
Chandrasekaran and Tellis (2008), and a measurement of the point of a substantial change in sales or market penetration has also been used (Agarwal and Bayus 2002) . For this study, the author has constructed 4 potential measures for takeoff point:

1. The first year since introduction where the change in market share for the following two years is more than $100 \%$ of the change in market share for the preceding two years, based upon a minimal amount of New World wine imports of 1 million litres within the year. This is loosely based upon the methodology employed by Agarwal and Bayus (2002) and Golder and Tellis (1997)

2. The first year since introduction where the change in market share for the following three years is more than $100 \%$ of the change in market share for the preceding three years, based upon a minimal amount of New World wine imports of 1 million litres within the year. This is loosely based upon the methodology employed by Agarwal and Bayus (2002) and Golder and Tellis (1997)

3. The first year since introduction where the change in market share for the following two years is more than $100 \%$ of the change in market share for the preceding two years, and where the change in market share for the following three years is more than $100 \%$ of the change in market share for the preceding three years. This is loosely based upon the methodology employed by Agarwal and Bayus (2002) and Golder and Tellis (1997).

4. The first year since introduction where the New World wine market share of total wine consumption crosses the two percent threshold based upon a minimal amount of New World wine imports of 1 million litres within the year. This is based upon Chandrasekaran and Tellis (2008).

The author employed a visual check of diffusion curves to determine the take off point measure that appears to correctly identify take off point in the most cases. Based on this check, option 3, which was accurate to within one year in $80 \%$ of cases was selected. This 'visual check' methodology has been previously employed in diffusion literature, including by Agarwal and Bayus (2002) and Golder and Tellis (1997).

For (3) above, the determination of the market potential presents several challenges. Firstly, while absolute market potential could be seen as new world wine market share reaching $100 \%$ of all wine consumed in the market, the author thinks that this is unrealistic for any 
market that has domestic wine production and in addition wresting complete market share from traditional wine producers in any market is extremely unlikely due to the long established branding and distribution channels in place. One possible solution to this is to use the expected market share of an already diffused similar product for each market. This option has been ruled out due to the difficulty in finding already diffused similar products for each market and even if possible, the difficulties in accessing the scale of data required. A second complication is the fact that New World wine is currently still diffusing in the vast majority (and possibly all) of the markets studied meaning that getting a defined market potential for markets within this study is impossible. The solution to this, and the measurement that will be used in this study, is a measurement of speed of diffusion from take off point for the following five years. The author feels that five years allows a comparison between global markets of the differences in diffusion shape after New World wine reaches take off point. A potential limitation with this construct measure is that, as pointed out above, take off point may not be reached within the study period for some countries/regions, and therefore speed after takeoff cannot be measured. In addition this measure would not be viable in any country/region where take off point is within 5 years of the final year of study (2006).

A key limitation with all of the dependent variables is that there are many factors outside of the independent variables studied that could be contributing to change in the dependent variables. The time and cost of controlling for all of these variables is outside of this study's reach but some of the more pertinent variables, as discussed in the literature review, are as follows:

- Changes in trading regulations including free trade agreements

- Changes in political status of countries/region

- Market based changes including over supply

- Wars and other events

Independent Variables

The independent variables within the study are as follows:

○ Prior experience with a previously introduced idea 
- Power Distance

○ Individualism

- Uncertainty Avoidance

○ Masculinity

○ Long Term Orientation

The independent variable 'Prior experience with a previously introduced idea', will be measured as prior experience with another wine class prior to the advent of new world wine on the global market. As has been described previously, New World wine 'exploded' onto the global market around 1990. In order to ascertain experience with other wine classes prior to this New World wine phenomenon, the research will use the measure 'wine as a $\%$ of total alcohol consumption in all countries studied between the years 1961-1984'. This will determine levels of wine consumption in classes other than New World wine within the global market, and provide a measure of 'wine experience' in these countries in the period leading up to the advent of new world wine. A limitation of this measure is that it infers that no 'New World' wine was imported into the countries/regions studied before 1984.

Although there may have been small levels of New World wine imports into global markets before 1984, it is of small enough levels to allow a reasonable measure of prior 'other wine class' experience.

Hofstede's cultural dimensions index will be used to ascertain levels of power distance, individualism, uncertainty avoidance, masculinity and long term orientation within the countries in the research. Hofstede's culture index has been used in various cross-national wine diffusion studies including Yeniyurt and Townsend (2003) and Dwyer et al (2008). One of the limitations of the data collection and measurement process is the fact that the countries that have assigned cultural dimension data may differ in some cases from the countries and regions within the 'wine compendium'. This limitation will be dealt with in the Data analysis chapter.

Moderating Variables

○ Socio Economic Wealth

○ Price 
GNP per capita will be used as a measure of socio economic wealth across the countries studied. GNP per capita has been summarized in the 'Global Wine Compendium' and therefore provides consistency with the majority of other construct variables. GNP per capita will be measured as an average GNP across the period (1988 - 2006) for each country/region.

Relative average unit value of imports from new world $\mathrm{v}$ other countries will be used as a measure for relative price. In this case a relative price of new world wine $\mathrm{v}$ other importing wine classes will be used to establish whether price is a moderator of the other independent variables. There are key limitations with this approach:

- Unit price for imports does not specifically determine the final selling price of the product due to added distribution and marketing costs as well as price point discounting

- The data set does not provide the price of domestically produced wine and therefore does not provide an accurate gauge of relative price across all wine types available for consumption.

Despite these limitations the author feels that a measure for relative price is an important variable within this study, in line with price being considered the most important factor within the wine choice literature, and affordability being forwarded as being a success factor for New World wine. In addition, Golder and Tellis (1997) state that there is strong support for incorporating a price relative to a reference price in econometric modeling.

\subsection{Data Analysis}

This research will use correlation modelling to assess positive or negative relationships between the dependent and independent variables. Correlation is "a measure of the degree of correspondence between variables" (Burns and Burns 2008:p 342). Burns and Burns (2008) note that correlation does not define any one variable causing an 'effect' in another. In the authors opinion this is especially evident in this study where several other variables may be at play. Burns and Burns (2008) note that correlation is different from inferential statistics like t-tests and ANOVA's which compare groups with groups, and not individual populations as 
happens in correlation. They add that when investigating relationships, the strength of a connection is examined between two characteristics shared by the same individual/event/equipment. Pearson's correlation coefficient will be used in this study to ascertain correlation sign. Burns and Burns (2008) state that the Pearson correlation coefficient is the most widely used correlation coefficient and is employed when both variables are expressed as scale data (interval or ratio). This is the case within this study.

Scattergraphs will be presented for each test within this study. Scattergraphs provide a visual impression of the sign of correlation and the slope of the linear trend line provides an indication of the sign of the correlation. Figure 7 below shows examples of perfect positive correlation and perfect negative correlation. Burns and Burns (2008) add only in extremely rare cases are correlations perfect, but the strength of the correlation can be analysed against these perfect correlations.

Figure 7: $\quad$ Examples of Perfect Positive and Perfect Negative Correlations on a Scattergraph
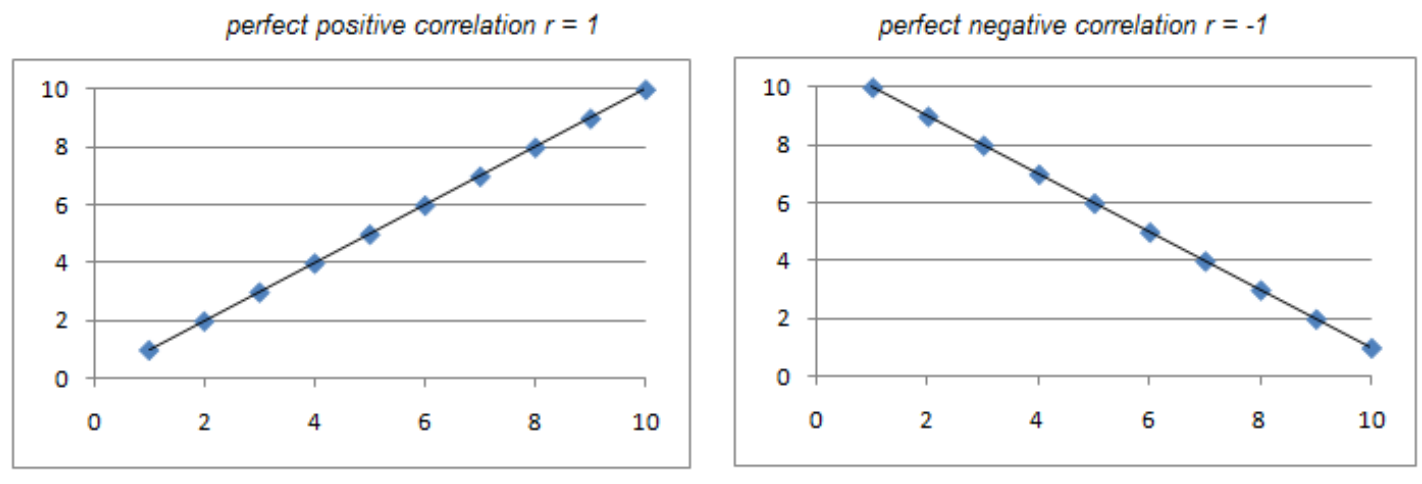

In addition to the correlation coefficient $(r)$, this research will use the $r$ squared measure $\left(r^{2}\right)$, also known as coefficient of determination, to determine relationship strength. Burns and Burns (2008) state that the correlation of determination provides the amount of common variation between the two variables or the amount of variation in $\mathrm{Y}$ explained by variation in $\mathrm{X}$ when converted to a percentage. They add that correlation of determination defines the strength of a relationship in a far more precise way than the correlation coefficient alone. The determination of whether an $\mathrm{r}^{2}$ value represents a strong or weak relationship is very dependent upon situation and the number of other potential explanatory variables that are not tested for. Green, Tull and Albaum (1988, p.489) state that, "effects explaining as little as 5 percent (perhaps even 1 percent) of variance may well be considered either theoretically or practically important. Since large effect sizes are more likely to exist for relationships that are 
'obvious', it may be argued that these are situations whereby no new knowledge is contributed by the research". In this research there are large numbers of factors outside of the focus of the explanatory variables of this study e.g., distribution measures, marketing spend etc. Therefore, this will study will use an $\mathrm{r}^{2}$ value of $5 \%$ or above to indicate an important effect. An $\mathrm{r}^{2}$ value of less than $5 \%$ will be considered to be too weak to support the hypothesis.

This research will only accept hypotheses where the statistical significance value (p) is less than or equal to 0.05 for a linear relationship. Bryman and Bell (2007) state that this level of significance is acceptable within business research. In this research, the dependent variable of market share growth contains the entire population. In tests where the full population is used (across dependent and independent variables), statistical significance will not be used to accept or reject the hypothesis. To ascertain statistical significance for models where moderating variables are added, the f statistic will be used. Moderating variables will only be used where there is a statistically significant relationship between the independent and dependent variables.

Pearson's correlation coefficient (r) will be ascertained in Excel using the PEARSON function. $\mathrm{r}^{2}, \mathrm{p}$ and $\mathrm{f}$ will be measured using the regression function in Excel 2007.

\section{Hypothesis Acceptance Criteria}

Hypotheses will be accepted within this research where the resulting correlation sign is in line with the expectation, $\mathrm{r}^{2}$ is over $5 \%$, and the results are statistically significant. Where hypothesis tests show a correlation sign in line with expectation but not at a statistically significant level, the hypothesis will not be supported. Where the correlation sign is different from expectation, and the result is statistically significant, the hypothesis will be rejected.

\subsection{Chapter Summary}

The methodology chapter has outlined the research approach, the data sources and the construct measures for analysis. It has explained the data analysis methodologies and measures and has outlined the hypothesis acceptance criteria. Chapter 5 will present the results and findings of the hypothesis testing. 
Table 15 shows the results of the analysis on hypothesis 1 . The hypothesis of a positive correlation between prior experience with a similar product and market share growth was rejected. Instead a fairly strong negative correlation was found. The $r$ value of -0.60 and the r squared value of 0.36 , along with a significance level of less than .0001. The r-squared value of 0.36 represents a strong relationship. Figure 8 shows the scatterplot graph of hypothesis 1 and indicates the strong negative correlation.

\section{Moderating Variable Analysis}

As described in the methodology section, effects of moderating variables will be assessed against the independent variable in hypothesis 1 . The moderating variables are:

- Socio economic wealth

- Price

Socio Economic Wealth (measured as GNP per capita)

Results: 
Table 16: Moderator 1 effect on Hypothesis 1

\begin{tabular}{|c|c|c|c|}
\hline country & NWV wine growth rate $(1988-2006)$ & wine as $\%$ alc (1961 - 1984) & Average GNP per capita (USD) \\
\hline Argentina & $0.00 \%$ & $90 \%$ & $\$ 6,831$ \\
\hline Australia & $0.21 \%$ & $20 \%$ & $\$ 22,892$ \\
\hline Austria & $0.06 \%$ & $40 \%$ & $\$ 29,208$ \\
\hline Brazil & $0.41 \%$ & $30 \%$ & $\$ 3,923$ \\
\hline Bulgaria & $0.01 \%$ & $42 \%$ & $\$ 2,000$ \\
\hline Canada & $2.25 \%$ & $11 \%$ & $\$ 23,292$ \\
\hline Chile & $0.14 \%$ & $85 \%$ & $\$ 4,892$ \\
\hline China & $1.12 \%$ & $0 \%$ & $\$ 946$ \\
\hline Denmark & $2.05 \%$ & $18 \%$ & $\$ 36,046$ \\
\hline Finland & $0.76 \%$ & $10 \%$ & $\$ 26,862$ \\
\hline France & $0.07 \%$ & $75 \%$ & $\$ 27,362$ \\
\hline Germany & $0.40 \%$ & $23 \%$ & $\$ 28,562$ \\
\hline Greece & $0.00 \%$ & $74 \%$ & $\$ 13,500$ \\
\hline Hungary & $0.00 \%$ & $40 \%$ & $\$ 6,185$ \\
\hline Ireland & $2.86 \%$ & $5 \%$ & $\$ 25,931$ \\
\hline Italy & $0.12 \%$ & $84 \%$ & $\$ 21,423$ \\
\hline Japan & $-0.12 \%$ & $2 \%$ & $\$ 36,792$ \\
\hline Mexico & $4.27 \%$ & $2 \%$ & $\$ 4,392$ \\
\hline Netherlands & $1.70 \%$ & $17 \%$ & $\$ 26,954$ \\
\hline Other Africa & $0.78 \%$ & $0 \%$ & $\$ 392$ \\
\hline Portugal & $0.00 \%$ & $85 \%$ & $\$ 12,300$ \\
\hline Romania & $0.00 \%$ & $57 \%$ & $\$ 2,192$ \\
\hline Russia & $0.40 \%$ & $25 \%$ & $\$ 2,762$ \\
\hline Spain & $0.01 \%$ & $63 \%$ & $\$ 16,992$ \\
\hline Sweden & $2.21 \%$ & $17 \%$ & $\$ 28,869$ \\
\hline Switzerland & $0.31 \%$ & $52 \%$ & $\$ 43,831$ \\
\hline Turkey & $0.02 \%$ & $18 \%$ & $\$ 3,046$ \\
\hline Uruguay & $0.00 \%$ & $70 \%$ & $\$ 4,792$ \\
\hline Belgium-Luxembourg & $0.94 \%$ & $24 \%$ & $\$ 28,215$ \\
\hline United Kingdom & $2.48 \%$ & $10 \%$ & $\$ 24,585$ \\
\hline United States of America & $0.65 \%$ & $11 \%$ & $\$ 32,223$ \\
\hline Other North East Asia & $3.00 \%$ & $5 \%$ & $\$ 14,138$ \\
\hline Other Western Europe & $0.48 \%$ & $9 \%$ & $\$ 32,638$ \\
\hline Other Central Eastern Europe & $0.06 \%$ & $16 \%$ & $\$ 3,046$ \\
\hline New Zealand & $1.64 \%$ & $14 \%$ & $\$ 17,462$ \\
\hline Other Latin America Caribbean & $2.76 \%$ & $3 \%$ & $\$ 1,823$ \\
\hline South Africa & $0.08 \%$ & $37 \%$ & $\$ 3,446$ \\
\hline North Africa & $0.00 \%$ & $52 \%$ & $\$ 1,438$ \\
\hline \multirow[t]{4}{*}{ Middle East } & $1.81 \%$ & $0 \%$ & $\$ 2,862$ \\
\hline & & Pearson Correlation Coefficient & -0.603373328 \\
\hline & & $\mathrm{R}$ Square & 0.364059373 \\
\hline & & $\mathrm{F}$-significance & 0.0002894 \\
\hline
\end{tabular}

Table 16 shows the correlation coefficient and $\mathrm{r}$ squared values stayed the same and therefore there is no evidence to suggest that GNP has an effect as a moderating variable.

Price (measured as relative unit import price versus other wine classes)

Results:

Table 17: Moderator 2 effect on Hypothesis 1

\begin{tabular}{|c|c|c|c|}
\hline country & NWW wine growth rate (1988 - 2006) & wine as $\%$ alc $(1961$ - 1984) & NW unit value $v$ Other \\
\hline Canada & $2.25 \%$ & $11 \%$ & $-32 \%$ \\
\hline China & $1.12 \%$ & $0 \%$ & $-46 \%$ \\
\hline Denmark & $2.05 \%$ & $18 \%$ & $-21 \%$ \\
\hline Finland & $0.76 \%$ & $10 \%$ & $3 \%$ \\
\hline France & $0.07 \%$ & $75 \%$ & $79 \%$ \\
\hline $\begin{array}{l}\text { Germany } \\
\text { Ireland }\end{array}$ & $0.40 \%$ & $23 \%$ & $238 \%$ \\
\hline $\begin{array}{l}\text { Ireland } \\
\text { Italy }\end{array}$ & $\begin{array}{l}2.86 \% \\
0.12 \%\end{array}$ & $\begin{array}{l}5 \% \\
84 \%\end{array}$ & $-9 \%$ \\
\hline Japan & $-0.12 \%$ & ${ }_{2 \%}^{84 \%}$ & $-4 \%$ \\
\hline Mexico & $4.27 \%$ & & $-60 \%$ \\
\hline Netherlands & $1.70 \%$ & $17 \%$ & $-53 \%$ \\
\hline Russia & $0.40 \%$ & $25 \%$ & $\begin{array}{l}-15 \% \\
52 \%\end{array}$ \\
\hline Sweden & $2.21 \%$ & $17 \%$ & $-17 \%$ \\
\hline Switzerland & $0.31 \%$ & $52 \%$ & $-38 \%$ \\
\hline Belgium-Luxembourg & $0.94 \%$ & $24 \%$ & $13 \%$ \\
\hline United Kingdom & $2.48 \%$ & $10 \%$ & $98 \%$ \\
\hline \multirow{3}{*}{$\begin{array}{l}\text { United States of America } \\
\text { Other North East Asia }\end{array}$} & $0.65 \%$ & $11 \%$ & $3 \%$ \\
\hline & $3.00 \%$ & $5 \%$ & $-34 \%$ \\
\hline & & $\begin{array}{c}\text { Pearson Correlation Coefficient } \\
\text { R Square }\end{array}$ & $\begin{array}{r}-0.564018244 \\
0.318116579\end{array}$ \\
\hline
\end{tabular}


Table 17 shows the $r$ squared value reduced slightly indicating some moderating effect however the $\mathrm{f}$ value of the model was not statistically significant so there is no support for the moderating effect of price.

H2: Prior experience with other wine product classes negatively correlates with higher time to take off for New World wine.

Method:

- Take out all countries/regions where:

○ take off year does not have at least 1 million litres of New World wine imported

- New World wine market share percentage is over $0.50 \%$ in first year of study (1988) indicating that New World wine was introduced before the study period and therefore making a calculation of time (years) from introduction point to take off point impossible

- New World wine did not take off within the study period

- Perform correlation, $r$ squared and statistical significance measurements

Results:

Table 18: Hypothesis2 results

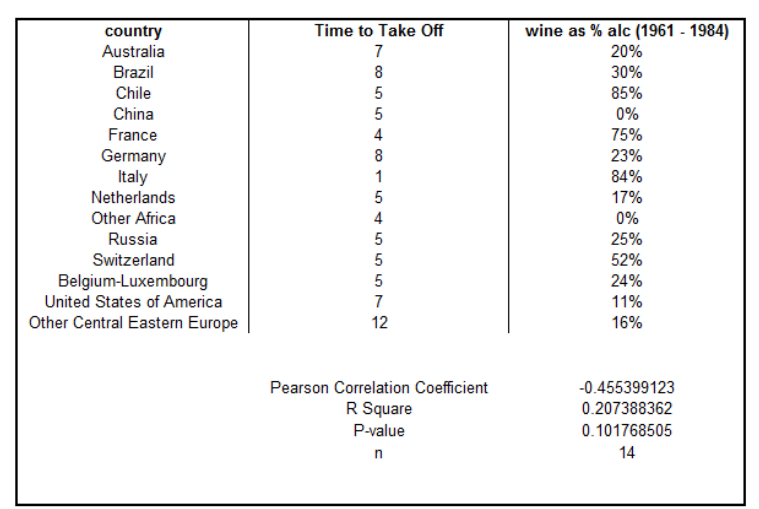

Figure 9: Scatterplot of Hypothesis 2

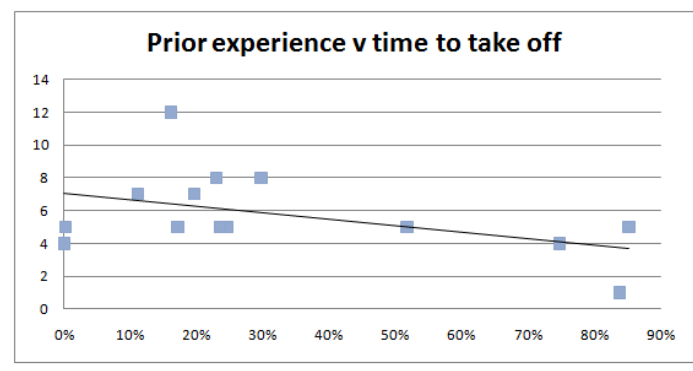

Table 18 shows a negative correlation was found to a moderate level in line with the hypothesis. Sample size reduced from a full potential population set of 47 countries/regions to 14 countries/regions. Results not found to be statistically significant at a 0.05 level, and therefore the hypothesis cannot be supported. Figure 9 shows the scatterplot graph for hypothesis 2 test. 
H3: Prior experience with other wine product classes positively correlates with the speed from take off point for new world wine.

Method:

- From all countries/regions in time to take off sample, take out those countries where:

- Take off point was within five years of the final date of study as unable to measure five years from take off point for these countries.

Results:

Table 19: Hypothesis 3 results

\begin{tabular}{|c|c|c|}
\hline country & speed from take off & wine as \% alc (1961 - 1984) \\
Brazil & $0.27 \%$ & $30 \%$ \\
Chile & $0.00 \%$ & $85 \%$ \\
China & $3.77 \%$ & $0 \%$ \\
Netherlands & $2.36 \%$ & $17 \%$ \\
Other Africa & $0.23 \%$ & $0 \%$ \\
Russia & $1.39 \%$ & $25 \%$ \\
Switzerland & $1.02 \%$ & $52 \%$ \\
Belgium-Luxembourg & $1.46 \%$ & $24 \%$ \\
United States of America & $0.56 \%$ & $11 \%$ \\
& & \\
& & -0.466260538 \\
& Pearson Correlation Coefficient & 0.217398889 \\
& R Square & 0.205834355 \\
& P-value & 9 \\
\hline
\end{tabular}

Figure 10: Scatterplot of Hypothesis 3

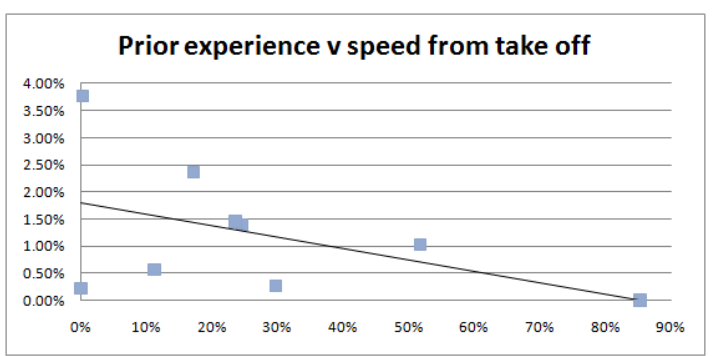

Table 19 shows there is no evidence to accept the hypothesis. A negative correlation was found to a moderate level in line with prior experience and market share growth. Sample size reduced from a full potential population set of 47 countries/regions to 9 countries/regions. Results not found to be statistically significant at a 0.05 level. Figure 10 shows a scatterplot graph of Hypothesis 3 test.

Hypotheses 4 -13 involve the independent variables of Hofstede's national cultural dimensions. As these dimensions relate to propensity to innovate or imitate, these independent variables will only seek to explain time to take off, and speed from take off.

H4: Countries with higher power distance positively correlates with higher time to take off for New World wine.

Method:

- Select all countries/regions with time to take off measures

- Discount all countries/regions with time to take off measures that do not have a Power Distance measurement

Results: 
Table 20: Hypothesis 4 results

\begin{tabular}{|c|c|c|}
\hline country & time to take off & Power Distance \\
\hline Australia & 7 & 36 \\
Brazil & 8 & 69 \\
Chile & 5 & 63 \\
China & 5 & 80 \\
France & 4 & 68 \\
Germany & 8 & 35 \\
Italy & 1 & 50 \\
Netherlands & 5 & 38 \\
Other Africa & 4 & 77 \\
Russia & 5 & 93 \\
Switzerland & 5 & 26 \\
Belgium-Luxembourg & 5 & 61 \\
United States of America & 7 & 40 \\
\multicolumn{2}{|c}{} & \\
& & -0.229528776 \\
& Pearson Correlation Coefficient & 0.052683459 \\
& R Square & 0.45063927 \\
& P-value & 13 \\
n & \\
\hline
\end{tabular}

Figure 11: Scatterplot of Hypothesis 4

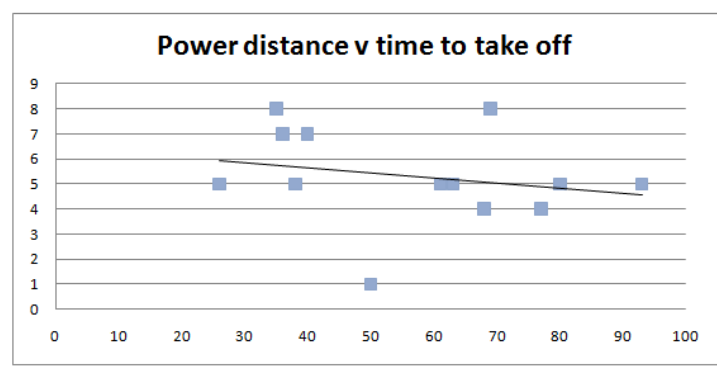

Table 20 shows a statistical significance not at a 0.05 level and therefore the hypothesis is not supported. Figure 11 shows the slightly negative relationship.

H5: Countries with higher power distance positively correlates with faster speed from take off for New World wine.

Method:

- Select all countries/regions with speed from take off measures

- Discount all countries/regions with speed from take off measures that do not have a Power Distance measurement

Results:

Table 21: Hypothesis 5 results

\begin{tabular}{|c|c|c|}
\hline country & speed from take off & Power Distance \\
Brazil & $0.27 \%$ & 69 \\
Chile & $0.00 \%$ & 63 \\
China & $3.77 \%$ & 80 \\
Netherlands & $2.36 \%$ & 38 \\
Other Africa & $0.23 \%$ & 77 \\
Russia & $1.39 \%$ & 93 \\
Switzerland & $1.2 \%$ & 26 \\
Belgium-Luxembourg & $1.46 \%$ & 61 \\
United States of America & $0.56 \%$ & 40 \\
& & \\
& & 0.105693895 \\
& Pearson Correlation Coefficient & 0.011171199 \\
& R Square & 0.786676568 \\
& P-value & 9 \\
\hline
\end{tabular}

Figure 12: Scatterplot of Hypothesis 5

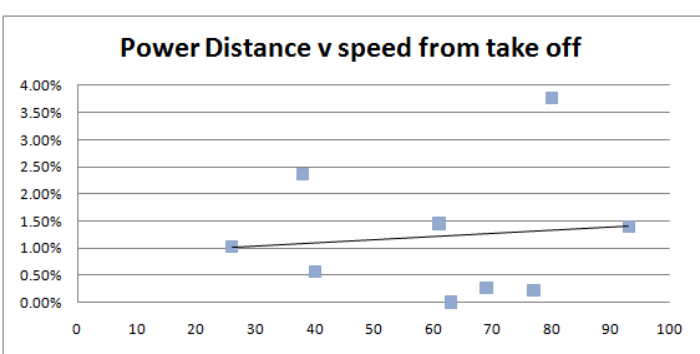

Table 21 shows a positive correlation in line with hypothesis but a very low R square measure and a statistical significance level not at a 0.05 level, combined with a very low sample size means the hypothesis cannot be supported. Figure 12 shows a scatterplot representation of the relationship.

H6: Countries with higher individualism negatively correlates with higher time to take off for New World wine.

Method:

- Select all countries/regions with time to take off measures 
- Discount all countries/regions with time to take off measures that do not have a Individualism measurement

Results:

Table 22: Hypothesis 6 results

\begin{tabular}{|c|c|c|}
\hline country & time to take off & Individualism \\
\hline Australia & 7 & 90 \\
Brazil & 8 & 38 \\
Chile & 5 & 23 \\
China & 5 & 20 \\
France & 4 & 71 \\
Germany & 8 & 67 \\
Italy & 1 & 76 \\
Netherlands & 5 & 80 \\
Other Africa & 4 & 20 \\
Russia & 5 & 39 \\
Switzerland & 5 & 69 \\
Belgium-Luxembourg & 5 & 78 \\
United States of America & 7 & 91 \\
\multicolumn{2}{c}{} & \\
& & 0.078562483 \\
& Pearson Correlation Coefficient & 0.006172064 \\
& R Square & 0.798636163 \\
& P-value & 13 \\
n & \\
\hline
\end{tabular}

Figure 13: Scatterplot of Hypothesis 6

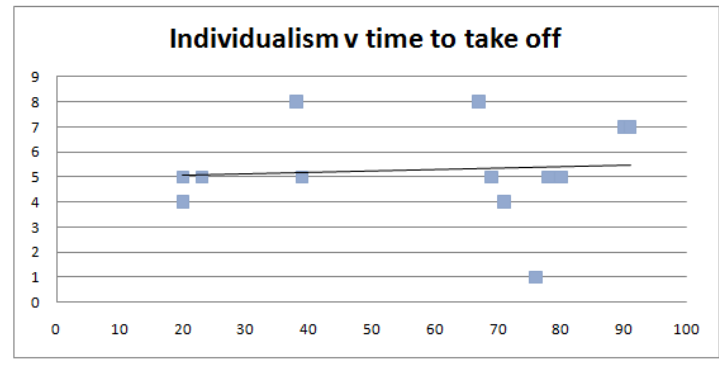

Table 22 shows a positive correlation, a very low $\mathrm{r}$ squared value and a very high $\mathrm{p}$ value means the hypothesis cannot be supported. Figure 13 shows a scatterplot representation of the data.

H7: Countries with higher individualism negatively correlates with faster speed from take off for New world wine

Method:

- Select all countries/regions with speed from take off measures

- Discount all countries/regions with speed from take off measures that do not have an individualism measurement

Results:

Table 23: Hypothesis 7 results

\begin{tabular}{|c|c|c|}
\hline country & speed from take off & Individualism \\
Brazil & $0.27 \%$ & 38 \\
Chile & $0.00 \%$ & 23 \\
China & $3.77 \%$ & 20 \\
Netherlands & $2.36 \%$ & 80 \\
Other Africa & $0.23 \%$ & 20 \\
Russia & $1.39 \%$ & 39 \\
Switzerland & $1.02 \%$ & 69 \\
Belgium-Luxembourg & $1.46 \%$ & 78 \\
United States of America & $0.56 \%$ & 91 \\
& & \\
& & 0.02064384 \\
& Pearson Correlation Coefficient & 0.000426168 \\
& R Square & 0.957959648 \\
& P-value & 9 \\
\hline & $n$ & \\
\hline
\end{tabular}

Figure 14: Scatterplot of Hypothesis 7

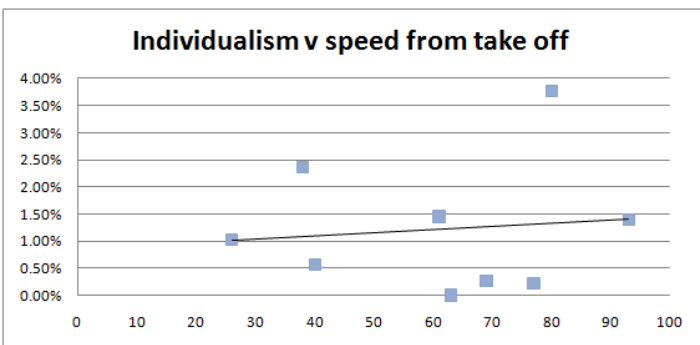

Table 23 shows a slight positive correlation, very low $\mathrm{r}$ squared value, high $\mathrm{p}$ value and low sample size mean the hypothesis is not supported. Figure 14 illustrates the data in a scatterplot graph. 
H8: Countries with higher uncertainty avoidance positively correlates with higher time to take off for New World wine.

Method:

- Select all countries/regions with time to take off measures

- Discount all countries/regions with time to take off measures that do not have a uncertainty avoidance measurement

Results:

Table 24: Hypothesis 8 results

Figure 15: Scatterplot of Hypothesis 8

\begin{tabular}{|c|c|c|}
\hline \multicolumn{3}{|r|}{$\begin{array}{l}\text { Uncertainty Avoidance } \\
51\end{array}$} \\
\hline $\begin{array}{c}\text { Australia } \\
\text { Brazil }\end{array}$ & 7 & $\begin{array}{l}51 \\
76\end{array}$ \\
\hline & 5 & $\begin{array}{l}16 \\
86\end{array}$ \\
\hline China & 5 & 30 \\
\hline $\begin{array}{c}\text { France } \\
\text { Germanov }\end{array}$ & 4 & 86 \\
\hline $\begin{array}{l}\text { Germany } \\
\text { Italy }\end{array}$ & ${ }_{1}^{8}$ & 65 \\
\hline $\begin{array}{l}\text { Netherlands } \\
\text { Int }\end{array}$ & $\begin{array}{l}1 \\
5\end{array}$ & $\begin{array}{l}15 \\
53\end{array}$ \\
\hline Other Africa & 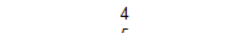 & 54 \\
\hline Russia & 5 & 95 \\
\hline $\begin{array}{l}\text { Switzerland } \\
\text { Belgium-Luxembou }\end{array}$ & & 56 \\
\hline 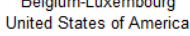 & 7 & 46 \\
\hline & $\begin{array}{l}\text { Pearson Correlation Coefficient } \\
\text { R Souare }\end{array}$ & $\begin{array}{l}-0.229528776 \\
0.037657384\end{array}$ \\
\hline & P-value & $\begin{array}{l}0.525258683 \\
13\end{array}$ \\
\hline
\end{tabular}

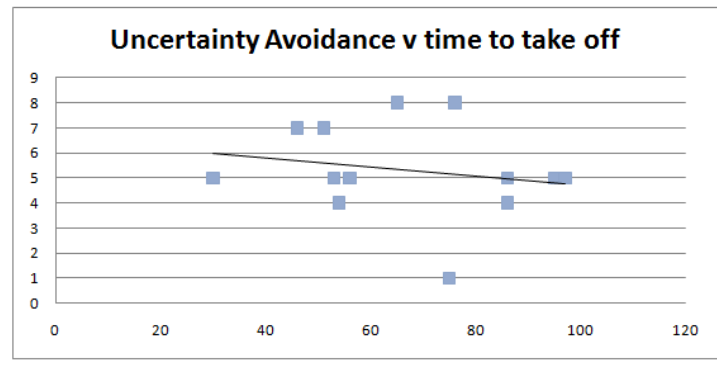

Table 24 shows a negative correlation, a low $\mathrm{r}$ squared value meaning the relationship is not strong and a palue of above 0.05 means that the sample is not statistically significant.

Therefore the hypothesis is not supported.

H9: Countries with higher uncertainty avoidance positively correlates with faster speed from take off for New World wine.

Method:

- Select all countries/regions with speed from take off measures

- Discount all countries/regions with speed from take off measures that do not have an uncertainty avoidance measurement

Results: 
Table 25: Hypothesis 9 results

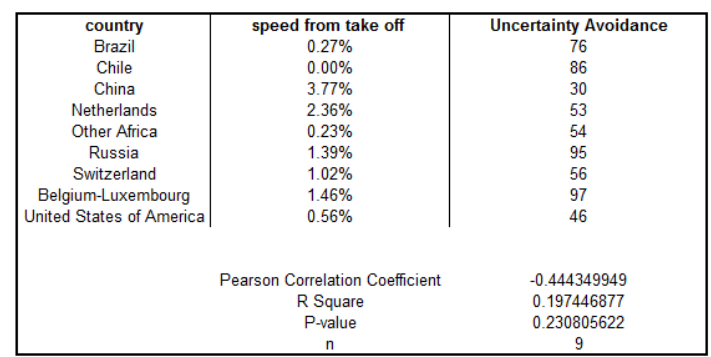

Figure 16: Scatterplot of Hypothesis 9

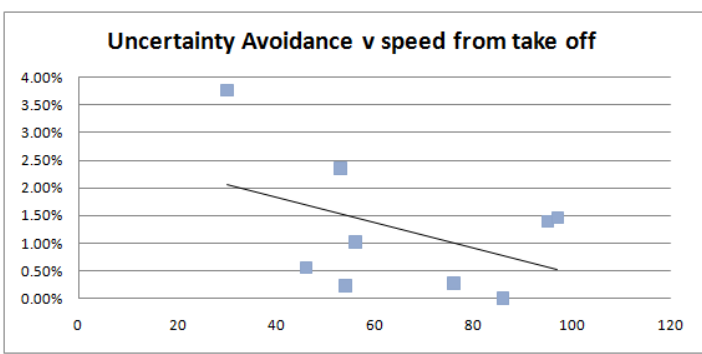

Table 25 shows a negative correlation, a fairly low $r$ squared measure and a $p$ value above the 0.05 statistical significance level. The hypothesis is not supported. Figure 16 shows a scatterplot representation of the data.

H10: Countries with higher masculinity negatively correlates with higher time to take off for New World wine.

Method:

- Select all countries/regions with time to take off measures

- Discount all countries/regions with time to take off measures that do not have a masculinity measurement

Results:

Table 26: Hypothesis 10 results

\begin{tabular}{|c|c|c|}
\hline country & time to take off & Masculinity \\
\hline Australia & 7 & 61 \\
Brazil & 8 & 49 \\
Chile & 5 & 28 \\
China & 5 & 66 \\
France & 4 & 43 \\
Germany & 8 & 66 \\
Italy & 1 & 70 \\
Netherlands & 5 & 14 \\
Other Africa & 4 & 46 \\
Russia & 5 & 36 \\
Switzerland & 5 & 72 \\
Belgium-Luxembourg & 5 & 43 \\
United States of America & 7 & 62 \\
& & \\
& & 0.050329328 \\
& Pearson Correlation Coefficient & 0.002533041 \\
& R Square & 0.870296469 \\
& P-value & 13 \\
n & \\
\hline
\end{tabular}

Figure 17: Scatterplot of Hypothesis 10

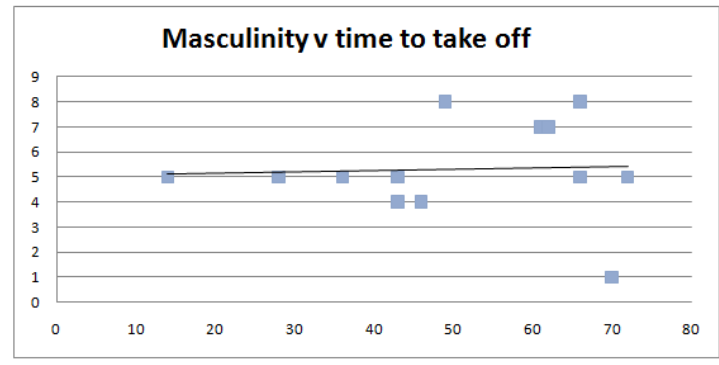

Table 26 shows a positive correlation, a very small $r$ squared value and very large $p$ value. There is no evidence to support the hypothesis. Figure 17 presents a scatterplot representation of the data.

H11: Countries with higher masculinity negatively correlates with faster speed from take off for New World wine. 
Method:

- Select all countries/regions with speed from take off measures

- Discount all countries/regions with speed from take off measures that do not have an masculinity measurement

Results:

Table 27: Hypothesis 11 results

Figure 18: Scatterplot of Hypothesis 11

\begin{tabular}{|c|c|c|}
\hline country & speed from take off & Masculinity \\
Brazil & $0.27 \%$ & 49 \\
Chile & $0.00 \%$ & 28 \\
China & $3.77 \%$ & 66 \\
Netherlands & $2.36 \%$ & 14 \\
Other Africa & $0.23 \%$ & 46 \\
Russia & $1.39 \%$ & 36 \\
Switzerland & $1.02 \%$ & 72 \\
Belgium-Luxembourg & $1.46 \%$ & 43 \\
United States of America & $0.56 \%$ & 62 \\
& & \\
& & \\
& Pearson Correlation Coefficient & 0.08615193 \\
& R Square & 0.007422155 \\
& P-value & 0.825574642 \\
& $n$ & 9 \\
\hline
\end{tabular}

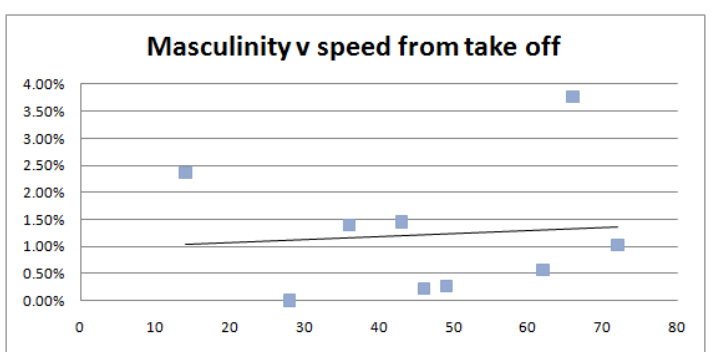

Table 27 shows a positive correlation, a low $r$ squared value and a high $\mathrm{p}$ value. There is no evidence to support the hypothesis. Figure 18 shows a scatterplot representation of the data.

H12: Countries with higher ratings in Long Term Orientation positively correlates with higher time to take off for New World wine.

Method:

- Select all countries/regions with time to take off measures

- Discount all countries/regions with time to take off measures that do not have a long term orientation measurement

Results:

Table 28: Hypothesis 12 results

Figure 19: Scatterplot of Hypothesis 12

\begin{tabular}{|c|c|c|}
\hline country & time to take off & Long term Orientation \\
\hline Australia & 7 & 31 \\
Brazil & 8 & 65 \\
China & 5 & 118 \\
France & 4 & 39 \\
Germany & 8 & 31 \\
Italy & 1 & 34 \\
Netherlands & 5 & 44 \\
Other Africa & 4 & 16 \\
Switzerland & 5 & 40 \\
Belgium-Luxembourg & 5 & 38 \\
United States of America & 7 & 29 \\
& & \\
& & \\
& & \\
& & \\
& Pearson Correlation Coefficient & 0.072222955 \\
& R Square & 0.005216155 \\
& P-value & 0.832869118 \\
n & 11 \\
\hline
\end{tabular}

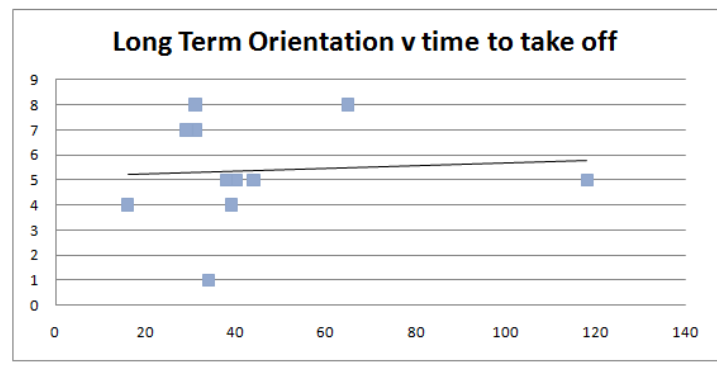


Table 28 shows a positive correlation was recorded in line with the hypothesis. A low $r$ squared value and a high $p$ value mean the hypothesis cannot be supported. Figure 19 shows a scatterplot representation of the data.

H13: Countries with higher ratings in Long Term Orientation positively correlates with faster speed from take off for New World wine.

Method:

- Select all countries/regions with speed from take off measures

- Discount all countries/regions with speed from take off measures that do not have an long term orientation measurement

Results:

Table 29: Hypothesis 13 results

\begin{tabular}{|c|c|c|}
\hline country & speed from take off & Long Term Orientation \\
Brazil & $0.27 \%$ & 65 \\
China & $3.77 \%$ & 118 \\
Netherlands & $2.36 \%$ & 44 \\
Other Africa & $0.23 \%$ & 16 \\
SWitzerland & $1.02 \%$ & 40 \\
Belgium-Luxembourg & $1.46 \%$ & 38 \\
United States of America & $0.56 \%$ & 29 \\
& & \\
& & \\
& & \\
& & \\
& & \\
& Pearson Correlation Coefficient & 0.76646809 \\
& RSGuare & 0.587473333 \\
& P-value & 0.044433 \\
n n & 7 \\
\hline
\end{tabular}

Figure 20: Scatterplot of Hypothesis 13

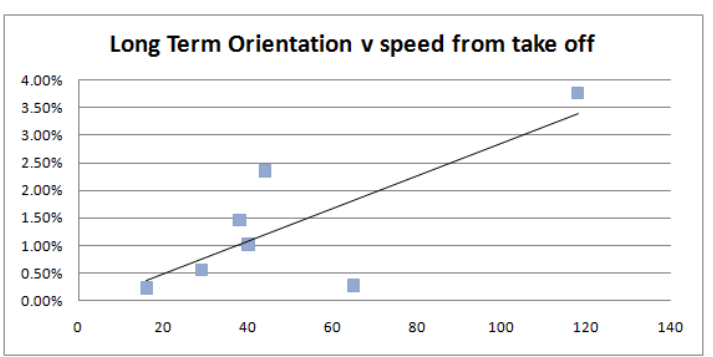

Findings:

Table 29 shows that correlation is in line with hypothesis with strong $\mathrm{r}$ squared level and within a 0.05 significance level. However a sample size of 7 means the hypothesis cannot be supported. Figure 20 shows a scatterplot representation of the data that shows a strong positive correlation trendline.

Moderating Variables:

As no hypotheses involving Hofstede's cultural dimensions were supported at a statistically significant level, no moderating effects were analysed.

\subsection{Summary of Findings}

Table 30 below provides a summary of findings from the hypothesis tests. It provides the correlation sign of the test, the $\mathrm{r}$ squared value to show the strength of relationship, and the 
statistical significance measure where appropriate. In states whether the hypothesis has been accepted, rejected or not supported and provides comments from the author for each hypothesis.

\section{Summary of Findings}

Table 30 below presents the summary table of findings.

Table 30: Summary of findings

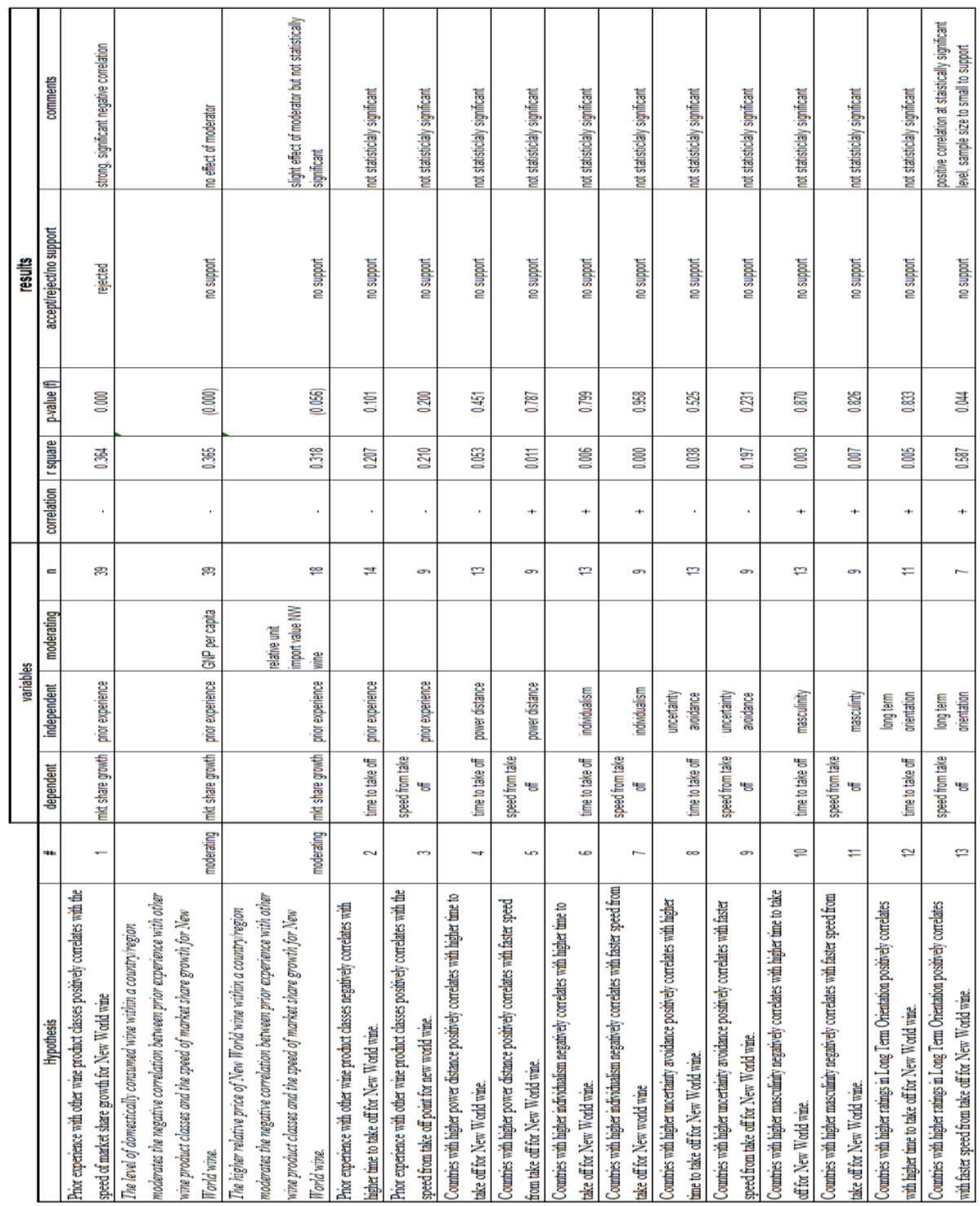




\subsection{Chapter Summary}

This chapter has outlined the results of testing of hypotheses relating to the research problem. A strong negative correlation was found between "prior experience with a previously introduced idea' and New World wine market share growth. This will be discussed in the next chapter. Results from tests involving the effect of cultural dimensions on time from introduction to take off, and speed from take off, were found to be not statistically significant. 


\section{CHAPTER SIX: DISCUSSION AND CONCLUSION}

Although there have been efforts in the wine literature at understanding cultural dimensions and country specific explanatory factors around wine consumption at a single or two country level, there have been no studies, to the authors knowledge, that look at these variables on a global level. In addition to the insights delivered, this research sets a foundation for further study in this growing area.

This chapter will be split into 4 sections:

- Discussion of Key Findings

○ Conclusions

- Limitations of the Research

- Managerial Implications

- Areas of Further Research

\subsection{Discussion of Key Findings}

The key finding from this research was the strong and statistically significant negative correlation found between prior experience of a previously introduced idea, and market share growth of New World wine. The author hypothesized that there would be positive correlation between these two variables i.e., that more prior experience with other wine product classes, would lead to a faster adoption rate for the new product class (New World wine). The key reason behind this hypothesis was that there is less uncertainty in the new product class when there is more experience with the old product class. Rogers' (2003) diffusion theory described results of positive correlation and negative correlation for this explanatory variable for various within-country diffusion studies. In any event, the hypothesis was strongly defeated. In this section the author outlines and investigates in detail two of the key potential reasons for this, and identifies and outlines other potential factors that could have lead to this result.

The author forwards the following potential reasons for the strong negative correlation result:

- Status and reputation of the New World wine producers versus existing wine producers 
- Protectionist economic policies for domestically produced wine in countries with high levels of prior wine experience

- Other potential factors:
○ Brand loyalty effects
$\circ$ Country of origin effects
- Established distribution systems in place for existing wine producers
- New World wine acting as a more effective substitute for other alcohol types in those countries with low levels of experience of other wine classes
- New World wine marketing mix strategies

These reasons are discussed in more detail below:

Podolny (1993) explains that consumers make purchase decisions based upon quality perceptions of the product and the producer. He explains that this quality perception is a function of the reputation and perceived status hierarchy of the producer in the eyes of the market. In the case of a new product class entering an established market, consumers cannot place the new product class or producer into the status hierarchy and therefore perceive the quality as lower resulting in slower diffusion rates (Podolny 1993). Podolny (1993) explains that when a new product class enters a market that has a lesser established status hierarchy (e.g., low levels of prior wine experience), diffusion rates are relatively higher as the consumer regards the new product class with a more open mind. Podolny (1993) goes on to say that when a new product class establishes a position in the perceived status hierarchy (through mass market and interpersonal information), the new product begins to achieve market share growth. Podolny (1993:p 832) provides an example of this phenomenon in the case of Japanese automobiles entering the US market in the last 40 years of the $20^{\text {th }}$ century. He explains that when Japanese manufacturers entered the US market in the 1960s and 1970 's, their position in the producer status hierarchy was very low, quality perceptions were low and market share penetration was very low. As more information and around the actual quality of Japanese cars filtered into the market, consumers increased their position in the status hierarchy and market share grew. By the 1990's, many U.S. consumers did not even consider U.S. made cars as an alternative to Japanese made cars. The author considers this case to be analogous to New World wine producers entering markets where there is an 
established market of wine consumers and therefore an existing producer status hierarchy in place.

Closely linked to the idea of status hierarchy and its effect on diffusion is the idea of 'reputation' of existing products. In their study of the use of quality and reputation indicators by consumers in the case of Bordeaux wine, Landon and Smith (1993) found that the long term reputation of wine is considerably more important to a consumer's willingness to purchase wine, than any short term perceived quality change. Landon and Smith (1993) add that 'collective reputation' (meaning associated reputation of products that this product is identified with) has as large an impact on consumers willingness to pay, as any individual firm or product reputation.

Lecocq and Visser (2006) extend the idea of wine reputation to take into account sensory cues such as labeling and ranking systems in determining consumer quality perceptions of wine. They state that ranking systems inherent in Old World wines (e.g., appellations etc), become a key quality reference for consumers with experience with these products. When new products or product classes enter the market that don't use these quality ranking cues, consumers perceive these to be outside of their quality reference structure and therefore perceive these products to be of lower quality.

The classification of wine as a 'status' product, and an 'experience' good, exacerbate the above phenomena in relation to diffusion rates. Benjamin and Podolny (1999) state that wine is a 'status' product as the decision about choice of wine to consume provides cues to the social group of an actor's social status. The effect of this on wine consumers is that the decision to consume a wine that is perceived as low quality by the social group, provides a far more significant risk to the consumer's social status than with other product types, such as functional products (e.g., consumer durables). In addition, wine is considered an 'experience' good (Nelson 1970). This means that actual quality cannot be judged before experiencing the product and therefore quality perceptions and reputation takes on a far higher significance in choosing to consume a wine for the first time. This affects New World wine diffusion in that in order to change quality perceptions, there is a higher need for consumers to experience the product, than is the case with other product types where quality cues through other sensory information. 
In countries that have a high level of existing wine production in the years before the 'explosion' of New World wine in the early 1990's, government protectionist policies have allowed significant cost advantages to domestic producers in their domestic consumption markets (Berger and Anderson 1999). These cost advantages manifest as cheaper relative prices to consumers for those wines that are produced in that country. These policies are especially strong in Old World wine countries, where the wine industry is relatively more important to the wealth of that country. Berger and Anderson (1999) completed a study of various countries and regions within the world in 1996 that shows the import tariff, domestic taxes applied to wine purchase, and percentage of import tariff versus all taxes imposed on wine sales of premium and non premium wines within each country. Table 31 below shows these measures:

Table 31: \% tax on wine sales, import tariff \% of total taxes, selected countries, 1996

\begin{tabular}{|c|c|c|c|}
\hline & \% tax (on sales price)-non premium & \% tax (on sales price)-premium & Import Tariff as a \% total tax \\
\hline Australia & $5 \%$ & $5 \%$ & $10 \%$ \\
New Zealand & $13 \%$ & $13 \%$ & $17 \%$ \\
France & $12 \%$ & $4 \%$ & $63 \%$ \\
Italy & $12 \%$ & $4 \%$ & $100 \%$ \\
Greece & $12 \%$ & $4 \%$ & $100 \%$ \\
Portugal & $12 \%$ & $4 \%$ & $100 \%$ \\
Spain & $12 \%$ & $4 \%$ & $100 \%$ \\
Denmark & $12 \%$ & $4 \%$ & $14 \%$ \\
Finland & $12 \%$ & $4 \%$ & $5 \%$ \\
Iceland & $0 \%$ & $0 \%$ & $0 \%$ \\
Norway & $12 \%$ & $4 \%$ & $3 \%$ \\
Sweden & $12 \%$ & $4 \%$ & $5 \%$ \\
Austria & $12 \%$ & $4 \%$ & $100 \%$ \\
Belgium-Luxembourg & $12 \%$ & $4 \%$ & $28 \%$ \\
Germany & $12 \%$ & $4 \%$ & $10 \% \%$ \\
Ireland & $12 \%$ & $4 \%$ & $5 \%$ \\
Netherlands & $12 \%$ & $4 \%$ & $23 \%$ \\
Switzerland & $69 \%$ & $17 \%$ & $100 \%$ \\
United Kingdom & $12 \%$ & $4 \%$ & $8 \%$ \\
United States of America & $6 \%$ & $1 \%$ & $30 \%$ \\
Canada & $3 \%$ & $1 \%$ & $12 \%$ \\
Mexico & $20 \%$ & $20 \%$ & $40 \%$ \\
Japan & $21 \%$ & $22 \%$ & $45 \%$ \\
China & $70 \%$ & $70 \%$ & $100 \%$ \\
Malaysia & $331 \%$ & $106 \%$ & $83 \%$ \\
Other North East Asia & $30 \%$ & $30 \%$ & $14 \%$ \\
Thailand & $60 \%$ & $30 \%$ & $48 \%$ \\
Singapore & $418 \%$ & $100 \%$ & $10 \% \%$ \\
South Africa & $5 \%$ & $10 \%$ & $47 \%$ \\
Russia & $10 \%$ & & $24 \%$ \\
\hline
\end{tabular}

Upon visual inspection the import tariff as a percentage of total taxes on wine products shows that countries with a high percentage of tariffs $\mathrm{v}$ all taxes are the more traditional wine producing countries e.g., France and Italy. Using correlation analysis it is shown that there is indeed a strong significantly significant positive relationship between import tariff $\%$ of total taxes and prior experience of wine $(\mathrm{r}=.63, \mathrm{r}$ squared $=.396, \mathrm{p}=.000093)$. In addition, correlating tariff $\%$ of total taxes with New World wine market share growth $1988-2006$ 
shows a strong negative relationship at a statistically significant level $(r=-.57, \mathrm{r}$ squared $=$ $.325, \mathrm{p}=.00036)$.

These results indicate that the government policies that have protected domestically produced wines in those markets that have high levels of wine experience, have corresponded with slower diffusion rates of New World wines in those markets. The reasons for this are that relative costs for domestic producers in these markets result in potential lower costs to the consumer as relative to imported wine which endures import tariffs.

Other potential factors that may explain the strong negative correlation are listed and explained as follows:

- Brand Loyalty. Rundle-Thiele and Bennett (2001) state that while brand loyalty is a crucial element to maximizing market share in a market, the concept of brand loyalty differs based upon market type, product type and situation. In high wine experience markets, there may be potentially higher levels of brand loyalty for the following reasons:

- There is more experience with particular brands allowing a higher level of knowledge and product involvement. Higher levels of product involvement with wine purchases is linked to higher levels of purchasing behavior based upon perceived quality(Geraghty \& Torres 2009). Taking into account the status and quality hierarchy concept discussed above, a higher level of product involvement should correspond to a higher predisposition to choose a wine brand from the established status hierarchy and therefore slows the diffusion of a new product class in the market.

- While costs of switching brands are low in a financial sense in high experience markets, the potential social costs may be perceived as being very high.

- In high experience markets it is logical to assume that there is more wine choice. Large levels of wine choice can be confusing to the consumer and therefore the customer may be more inclined to choose a brand that is 'tried and true' (Jennings and Wood 1994).

- Country of Origin effects. Ballestrini and Gamble (2006) explain that country of origin effects are higher for high involvement and social status products. Country of Origin effects are defined as when consumers have an image, product or concept that 
is associated with a country (Ballestrini and Gamble 2006). In the wine market the classic country of origin effect relates to French and Italian wine, both of which are traditionally perceived as being of high quality (Al-Sulaiti and Baker 1998). The author feels that it is possible that in high experience countries, a negative association of country of origin for a new product class may impede the diffusion of the new product class from that country. While this may be true of low experience countries also, the status hierarchy is not as strong in these countries and therefore may not have as stronger definition of perceived quality.

- Established Distribution Systems. In countries with higher levels of wine experience it is logical that existing wine producers that sell in the country have higher distribution strength within the market. Brown and Butler (1995) explain that strong distribution networks can be developed through relationships that build over time. In the authors opinion it therefore seems apparent that producers with existing distribution systems in place, such as is the case with high experience markets, have advantages over new product class producers who do not have the advantage of existing distribution systems. This factor could therefore lead to lower levels of product diffusion for producers of a new product class such as New World wine. It is interesting to note that, as the literature review points out, New World wine producers have achieved some cost advantages and distribution advantages by using a more consolidated and integrated structure, however these have seemed to have gained more advantage in low experience, non-traditional markets than in those high experience markets that have legacy, traditional distribution networks.

- New World wine as a substitute for existing alcohol choice in low experience countries. Consumers in countries/regions with a lower level of prior experience with other wine classes may see New World wine as a better substitute for their current alcohol choice, than other wine classes. As described in the literature review, New World wine generally has more fruity flavours and could therefore be perceived to be 'easier to drink' for a new wine consumer than other wine product classes.

- New World wine producers marketing mix variables may be more attractive to low experience markets than high experience markets.

○ Mass media promotional efforts to attract new markets that are a hallmark of New World wine producers may be more effective in low experience markets 
as they can attract a new market of wine drinker, with no established quality or status hierarchy.

- Affordable price points, another hallmark of New World wine, may attract new market segments in low experience markets (Anderson 2003), while in high experience markets these lower prices can be perceived as a reflection of lower quality (Schnabel and Storchmann 2010).

○ New World wine producers have used the placement of product in supermarkets to fuel market share growth (Anderson 2003). This strategy has been enabled through a more consolidated company structure and vertical integration and has been achieved more easily in countries where existing distribution networks and relationships are relatively weaker (Campbell and Guibert 2006). It is logical that this situation is more likely to occur in low experience markets.

- Innovative labeling, packaging and product presentation are another key success factor for New World wine. Within high experience countries with an in place reference hierarchy for denoting quality of wine, these innovations may be perceived as cues for a low quality product. In low experience countries however, these innovations may attract a new market with less preconceived ideas around wine quality. An example of this may be the 'screw cap' innovation which has been far slower to take off in countries with an established wine drinking tradition (Campbell and Guibert 2006).

\subsubsection{Conclusion}

This thesis has sought to understand how country specific factors affect cross national diffusion of a new product class. The growth of New World wine exports in the global market has been used to test the effect of several variables that comprise the 'compatibility' attribute of diffusion theory. Additionally this research has sought to provide further explanations and insights on drivers of wine purchase behavior across countries.

This research has looked at two 'new' areas of cross national diffusion theory. It therefore has an exploratory feel with very little directly relevant existing literature. 
Firstly, the cross national diffusion of a new product class is a new area of study. Most existing cross national diffusion studies have concentrated upon product innovations, especially in the area of consumer durables and technology products. A study of a new product class means that there is less 'innovativeness' within the product and therefore different purchase behaviours. Furthermore, a study of a new brand has even less innovativeness than a new product class and therefore engendering different purchase behaviours. The efforts of this study to understand cross national diffusion for a new product class provides insights into this area and provide a foundation for further research.

Secondly, this research has looked at 'prior experience with a previously introduced idea' as an explanatory variable at a cross national level. Prior experience with a previously introduced idea is a core part of the compatibility attribute of Rogers' diffusion theory however has not been studied within any cross national diffusion research known to the author. A key reason for this is that existing research has dealt with products that are highly innovative and therefore prior experience with a previously introduced idea is not as relevant as it is with the diffusion of a new product class. The nature of this study allows and even encourages the use of this independent variable to explain New World wine diffusion and therefore provides direct insights into this explanatory variable and a foundation for further research.

The key finding of this research is a strong negative correlation between 'prior experience of a previously introduced idea' and market share growth of a new product class (New World wine). The author hypothesized that higher levels of prior experience with similar product would mean less uncertainty within the market and therefore faster diffusion within those markets, as compared with markets with less prior experience. This hypothesis was in line with Roger's (2003) diffusion of innovations theory relating to higher levels of an innovation's compatibility with the society (market) leading to higher diffusion rates. It should be noted that while Rogers did hypothesize that higher prior experience should lead to higher diffusion, he had found mixed results.

The author sees the rejection of the hypothesis and the resulting strong negative correlation as a positive result in the pursuit of knowledge and understanding in this area. Popper (1972) explains that existing theories and paradigms are fallible and alternative ones emerge recurrently, and that new knowledge and discovery is often created through learning from 
mistakes and creating new insights from these. Indeed in this case, the rejection of the hypothesis opened new avenues of research into the explanation of how high levels of prior experience can lead to slower adoption of a new product class.

The author concludes from this research that for new product classes that can be defined as 'status' products, higher levels of prior experience with a similar product lead to a slower rate of diffusion in that market. While there are a variety of potential factors to explain this, in the author's opinion the key factor is the existence of a product (producer) status hierarchy that defines the level of quality in the mind of the consumer before the new product class enters the market. In this circumstance, the new product class needs to establish a position within this perceived hierarchy in order to increase market share. Alternatively, in a market where this status hierarchy does not exist to the same level, the new product class can achieve higher diffusion rates as the consumer is more open-minded to the quality of the new product class when it enters the market. In addition, producers of the new product class can potentially achieve greater gains in a low experience market through price and promotion, and thus achieve faster market share growth.

In the author's opinion, the product type of the new product class is a key variable that is outlined in this research. A 'status' product such as wine would appear to have far higher social status risk if a perceived lower quality product is consumed within a market with an existing status hierarchy, than does a functional product. As more products that once were considered functional become status products e.g. phones and computers, the higher the effect of the status hierarchy becomes.

In addition to the managerial implications outlined in a later section, the author suggests that this research is valuable in furthering cross national diffusion theory. When a new product class enters a market, and the product can be classified as a 'status' product, this research suggests that the 'prior experience with a previously introduced idea' construct of the compatibility attribute needs to be extended. This extension should measure the strength of the perceived status hierarchy in place in the society (market) to help determine the rate of adoption. This addition to the diffusion theory may help explain why Rogers (2003) found mixed results when using 'prior experience with a previously introduced idea' as an explanatory variable in diffusion rate. 


\subsection{Limitations of the Research}

Research limitations have meant that there are a large percentage of unsupported and rejected hypotheses. The literature review discussed the importance of dividing the diffusion curve into two parts: time from introduction to take off, and time from take off to market potential. It was important to reflect these two areas in the diffusion rate dependent variable and thus they were added to market share growth as additional dependent variables.

For the 'time from introduction to take off' dependent variable several limitations meant that sample size was reduced from 47 countries/regions to 13 countries regions. These limitations were as follows:

- New World wine import data was only available from 1988 for all the majority of countries/regions within the study. In several cases New World wine had been introduced before 1988 and therefore these countries/regions had to be discounted for the dependent variable

- Some countries/regions within the study did not reach take off point in the period studied further decreasing sample size (in addition to those that were already 'introduced' before period of study began) shall you relocate this to the end of your thesis as part of an overall reflection of the thesis's limitations?

- Some countries/regions did not reach the minimal level of New World wine imports at take off point (1 million litres) further decreasing sample size

- The use of the take off point measure requires the take off point to be 3 years after the first year of study and 3 years before the last year of the study. This takes the period of potential take off down to between 1991 - 2003 further decreasing sample size

For the 'speed from take off' dependent variable further limitations were encountered. Importantly, no countries within the study had reached market potential (although there is some debate around UK, Canada) and therefore a new measure for speed from take off needed to be constructed. Speed from take off for the next five years was used to ascertain diffusion speed. With this measure constructed further challenges and limitations were encountered, bringing the sample size down to 9 countries/regions. These limitations were:

- Those countries that had a take off point within the study period potentially did not have five years of diffusion data within the period bounds of the study. 
Other limitations within the study, in addition to the variables outlined in the discussion section of this chapter, include the consideration of any political, social and market changes over the time period that would have impacted diffusion patterns within these markets.

A further potential limitation of the study is that New World wine has been used to represent the category of 'new product class'. A new product class within a different product type may yield different results due to wine being a 'status' product (and an 'experience' product). A more functional new product class that does not have as much status acquiring characteristics may diffuse differently.

One of the key challenges of the study was to determine how to define take off point. The author was surprised to learn that there are a variety of ways of measuring take off point and differences between the measures and methodologies are considerable. Several studies have focused on developing a measure for take off point however no common methodology has been developed. Within this study the author reviewed a large selection of literature on the subject and decided to use measure that determines a large level of market share change within in year based upon parallel periods. The author feels confident that this approach was the correct approach however concedes that measure for take off point is debatable.

\subsection{Managerial Implications}

The key managerial implication to come from this research is based around the evidence of strong negative correlation between 'prior experience with a previously introduced idea' and the market share growth of New World wine.

For marketing managers looking to sell a new product class in global markets it is important to predict which markets to target for early growth and which markets will take longer to establish market share. This research presents evidence that those countries with previous experience of a different product class may not be markets where early high growth can be expected, and that these markets should be approached with different strategies. On the other hand, managers can look to target countries without the prior experience with a similar product to unlock new markets in the short term. 
For wine marketers this research provides a deeper understanding of the reasons why marketing strategies work more effectively in some markets than in others and when used in conjunction with marketing spend and distribution channel strength can provide a fuller picture of the market in order to develop further strategy.

Apart from the implication for 'market segmentation and targeting', there are also implications for promotion, pricing, placement and product labeling.

In the area of promotion, this research suggests that within countries where there are large amounts of existing experience with a similar product, expensive advertising campaigns through the use of mass media around product launch may not result in as higher short term returns as within a country with less experience. The research indicates that a more sensible approach in high experience markets is to slowly build reputation and establish the product and producer reputation within the product status hierarchy. Weighting marketing spend to a time when the product has established itself within the market would seem to a more effective approach. Conversely, in markets where there is little prior experience with a similar product, a more aggressive approach would appear to bring higher benefits.

As with promotion, an aggressive pricing strategy would appear to have far greater benefits in those markets that have little prior experience with a similar product, especially if this product is a 'status' and 'experience' product as is the case with wine. In established markets, a low price for a new product class reinforces (over and above the lack of position in the status hierarchy) the perception within the market that the product is of low quality (Schnabel and Storchmann, 2010). Schnabel and Storchmann (2010) add that this perception may be impossible to shift in the minds of the consumer. Alternatively, in markets where there is little prior experience, a cheaper price point may encourage new users of the product and increase rates of diffusion. Anderson (2003) outlines that this has been an effective strategy for New World wines in 'non-traditional' markets.

The research would indicate that effective product placement for a new product class (especially a 'status' and 'experience' product) in a market with existing experience would involve ensuring that the market sees the product in a quality setting and can associate the product with other high quality products and services. This may involve positioning the product with quality events, and with distributors (retail and wholesale) who have high 
quality reputations. In addition, efforts should be made to allow the market to 'experience' the product in these markets. In the case of wine this could mean wine tasting, and in the case of cars this could mean test-drive opportunities. In markets where there is little prior experience and no established status hierarchy, positioning in places with high market reach may be a more appropriate strategy. This could be in the form of mass media or within high volume distribution channels such as supermarkets.

The research also would seem to provide some clues as to effective use of the product within markets, depending on the level of prior experience within these markets. In the case of wine, innovative labeling and presentation such as different bottle shapes, screw top corks and colourful labeling, it could be implied from the research that these 'innovations' would not be best suited to markets with high levels of prior experience as these signals could be perceived as outside of the established status hierarchy and therefore as low quality. Alternatively, in markets that have no prior experience and expectations, these 'innovative' ideas may attract new customers to these products.

\subsection{Areas of Further Research}

In the author's opinion the key areas of further research could fall into a few areas.

- More years of data will provide more statistically significant results especially in the areas of time to take off and speed (time) from take off.

- A more detailed investigation of the relationship between 'status and reputation' and the prior experience/diffusion rate correlation, as outlined in the discussion section of this chapter, could provide a rich area of further study.

- A more detailed look at protectionist economic policies (especially the change in these over time) and the link with the prior experience/diffusion rate correlation could provide a fertile area for further investigation.

- The addition of further marketing mix variables such as distribution channel strength, marketing spend and retail pricing and discounting would provide a more complete picture of drivers of market share growth for New World wine.

- Also, the use of these independent and dependent variables for a new product class for a different type of product e.g., hybrid cars, could be a logical and interesting area to study. The study of a 'functional' product type in light of the potential effects of the 
'status hierarchy' concept may be especially interesting. This could take the form of researching the effect on diffusion rates in high experience $v$ low experience markets where the strength of the status hierarchy in high experience markets is lower due to the 'functional' nature of the product. 


\section{BIBLIOGRAPHY}

"Australia Food \& Drink Report - Q2 2010." Australia Food and Drink Report: 1. 15(4), s.34-41.

Agarwal, R., and B.L. Bayus (2002), "The Market Evolution and Take-off of New Product Innovations," Management Science, 48(5), 1024-41.

Al-Sulaiti, K.I., Baker, M.J. (1998) "Country-of-origin effects: a literature review", Marketing Intelligence \& Planning, Vol.16 No.3 pp150-99

Anderson, K. (2003), “Wine's new world”, Foreign Policy, Vol. 136, pp. 47-54.

Anderson, K. and Whitwer G., 2007. Global Wine Markets, 1961 to 2006: A statistical compendium. Centre for International Economic Studies, Adelaide University.

Anderson, K., Norman, D. and Wittwer, K. (2003), "Globalisation of the world's wine markets", The World Economy, 26 May, pp. 659-87.

Arkell, J. (1999). New World Wines. London: Ward Lock Publishing..

Aurifeille, J. M., P. G. Quester, et al. (2002). "Global vs international involvement-based segmentation: A cross-national exploratory study." International Marketing Review 19(4/5): 369.

Aylward, D. K.(2003) : A Documentary of Innovation Support Among New World Wine Industries. http://ro.uow.edu.au/commpapers/8

Bagwell, K. and Riordan, M.H. (1991). High and declining prices signal product quality. American Economic Review, 81, 224-239.

Ballestrini, P., Gamble, P. (2006) "Country of origin effects on Chinese wine consumers", British Food Journal, Vol.108 No.5 pp396-412

Bass, F. M. (2004). "A New Product Growth for Model Consumer Durables/Comments on "A New Product Growth for Model Consumer Durables". Management Science 50(12): 1825.

Bass, F.M. (1969). "A new product growth for model consumer variables", Management Science (pre-1986) 15(5): 215.

Batt, P.J. and Dean, A. (2000) "Factor's Influencing the Consumer's Decision," Australian and New Zealand Wine Industry Journal.

Beal, T. and Rod, M. (2009), "Riding social change: The New Zealand experience in the evolving wine markets of Japan and Singapore", a report to the Asia:NZ Foundation.

Benjamin B., and Podolny J., (1999) " Status, Quality and Social Order in the California Wine Industry", Administrative Science Quarterly, Vol. 44, 1999 
Berger N., and Anderson K., (1999) " Consumer and Import Taxes in eth world Wine Market: Australia in International Perspective", CIES Policy Discussion Paper 99/03

Beverland, M. (2002). "Unlocking the Asian wine market: An exploratory case study." International Journal of Wine Marketing 14(3): 53.

Brown, B. and Butler, J (1995) “Competitors as Allies.” Journal of Small Business Management, Vol. 33

Bryman, A and Bell, E. (2007) Business Research Methods, revised ed

Burns, R. and Burns, R (2008) Business Research Methods and Statistics Using SPSS. Oxford University Press.

Campbell, G. and Guibert, N. (2006). "Old World Strategies against New World competition in a globalizing wine industry”. British Food Journal, 108 (4): 233 - 242.

Chandrasekaran, D. and G. Tellis (2008). Global Takeoff of New Products: Culture, Wealth, or Vanishing Differences? Marketing Science 27: 844.

Cholette S. (2004). A Tale of Two Wine Regions: Similarities, Differences and Trends in the French and Californian Wine Industries, International Journal of Wine Marketing, 14 (2).

Dekimpe, M. G., Parker, P. M., \& Sarvary, M. (2000). Global diffusion of technological innovations: A coupled hazard approach. Journal of Marketing Research, 37(February), 4759.

Dwyer, S., H. Mesak, et al. (2005). "An Exploratory Examination of the Influence of National Culture on Cross-National Product Diffusion." Journal of International Marketing 13(2): 1 .

Ganesh, J. and V. Kumar (1996). "Capturing the cross-national learning effect: An analysis of an industrial technology diffusion." Academy of Marketing Science. Journal 24(4): 328.

Garber, T., J. Goldenberg, B. Libai and E. Muller (2004), 'From density to destiny: using spatial analysis for early prediction of new product success,' Marketing Science, 23(3), 419429.

Gatignon, H., J. Eliashberg, et al. (1989). "Modeling Multi-National Diffusion Patterns: An Efficient Methodology." Marketing Science (1986-1998) 8(3): 231.

Geraghty, S M. Torres, (2009) "The Irish wine market: a market segmentation study", International Journal of Wine Business Research, Vol. 21 Iss: 2, pp.143 - 154

Goldenberg, J., Libai, B., \& Muller, E. (2002). Riding the saddle: How cross-market communication can create a major slump in sales. Journal of Marketing, 66(2), 1 - 16.

Golder, P. N. and G. J. Tellis (1997), 'Will it ever fly? Modelling the takeoff of really new consumer durables,' Marketing Science, 16(3), 253-270. 
Goodman, S. (2009). "An international comparison of retail consumer wine choice." International Journal of Wine Business Research 21(1): 41.

Green, P. E., D. S. Tull, et al. (1988). Research for Marketing Decisions. Englewood Cliffs, NJ, Prentice-Hall.

Hall, (1976) Beyond Culture T Edward - New York: Anchor Books.

Hall, D.W. Lamb, B. Holzapfel and J. Louis , Optical remote sensing applications in viticulture: a review. Aust. J. Grape Wine Res. 8 (2002), pp. 36-47.

Hall, E.T., Hall, M.R. (1987) "Selling to a Japanese", Sales and Marketing Management, Vol.139 pp58-60

Helsen, K., K. Jedidi, et al. (1993). "A new approach to country segmentation utilizing multinational diffusion patterns." Journal of Marketing 57(4): 60.

Hofstede, G. (2001). Culture's consequences (2nd ed.). Beverly Hills, CA7 Sage.

Hoppe, M. (1990) A comparative study of country elites :--international differences in workrelated values and learning and their implications for management training and development ( $\mathrm{PhD}$ thesis)

Hussain, M., S. Cholette, et al. (2007). An Analysis of Globalization Forces in the Wine Industry: Implications and Recommendations for Wineries. 21: 33.

Jaishankar, G., V. Kumar, et al. (1997). "Learning effect in multinational diffusion of consumer durables: An exploratory investigation." Academy of Marketing Science Journal 25(3): 214.

Jennings D., and Wood C.,, (1994) "Wine: Achieving Competitive Advantage Through Design", International Journal of Wine Marketing, Vol. 6 Iss: 1, pp.49 - 61

Kalish, S., V. Mahajan, et al. (1995). "Waterfall and sprinkler new-product strategies in competitive global markets." International Journal of Research in Marketing 12(2): 105.

Kumar, V., J. Ganesh, et al. (1998). "Cross-national diffusion research: What do we know and how certain are we?" The Journal of Product Innovation Management 15(3): 255.

Kumar, V. and T. V. Krishnan (2002). "Research note: Multinational diffusion models: An alternative framework." Marketing Science 21(3): 318.

Landon, S. and Smith, C.E. (1997). The use of quality and reputation indicators by consumers: The case of Bordeaux Wine. Journal of Consumer Policy, 20, 289-323.

Laudan, L.,(1996) Beyond positivism and relativism: Theory, method, and evidence Oxford: Oxford University Press

Lecocq, S. and Visser, M. (2006). What determines wine prices: Objective vs. sensory characteristics. Journal of Wine Economics, 1, 42-56. 
Ling B.H. and Lockshin L., Components of wine prices for Australian wine: How winery reputation, wine quality, region, vintage and winery size contribute to the price of varietal wines, Australasian Marketing Journal 11 (2003) (3), pp. 19-32

Lockshin, L. and Hall, J. (2003). "Consumer Purchasing Behaviour for Wine: What We M. Tustin and L. Lockshin, Region of origin: Does it really count?, Australia and New Zealand Wine Industry Journal 16 (2001), pp. 139-143.

Mahajan, V., Muller, E., \& Bass, F. M. (1990). New productdiffusion models in marketing: A review and direction for research. Journal of Marketing, 54(1), 1- 26.

Marnik, G. D., M. P. Philip, et al. (2000). "Global diffusion of technological innovations: A coupled-hazard approach." JMR, Journal of Marketing Research 37(1): 47.

Nakata, C. and K. Sivakumar (2001). Instituting the marketing concept in a multinational setting: The role of national culture. Journal of International Business Studies 29: 255.

Olhavsky, R. (1980). "Time and the Rate of Adoption of Innovations." Journal of Consumer Research (pre-1986) 6(4): 425.

Parker, P. and H. Gatignon (1994). "Specifying competitive effects in diffusion models: An empirical analysis." International Journal of Research in Marketing 11(1): 17.

Podolny, J.M. (1993). A status-based model of market competition. American Journal of Sociology, 98, 829-872.

Popper, K. R. 1972. Conjectures and Refutations. London: Routledge and Kegan Paul.

Putsis, W. P., Jr., S. Balasubramanian, et al. (1997). "Mixing behavior in cross-country diffusion." Marketing Science 16(4): 354.

Quester, P.G., Smart, J. (1998) "The influence of consumption situation and product involvement over consumers' use of product attribute", Journal of Consumer Marketing, Vol.15 No.3 pp220-38

Rogers, Everett (2003), Diffusion of Innovations, Free Press, New York, $5^{\text {th }}$ Edition.

Rose, R. and Gordon, W. (2006), Wine Industry: Strategic Global Directions and Australia Outlook to 2010-11, ABARE, Canberra

Roth, M. S. (1995). "The effects of culture and socioeconomics on the performance." JMR, Journal of Marketing Research 32(2): 163.

Rundle-Thiele, S., \& Bennett, R. (2001). A brand for all seasons? A discussion of brand loyalty approaches and their applicability for different markets. Journal of Product and Brand Management, 10(1), 25-37.

Schnabel, H. And Storchmann, K (2010) "Prices as Quality Signals: Evidence from the Wine Market," Journal of Agricultural \& Food Industrial Organization: Vol 8: Iss 1, Article 2. 
Singh, S. (2006). "Cultural differences in, and influences on, consumers' propensity to adopt innovations." International Marketing Review 23(2): 173.

Sivakumar, K. and C. Nakata (2001). "The stampede toward Hofstede's framework: Avoiding the sample design pit in cross-cultural research." Journal of International Business Studies 32(3): 555.

Sondergaard, M. Research note: Hofstede's consequences: A study of reviews, citations and replications. Organization Studies, 1994, 15(3), 447-56.

Steenkamp E. M., J.-B., F. t. Hofstede, et al. (1999). "A cross-national investigation into the individual and national cultural antecedents of consumer innovativeness." Journal of Marketing 63(2): 55.

Takada, H. and D. Jain (1991). "Cross-National Analysis of Diffusion of Consumer Durable Goods in Pacific Rim Countries." Journal of Marketing 55(2): 48.

Talukdar, T., K. Sudhir, et al. (2002). "Investigating new product diffusion across products and countries." Marketing Science 21(1): 97

Tellis, G. J., Stremersch, S., \& Yin, E. (2003). The international takeoff of new products: Economics, culture, and country innovativeness. Marketing Science, 22(2), 188-208.

Thomas, A. (2000). Elements influencing wine purchasing: A New Zealand view. International Journal of Wine Marketing 12: 47.

Thorpe, Michael (2009) "The globalisation of the wine industry: new world, old world and China", China Agricultural Economic Review, Vol. 1 Iss: 3, pp.301 - 313

Van den Bulte, C., \& Stremersch, S. (2004). Social contagion and income heterogeneity in new product diffusion: A meta-analytic test. Marketing Science, 23(4).

Yalcinkaya, G. (2008). A culture-based approach to understanding the adoption and diffusion of new products across countries. International Marketing Review 25: 202.

Yaveroglu, S. and N. Donthu (2002). "Cultural influences on the diffusion of new products." Journal of International Consumer Marketing 14(4): 49.

Yeniyurt, S. and J. D. Townsend (2003). Does culture explain acceptance of new products in a country? An empirical investigation. International Marketing Review 20: 377. 
Appendix 1 - list of World Countries and Regions represented in Global Wine Compendium including New World Wine Growth Rate (NW imports/Total Consumption) (1988 - 2006)

\begin{tabular}{|c|c|c|}
\hline country & NW wine growth rate (1988 - 2006) & rank \\
\hline Argentina & $0.00 \%$ & 46 \\
\hline Australia & $0.21 \%$ & 24 \\
\hline Austria & $0.06 \%$ & 31 \\
\hline Azerbaijan & $0.00 \%$ & 38 \\
\hline Brazil & $0.41 \%$ & 19 \\
\hline Bulgaria & $0.01 \%$ & 34 \\
\hline Canada & $2.25 \%$ & 6 \\
\hline Chile & $0.14 \%$ & 25 \\
\hline China & $1.12 \%$ & 13 \\
\hline Croatia & $0.00 \%$ & 35 \\
\hline Denmark & $2.05 \%$ & 8 \\
\hline Finland & $0.76 \%$ & 16 \\
\hline France & $0.07 \%$ & 28 \\
\hline Georgia & $0.00 \%$ & 38 \\
\hline Germany & $0.40 \%$ & 20 \\
\hline Greece & $0.00 \%$ & 37 \\
\hline Hungary & $0.00 \%$ & 38 \\
\hline Ireland & $2.86 \%$ & 3 \\
\hline Italy & $0.12 \%$ & 26 \\
\hline Japan & $-0.12 \%$ & 47 \\
\hline Mexico & $4.27 \%$ & 1 \\
\hline Moldova & $0.00 \%$ & 38 \\
\hline Netherlands & $1.70 \%$ & 11 \\
\hline Other Africa & $0.78 \%$ & 15 \\
\hline Portugal & $0.00 \%$ & 36 \\
\hline Romania & $0.00 \%$ & 38 \\
\hline Russia & $0.40 \%$ & 21 \\
\hline Spain & $0.01 \%$ & 33 \\
\hline Sweden & $2.21 \%$ & 7 \\
\hline Switzerland & $0.31 \%$ & 22 \\
\hline Turkey & $0.02 \%$ & 32 \\
\hline Ukraine & $0.06 \%$ & 30 \\
\hline Uruguay & $0.00 \%$ & 38 \\
\hline Uzbekistan & $0.00 \%$ & 38 \\
\hline Belgium-Luxembourg & $0.94 \%$ & 14 \\
\hline United Kingdom & $2.48 \%$ & 5 \\
\hline United States of America & $0.65 \%$ & 17 \\
\hline Other North East Asia & $3.00 \%$ & 2 \\
\hline South East Asia & $1.77 \%$ & 10 \\
\hline Other Asia Pacific & $0.25 \%$ & 23 \\
\hline Other Western Europe & $0.48 \%$ & 18 \\
\hline Other Central Eastern Europe & $0.06 \%$ & 29 \\
\hline New Zealand & $1.64 \%$ & 12 \\
\hline Other Latin America Caribbean & $2.76 \%$ & 4 \\
\hline South Africa & $0.08 \%$ & 27 \\
\hline North Africa & $0.00 \%$ & 45 \\
\hline Middle East & $1.81 \%$ & 9 \\
\hline
\end{tabular}


Appendix 2: Hofstede 2005 National Cultural Dimension Data - Scores and Ranks

\begin{tabular}{|c|c|c|c|c|c|c|c|c|c|c|}
\hline \multirow{2}{*}{$\begin{array}{c}2005 \\
\text { country }\end{array}$} & \multicolumn{2}{|c|}{ Power Distance } & \multicolumn{2}{|c|}{ Individualism } & \multicolumn{2}{|c|}{ Masculinity } & \multicolumn{2}{|c|}{ Uncertaintly Avoidance } & \multicolumn{2}{|c|}{ Long Term Orientation } \\
\hline & Score & rank & Score & rank & Score & rank & Score & rank & Score & rank \\
\hline Middle East & 80 & 12 & 38 & 39 & 53 & 31 & 68 & 40 & & 40 \\
\hline Argentina & 49 & 52 & 46 & 33 & 56 & 28 & 96 & 6 & & 40 \\
\hline Australia & 36 & 62 & 90 & 2 & 61 & 20 & 51 & 55 & 31 & 27 \\
\hline Austria & 11 & 74 & 55 & 27 & 79 & 4 & 70 & 35 & 31 & 27 \\
\hline Bangladesh & 80 & 12 & 20 & 56 & 55 & 30 & 60 & 45 & 40 & 17 \\
\hline Belgium-Luxembourg & 61 & 39 & 78 & 8 & 43 & 47 & 97 & 5 & 38 & 21 \\
\hline Belguim Walloon & 67 & 30 & 72 & 12 & 60 & 21 & 93 & 10 & 38 & 21 \\
\hline Brazil & 69 & 26 & 38 & 39 & 49 & 37 & 76 & 31 & 65 & 7 \\
\hline Bulgaria & 70 & 22 & 30 & 46 & 40 & 55 & 85 & 23 & & 40 \\
\hline Canada & 39 & 60 & 80 & 4 & 52 & 33 & 48 & 60 & 23 & 35 \\
\hline Canada Quebec & 54 & 49 & 73 & 11 & 45 & 43 & 60 & 45 & 30 & 30 \\
\hline Chile & 63 & 37 & 23 & 55 & 28 & 67 & 86 & 18 & & 40 \\
\hline China & 80 & 12 & 20 & 56 & 66 & 11 & 30 & 68 & 118 & 1 \\
\hline Colombia & 67 & 30 & 13 & 70 & 64 & 14 & 80 & 29 & & 40 \\
\hline Costa Rica & 35 & 63 & 15 & 67 & 21 & 69 & 86 & 18 & & 40 \\
\hline Croatia & 73 & 20 & 33 & 44 & 40 & 55 & 80 & 29 & & 40 \\
\hline Czech Republic & 57 & 45 & 58 & 26 & 57 & 25 & 74 & 34 & 13 & 39 \\
\hline Denmark & 18 & 72 & 74 & 10 & 16 & 71 & 23 & 72 & 46 & 12 \\
\hline East Africa & 64 & 34 & 27 & 49 & 41 & 54 & 52 & 54 & 25 & 33 \\
\hline Ecuador & 78 & 15 & 8 & 73 & 63 & 17 & 67 & 42 & & 40 \\
\hline Estonia & 40 & 57 & 60 & 22 & 30 & 66 & 60 & 45 & & 40 \\
\hline Finland & 33 & 66 & 63 & 21 & 26 & 68 & 59 & 48 & 41 & 16 \\
\hline France & 68 & 27 & 71 & 13 & 43 & 47 & 86 & 18 & 39 & 20 \\
\hline Germany & 35 & 63 & 67 & 18 & 66 & 11 & 65 & 43 & 31 & 27 \\
\hline United Kingdom & 35 & 63 & 89 & 3 & 66 & 11 & 35 & 66 & 25 & 33 \\
\hline Greece & 60 & 41 & 35 & 43 & 57 & 25 & 112 & 1 & & 40 \\
\hline Guatemala & 95 & 3 & 6 & 74 & 37 & 61 & 101 & 3 & & 40 \\
\hline Hong Kong & 68 & 27 & 25 & 53 & 57 & 25 & 29 & 70 & 96 & 2 \\
\hline Hungary & 46 & 55 & 80 & 4 & 88 & 3 & 82 & 26 & 50 & 10 \\
\hline India & 77 & 17 & 48 & 31 & 56 & 28 & 40 & 64 & 61 & 8 \\
\hline Indonesia & 78 & 15 & 14 & 68 & 46 & 41 & 48 & 60 & & 40 \\
\hline Iran & 58 & 43 & 41 & 36 & 43 & 47 & 59 & 48 & & 40 \\
\hline Ireland & 28 & 69 & 70 & 15 & 68 & 9 & 35 & 66 & 43 & 15 \\
\hline Israel & 13 & 73 & 54 & 28 & 47 & 39 & 81 & 28 & & 40 \\
\hline Italy & 50 & 51 & 76 & 9 & 70 & 7 & 75 & 33 & 34 & 24 \\
\hline Jamaica & 45 & 56 & 39 & 37 & 68 & 9 & 13 & 73 & & 40 \\
\hline Japan & 54 & 49 & 46 & 33 & 95 & 2 & 92 & 12 & 80 & 4 \\
\hline Luxembourg & 40 & 57 & 60 & 22 & 50 & 34 & 70 & 35 & & 40 \\
\hline Malaysia & 104 & 1 & 26 & 52 & 50 & 34 & 36 & 65 & & 40 \\
\hline Malta & 56 & 47 & 59 & 25 & 47 & 39 & 96 & 6 & & 40 \\
\hline Mexico & 81 & 10 & 30 & 46 & 69 & 8 & 82 & 26 & & 40 \\
\hline Morocco & 70 & 22 & 46 & 33 & 53 & 31 & 68 & 40 & & 40 \\
\hline Netherlands & 38 & 61 & 80 & 4 & 14 & 72 & 53 & 53 & 44 & 13 \\
\hline New Zealand & 22 & 71 & 79 & 7 & 58 & 22 & 49 & 58 & & 40 \\
\hline Other Western Europe & 31 & 67 & 69 & 16 & 8 & 73 & 50 & 57 & 44 & 13 \\
\hline Pakistan & 55 & 48 & 14 & 68 & 50 & 34 & 70 & 35 & 0 & 40 \\
\hline Panama & 95 & 3 & 11 & 72 & 44 & 46 & 86 & 18 & & 40 \\
\hline Peru & 64 & 34 & 16 & 65 & 42 & 51 & 87 & 17 & & 40 \\
\hline Phillipines & 94 & 5 & 32 & 45 & 64 & 14 & 44 & 63 & 19 & 36 \\
\hline Poland & 68 & 27 & 60 & 22 & 64 & 14 & 93 & 10 & 32 & 26 \\
\hline Portugal & 63 & 37 & 27 & 49 & 31 & 65 & 104 & 2 & 30 & 30 \\
\hline Romania & 90 & 7 & 30 & 46 & 42 & 51 & 90 & 15 & & 40 \\
\hline Russia & 93 & 6 & 39 & 37 & 36 & 63 & 95 & 8 & & 40 \\
\hline Salvador & 66 & 32 & 19 & 62 & 40 & 55 & 94 & 9 & & 40 \\
\hline Serbia & 86 & 8 & 25 & 53 & 43 & 47 & 92 & 12 & & 40 \\
\hline Singapore & 74 & 19 & 20 & 56 & 48 & 38 & 8 & 74 & 48 & 11 \\
\hline Slovakia & 104 & 1 & 52 & 29 & 110 & 1 & 51 & 55 & 38 & 21 \\
\hline Slovenia & 71 & 21 & 27 & 49 & 19 & 70 & 88 & 16 & & 40 \\
\hline South Africa & 49 & 52 & 65 & 19 & 63 & 17 & 49 & 58 & & 40 \\
\hline Other North East Asia & 60 & 41 & 18 & 63 & 39 & 59 & 85 & 23 & 75 & 6 \\
\hline Spain & 57 & 45 & 51 & 30 & 42 & 51 & 86 & 18 & 19 & 36 \\
\hline Suriname & 85 & 9 & 47 & 32 & 37 & 61 & 92 & 12 & & 40 \\
\hline Sweden & 31 & 67 & 71 & 13 & 5 & 74 & 29 & 70 & 33 & 25 \\
\hline Switzerland French & 70 & 22 & 64 & 20 & 58 & 22 & 70 & 35 & 40 & 17 \\
\hline Switzerland & 26 & 70 & 69 & 16 & 72 & 6 & 56 & 50 & 40 & 17 \\
\hline Taiwan & 58 & 43 & 17 & 64 & 45 & 43 & 69 & 39 & 87 & 3 \\
\hline Thailand & 64 & 34 & 20 & 56 & 34 & 64 & 64 & 44 & 56 & 9 \\
\hline Other Latin America Caribbean & 47 & 54 & 16 & 65 & 58 & 22 & 55 & 51 & & 40 \\
\hline Turkey & 66 & 32 & 37 & 41 & 45 & 43 & 85 & 23 & & 40 \\
\hline United States of America & 40 & 57 & 91 & 1 & 62 & 19 & 46 & 62 & 29 & 32 \\
\hline Uruguay & 61 & 39 & 36 & 42 & 38 & 60 & 100 & 4 & & 40 \\
\hline Venezuela & 81 & 10 & 12 & 71 & 73 & 5 & 76 & 31 & & 40 \\
\hline Vietnam & 70 & 22 & 20 & 56 & 40 & 55 & 30 & 68 & 80 & 4 \\
\hline Other Africa & 77 & 17 & 20 & 56 & 46 & 41 & 54 & 52 & 16 & 38 \\
\hline
\end{tabular}


Appendix 3 - List of amendments and proxies to match Hofstede country classifications with Global Wine Compendium country/regions classifications (where appropriate)

\footnotetext{
Belgium Flemish proxied for Belgium-Luxembourg as flemish largest speaking Trinidad proxied for Other Latin American Carribean as representative

West Africa proxied for Other africa as representative

Arab Countris proxied for Middle East

Switzerland Germand proxied for Switzerland as swiss German $=64 \%$ of population and swiss french $=20 \%$ of population South Korea proxied for Other North East Asia as $>80 \%$ of population of region

Norway proxied for other western europe as largest country within this region group
} 